\title{
ANÁlisE DO PADRÃO DE DISTRIBUIÇÃO ESPACIAL DO PALMITEIRO (Euterpe edulis) UTILIZANDO A FUNÇÃO K DE RIPLEY
}

\author{
ADILSON DOS ANJOS
}

Engenheiro Agrônomo

Orientador: Prof. Dr. HILTON THADEU ZARATE DO COUTO

Dissertação apresentada à Escola Superior de Agricultura "Luiz de Queiroz", Universidade de São Paulo, para obtenção do título de Mestre em Agronomia, Área de Concentração: Estatística e Experimentação Agronômica.

PIRACICABA

Estado de São Paulo-Brasil

Abril - 1998 
Dados Internacionais de Catalogação na Publicação (CIP) DIVISÃO DE BIBLIOTECA E DOCUMENTAÇÃO - Campus "Luiz de Queiroz"/USP

Anjos, Adilson dos

Análise do padrão de distribuição espacial do palmiteiro (Euterpe edulis) utilizando a função K de Ripley / Adilson dos Anjos. - - Piracicaba, 1998.

$113 \mathrm{p}$.

Dissertação (mestrado) - Escola Superior de Agricultura Luiz de Queiroz, 1998. Bibliografia.

1. Árvore florestal 2. Distribuição espacial 3. Estatística florestal 4. Função matemática l. Título

CDD 634.9825 


\section{ANÁlISE DO PADRÃO DE DISTRIBUIÇÃO ESPACIAL DO PALMITEIRO (Euterpe edulis) UTILIZANDO A FUNÇÃO K DE RIPLEY}

Aprovado em:

Comissão julgadora:

Prof. Dr. Hilton Thadeu Zarate do Couto

ESALQ/USP

Prof. Dr. João Luiz Ferreira Batista

ESALQ/USP

Profa. Dra. Maria Cristina Stolf Nogueira

ESALQ/USP

Prof. Dr. HILTON THADEU ZARATE DO COUTO 


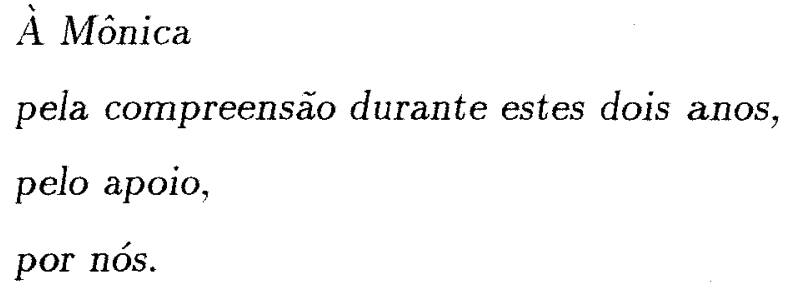

À minha Familia. 


\section{AGRADECIMENTOS}

Agradeço ao Prof. Dr. Hilton Thadeu Zarate do Couto, meu orientador, pelo incentivo durante o curso de mestrado, pelo apoio nos momentos difíceis e pelos conselhos.

Agradeço ao Prof. Dr. João Luiz Ferreira Batista, por fornecer os programas computacionais, pelas sugestões na elaboração desta dissertação e por acreditar no meu trabalho.

Agradeço ao Prof. Dr. Ademir Reis, pelo apoio ao ingresso neste curso, pelo fornecimento dos dados de sua tese, pela amizade e por seu papel na minha formação como profissional.

Agradeço ao Prof. Dr. Maurício Sedrez dos Reis, pelas sugestões na elaboração desta dissertação, pelo fornecimento dos dados que serviram de preparação para este trabalho. Agradeço ainda pelo incentivo e apoio durante o curso, em especial pela acolhida em Piracicaba nas primeiras semanas.

Agradeço à Profa. Dra. Roseli Aparecida Leandro, pela ajuda na elaboração dos programas no software S-plus.

Agradeço em especial aos Professores Paulo Ogliari e Francisco Chagas pelos conselhos, companheirismo e amizade.

Agradeço aos professores do Departamento de Matemática e Estatística que contribuíram para minha formação.

Agradeço aos colegas de curso, Afrânio, Cecília Cândolo, Cristián, Denise, Guilherme, Leonardo, Helena, Idemauro, Jeanete, João Batista Duarte, Sandra, Sérgio, Sílvia Helena, Sílvia Freitas, Leda, Wilson, e a todas as famílias que 
eles representam, pelos bons momentos de convívio, pelas amizades e pela grande experiência de vida que é a relação social.

Agradeço também aos funcionários do Departamento de Matemática e Estatística, Expedita, Jorge, Luciane, Rosa, Rosni, Solange, por toda a ajuda durante este período.

Ao CNPq pela concessão da bolsa de estudos.

Agradeço àqueles que de alguma forma contribuíram direta ou indiretamente para a conclusão deste trabalho. 


\section{SUMÁRIO}

Página

LISTA DE FIGURAS $\ldots \ldots \ldots \ldots \ldots \ldots \ldots \ldots \ldots \ldots \ldots \ldots \ldots \ldots \ldots \ldots$

LISTA DE TABELAS $\ldots \ldots \ldots \ldots \ldots \ldots \ldots \ldots \ldots \ldots \ldots \ldots \ldots \ldots \ldots \ldots \ldots$

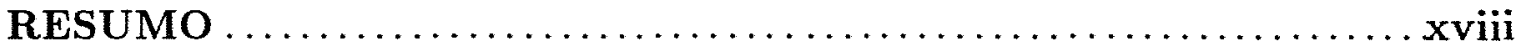

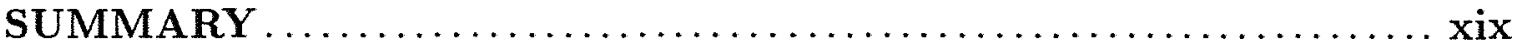

CAPÍTULO 1 - INTRODUÇÃO 1

CAPÍTULO 2 - REVISÃO DE LITERATURA 4

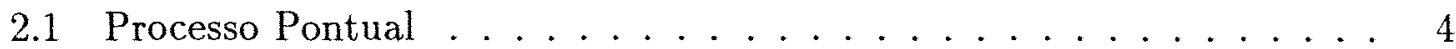

2.2 Completa Aleatoriedade Espacial . . . . . . . . . . . 6

2.3 A Função K de Ripley .................... 7

2.4 Processo Pontual Marcado .................... 14

2.5 Processo Pontual Bivariado ................... 16

2.6 Processo Pontual Marcado Bivariado . . . . . . . . . . . . 20 
2.7 Perda de Eventos $\ldots \ldots \ldots \ldots \ldots \ldots$

CAPÍtulo 3 - Análise do Padrão de Distribuição Espacial do Palmiteiro (Euterpe edulis) Utilizando a Função K de Ripley

3.1 Introdução . . . . . . . . . . . . . . . 23

3.2 Material e Métodos . . . . . . . . . . . . . 27

3.3 Resultados e Discussão . . . . . . . . . . . . . . . . . . . . 29

3.3 .1 Caso Univariado . . . . . . . . . . . . . . 29

3.3 .2 Caso Bivariado . . . . . . . . . . . . . 45

3.4 Conclusões . . . . . . . . . . . . . . . . . . . . 54

CAPÍTUlO 4 - Análise do Padrão de Distribuição Espacial, Utilizando a Função K de Ripley, Quando há Perda de Eventos 56

4.1 Introdução . . . . . . . . . . . . . . 56

4.2 Material e Métodos . . . . . . . . . . . . . 58

4.3 Resultados e Discussão . . . . . . . . . . . . . . . . . 66

4.3 .1 Padrão Aleatório . . . . . . . . . . . . . . . 72

$4.3 .2 \quad$ Padrão Regular . . . . . . . . . . . . . . . . 76

4.3 .3 Padrão Agregado . . . . . . . . . . . . . . . . 80

4.4 Conclusões . . . . . . . . . . . . . . . . . . . . . . . 92 
CAPÍtulo 5 - Análise do Efeito do Manejo em Regime de Rendimento Sustentável sobre o Padrão de Distribuição Espacial do Palmiteiro (Euterpe edulis) Através de Simulação

5.1 Introdução . . . . . . . . . . . . . . . 93

5.2 Material e Métodos . . . . . . . . . . . . . . 96

5.3 Resultados e Discussão . . . . . . . . . . . . . . . 100

5.4 Conclusões . . . . . . . . . . . . . . . . 105

CAPÍTULO 6 - CONCLUSÕES

A Programa para Simulação de um Padrão Aleatório

B Programa para Simulação de um Padrão Agregado

C Programa para Simulação de um Padrão Regular

D Programa para Criação de uma Matriz Amostral (ret)

115

E Programa para Simulação de Perda de Eventos 


\section{LISTA DE FIGURAS}

2.1 a) método do vizinho mais próximo e b) método de contagen sobre parcelas contínuas. . . . . . . . . . . . .

2.2 Caracterização gráfica do uso da função K de Ripley. . . . . . . . 10

3.3 a) Plantas de palmiteiro do estádio imaturos $1(\mathrm{n}=1598)$, mapeadas dentro da parcela de $340 \times 160 \mathrm{~m} ;$ b) análise do padrão de distribuição espacial através da função $\mathrm{K}$ de Ripley. Linhas pontilhadas representam envelopes de confiança construídos com 99 simulações. . . . . . 30

3.4 a) Plantas de palmiteiro do estádio imaturos $1(n=1598)$, mapeadas dentro da parcela de $340 \times 160 \mathrm{~m}$; b) análise da correlação entre as alturas, através da função K de Ripley. Linhas pontilhadas representam envelopes de confiança construídos com 99 simulações. . . . . . . . 31

3.5 a) Plantas de palmiteiro do estádio imaturos $2(n=1680)$, mapeadas dentro da parcela de $340 \times 160$ m; b) análise do padrão de distribuição espacial através da função $\mathrm{K}$ de Ripley. Linhas pontilhadas representam envelopes de confiança construídos com 99 simulações. . . . . 32 
3.6 a) Plantas de palmiteiro do estádio imaturos $2(n=1680)$, mapeadas dentro da parcela de $340 \times 160 \mathrm{~m} ; \mathrm{b}$ ) análise da correlação entre as alturas, através da função K de Ripley. Linhas pontilhadas representam envelopes de confiança construídos com 99 simulações.

3.7 a) Plantas de palmiteiro do estádio imaturos $2(n=1680)$, mapeadas dentro da parcela de $340 \times 160 \mathrm{~m}$; b) análise da correlação entre os diâmetros, através da função $\mathrm{K}$ de Ripley. Linhas pontilhadas representam envelopes de confiança construídos com 99 simulações. .

3.8 a) Plantas de palmiteiro do estádio adulto $(\mathrm{n}=297)$, mapeadas dentro da parcela de $340 \times 160 \mathrm{~m}$; b) análise do padrão de distribuição espacial através da função $\mathrm{K}$ de Ripley. Linhas pontilhadas representam envelopes de confiança construídos com 99 simulações.

3.9 a) Plantas de palmiteiro do estádio adulto $(n=297)$, mapeadas dentro da parcela de $340 \times 160 \mathrm{~m}$; b) análise da correlação entre as alturas, através da função $\mathrm{K}$ de Ripley. Linhas pontilhadas representam envelopes de confiança construídos com 99 simulações. . . . . . . .

3.10 a) Plantas de palmiteiro do estádio adulto $(n=297)$, mapeadas dentro da parcela de $340 \times 160 \mathrm{~m}$; b) análise da correlação entre os diâmetros, através da função $\mathrm{K}$ de Ripley. Linhas pontilhadas representam envelopes de confiança construídos com 99 simulações. . . . . . . .

3.11 a) Plantas de palmiteiro dos estádios imaturos $1(\mathrm{n}=1598), 2(\mathrm{n}=1680)$ e adultos $(\mathrm{n}=297)$, mapeadas dentro da parcela de $340 \times 160 \mathrm{~m}$; b) análise do padrão de distribuição espacial através da função $K$ de Ripley. Linhas pontilhadas representam envelopes de confiança construídos com 99 simulações. 
3.12 a) Plantas de palmiteiro dos estádios imaturos $1(\mathrm{n}=1598), 2(\mathrm{n}=1680)$ e adultas $(n=297)$, mapeadas dentro da parcela de $340 \times 160 \mathrm{~m} ; \mathrm{b})$ análise da correlação entre as alturas, através da função K de Ripley. Linhas pontilhadas representam envelopes de confiança construídos com 99 simulações. . . . . . . . . . . . . . . . . 4

3.13 a) Plantas de palmiteiro dos estádios imaturos $2(n=1680)$ e adultas $(\mathrm{n}=297)$, mapeadas dentro da parcela de $340 \times 160 \mathrm{~m} ; \mathrm{b})$ análise do padrão de distribuição espacial através da função $\mathrm{K}$ de Ripley. Linhas pontilhadas representam envelopes de confiança construídos com 99 simulaçôes. . . . . . . . . . . . . . . . .

3.14 a) Plantas de palmiteiro dos estádios imaturos $2(n=1680)$ e adultas $(\mathrm{n}=297)$, mapeadas dentro da parcela de $340 \times 160 \mathrm{~m} ; \mathrm{b})$ análise da correlação entre as alturas, através da função K de Ripley. Linhas pontilhadas representam envelopes de confiança construídos com 99 simulações.

3.15 a) Plantas de palmiteiro dos estádios imaturos $2(n=1680)$ e adultas $(\mathrm{n}=297)$, mapeadas dentro da parcela de $340 \times 160 \mathrm{~m} ; \mathrm{b})$ análise da correlação entre os diâmetros, através da função $\mathrm{K}$ de Ripley. Linhas pontilhadas representam envelopes de confiança construídos com 99 simulações.

3.16 a) Plantas de palmiteiro dos estádios imaturos $1(\cdot)(\mathrm{n}=1598)$ e imaturos $2(+)(n=1680)$, mapeadas dentro da parcela de $340 \times 160 \mathrm{~m}$; b) análise da dependência espacial através da função $K$ de Ripley. Linhas pontilhadas representam envelopes de confiança construídos com 99 simulaçães. 
3.17 Análise da correlação entre as alturas dos estádios imaturos 1 e imaturos 2 , através da função $\mathrm{K}$ de Ripley. Linhas pontilhadas representam envelopes de confiança construídos com 99 simulações. . . . . . . . 47

3.18 a) Plantas de palmiteiro do estádio imaturos $1(\cdot)(\mathrm{n}=1598)$ e adultas $3(+)(n=297)$, mapeadas dentro da parcela de $340 \times 160 \mathrm{~m} ; \mathrm{b})$ análise da dependência espacial, através da função $K$ de Ripley. Linhas pontilhadas representam envelopes de confiança construídos com 99 simulações.

3.19 Análise da correlação entre as alturas dos estádios imaturos 1 e adultas, através da função $K$ de Ripley. Linhas pontilhadas representam envelopes de confiança construídos com 99 simulações.

3.20 a) Plantas de palmiteiro do estádio imaturos $2(\cdot)(n=1680)$ e adultas $(+)(n=297)$, mapeadas dentro da parcela de $340 \times 160 \mathrm{~m}$; b) análise da dependência espacial, através da função $\mathrm{K}$ de Ripley. Linhas pontilhadas representam envelopes de confiança construídos com 99 simulações.

3.21 Análise da correlação entre as alturas dos estádios imaturos 2 e adultos, através da função $\mathrm{K}$ de Ripley. Linhas pontilhadas representam envelopes de confiança construídos com 99 simulações.

3.22 Análise da correlação entre os diâmetros dos estádios imaturos $2 \mathrm{e}$ adultos, através da função $\mathrm{K}$ de Ripley. Linhas pontilhadas representam envelopes de confiança construídos com 99 simulações. . . . . . 51

4.23 Padrōes aleatórios simulados com n eventos: a) $n=50$, b) $n=100$ e c)

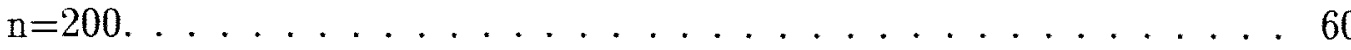


4.24 Padrões regulares simulados com $n$ eventos: a) $n=50$, b) $n=100$ e c) $n=200 \ldots \ldots \ldots \ldots \ldots$

4.25 Padrões agregados simulados ( $\lambda=$ intensidade de cada agregado): a) agregados $=10, \lambda=3$ (num. de eventos $=46$ ); b) agregados $=10, \lambda=7$ (num. de eventos $=60$ ); c) agregados $=10, \lambda=10$ (num. de eventos $=103$ ). 62

4.26 Padrões agregados simulados ( $\lambda=$ intensidade de cada agregado): a) agregados $=15, \lambda=3$ (num. de eventos $=40$ ); a) agregados $=15, \lambda=7$ (num. de eventos $=108$ ); a) agregados $=15, \lambda=7$ (num. de eventos $=129$ ). 63

4.27 Padrões agregados simulados ( $\lambda$-intensidade de cada agregado): a) agregados $=20, \lambda=3$ (num. de eventos $=59$ ); b) agregados $=20, \lambda=7$ (num. de eventos $=132$ ); c) agregados $=20, \lambda=10$ (num. de even$\operatorname{tos}=176) \ldots \ldots \ldots \ldots 64 \ldots \ldots \ldots \ldots$

4.28 Fluxograma de avaliação da simulação do efeito de perda de eventos em um padrão espacial pontual. ................ 65

4.29 Função K para padrões aleatórios simulados com n eventos: a) $n=50$, b) $n=100$ e c) $n=200$. Linhas pontilhadas representam envelopes de confiança construídos com 99 simulações.

4.30 Função $K$ para padrões regulares simulados com $n$ eventos: a) $n=50$, b) $n=100$ e c) $n=200$. Linhas pontilhadas representam envelopes de confiança construidos com 99 simulações.

4.31 Função K para padrões agregados simulados ( $\lambda=$ intensidade de eventos por agregado): a) agregados $=10, \lambda=3(\mathrm{n}=46) ; \mathrm{b})$ agregados $=10$, $\lambda=7(n=60) ; c)$ agregados $=10, \lambda=10(n=103)$. Linhas pontilhadas representam envelopes de confiança construídos com 99 simulações. 
4.32 Função K para padrões agregados simulados $(\lambda=$ intensidade de eventos por agregado): a) agregados $=15, \lambda=3(\mathrm{n}=40)$; b) agregados $=15$, $\lambda=7(\mathrm{n}=108) ; \mathrm{c})$ agregados $=15, \lambda=7(\mathrm{n}=129)$. Linhas pontilhadas representam envelopes de confiança construídos com 99 simulações. . 70

4.33 Função K para padrões agregados simulados $(\lambda=$ intensidade de eventos por agregado): a) agregados $=20, \lambda=3(\mathrm{n}=59)$; b) agregados $=20$, $\lambda=7(\mathrm{n}=132) ; \mathrm{c})$ agregados $=20, \lambda=10(\mathrm{n}=176)$. Linhas pontilhadas representam envelopes de confiança construídos com 99 simulações. . 71

4.34 Efeito da perda de eventos (p) em um padrão aleatório simulado com $\mathrm{n}=50$ eventos. LMin e LMax $(-\cdot-)$, LMed $(\cdot \quad \cdot \cdot)$, Env $(\cdots), \mathrm{L}$

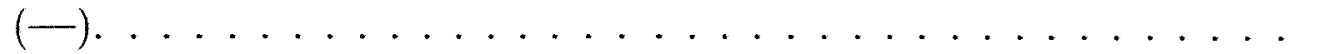

4.35 Efeito da perda de eventos (p) em um padrão aleatório simulado com

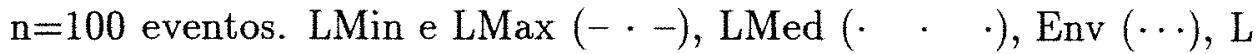

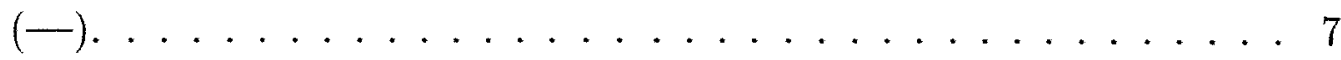

4.36 Efeito da perda de eventos (p) em um padrão aleatório simulado com $\mathrm{n}=200$ eventos. LMin e LMax $(-\cdot-), \operatorname{LMed}(\cdot \quad \cdot \quad \cdot), \operatorname{Env}(\cdots), \mathrm{L}$

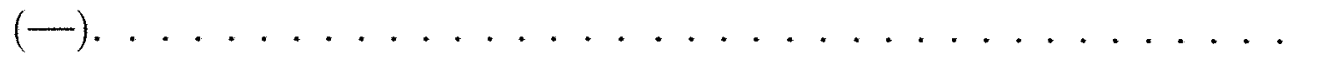

4.37 Efeito da perda de eventos (p) em um padrão regular simulado com

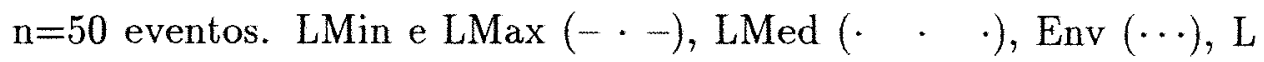

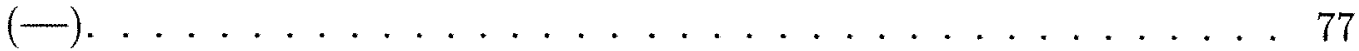

4.38 Efeito da perda de eventos (p) em um padrão regular simulado com

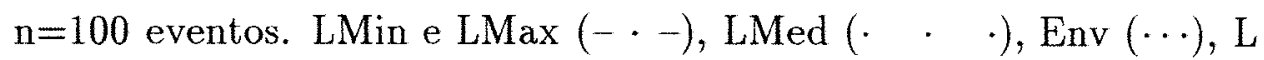

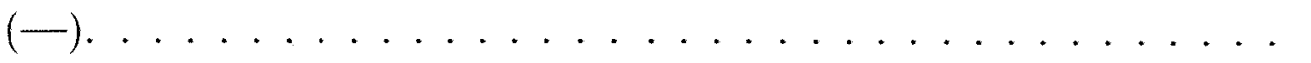


4.39 Efeito da perda de eventos (p) em um padrão regular simulado com $\mathrm{n}=200$ eventos. $\operatorname{LMin} \mathrm{e} \operatorname{LMax}(-\cdot-), \operatorname{LMed}(\cdot \quad \cdot \quad \cdot), \operatorname{Env}(\cdots), \mathrm{L}$ $(-) \ldots \ldots \ldots \ldots \ldots \ldots \ldots$

4.40 Efeito da perda de eventos $(\mathrm{p})$ em um padrão agregado simulado com agregados $=10$ e $\lambda=3 . \operatorname{LMin}$ e $\operatorname{LMax}(-\cdot-), \operatorname{LMed}(\cdot \cdot \cdot \cdot), \operatorname{Env}$ $(\cdots), \mathrm{L}(-)$.

4.41 Efeito da perda de eventos (p) em um padrão agregado simulado com agregados $=10$ e $\lambda=7$. LMin e $\operatorname{LMax}(-\cdot)$, LMed (. • • •), Env $(\cdots), \mathrm{L}(-)$.

4.42 Efeito da perda de eventos (p) em um padrão agregado simulado com agregados $=10$ e $\lambda=10$. LMin e $\operatorname{LMax}(-\cdot-), \operatorname{LMed}(\cdot \cdot \cdot \cdot)$, Env $(\cdots), \mathrm{L}(-)$

4.43 Efeito da perda de eventos (p) em um padrão agregado simulado com agregados $=15$ e $\lambda=3$. LMin e $\operatorname{LMax}(-\cdot-)$, LMed $(\cdot \cdot \cdot \cdot)$, Env $(\cdots), \mathrm{L}(-)$.

4.44 Efeito da perda de eventos (p) em um padrão agregado simulado com agregados $=15$ e $\lambda=7$. $\operatorname{LMin}$ e $\operatorname{LMax}\left(-^{-}\right)$, LMed $(\cdot \cdot \cdot \cdot)$, Env $(\cdots), \mathrm{L}(-)$

4.45 Efeito da perda de eventos (p) em um padrão agregado simulado com agregados $=15$ e $\lambda=10$. LMin e LMax $(-\cdot-), \operatorname{LMed}(\cdot \quad \cdot \cdot \cdot)$, Env $(\cdots), \mathrm{L}(-)$.

4.46 Efeito da perda de eventos (p) em um padrão agregado simulado com agregados $=20$ e $\lambda=3 . \operatorname{LMin}$ e $\operatorname{LMax}(-\cdot-), \operatorname{LMed}(\cdot \cdot \cdot \cdot)$, Env $(\cdots), L(-) . \ldots \ldots \ldots \ldots \ldots$ 
4.47 Efeito da perda de eventos (p) em um padrão agregado simulado com agregados $=20$ e $\lambda=7$. LMin e LMax $(-\cdot)$, LMed $(\cdot \cdot \cdot)$, Env $(\ldots), \mathrm{L}(-) . \ldots \ldots \ldots \ldots \ldots \ldots \ldots$

4.48 Efeito da perda de eventos (p) em um padrão agregado simulado com agregados $=20$ e $\lambda=10$. LMin e LMax $(-\cdot)$, LMed (. • · $\cdot)$, Env $(\ldots), L(-), \ldots \ldots \ldots \ldots \ldots \ldots \ldots \ldots$

5.49 Distribuição das plantas de Euterpe edulis com estipe maior ou igual a $1,30 \mathrm{~m}$ e sem evidências de reprodução (imaturos 2 ) . . . . . . 97

5.50 Classes diamétricas de plantas de palmiteiro do estádio imaturos 2 antes da exploração $(n=1680) \ldots \ldots \ldots \ldots \ldots$

5.51 Função K de Ripley, aplicada as plantas do estádio imaturos 2, em uma área de 5,44 ha, antes da simulação de corte. . . . . . . . . 102

5.52 Distribuição das plantas de Euterpe edulis do estádio imaturos 2 com $\mathrm{DAP} \geq 10 \mathrm{~cm}$.

5.53 a) Plantas de Euterpe edulis do estádio imaturos 2 após exploração (DAP $<10 \mathrm{~cm}, \mathrm{n}=1369)$, mapeadas dentro da parcela de $340 \times 160 \mathrm{~m} .103$

5.54 Função K de Ripley, aplicada as plantas do estádio imaturos 2 após a simulação de corte das plantas com DAP $\geq 10 \mathrm{~cm} . \ldots \ldots . . .104$ 


\section{LISTA DE TABELAS}

4.1 Número de pontos para cada padrão de agregado simulado, variando o número de agregados e a intensidade $\lambda \ldots \ldots \ldots \ldots 59$

5.2 Número de plantas classificadas por estádios e diâmetro na área de 5,44 ha. . . . . . . . . . . . . . . . . . 101 


\title{
ANÁliSE do PADRÃo DE DISTRIBUIÇÃO ESPACIAL DO PALMITEIRO (Euterpe edulis) UTILIZANDO A FUNÇÃO K DE RIPLEY
}

\author{
Autor: ADILSON DOS ANJOS \\ Orientador: Prof. Dr. HILTON THADEU ZARATE DO COUTO
}

\section{RESUMO}

Existem várias metodologias que são utilizadas para estudar o padrão de distribuição espacial. A grande maioria está baseada em métodos de contagem ou de distâncias. A função $K$ de Ripley considera tanto a contagem, como a distância entre os eventos. Estudou-se o padrão de distribuição espacial do palmiteiro (Euterpe edulis-MARTIUS) em uma área de 5,44 ha localizada na Mata Atlântica no município de Blumenau - SC, com pouca exploração de madeira ou palmito. Utilizou-se a função $\mathrm{K}$ de Ripley considerando os casos univariado e bivariado, sem marcas e com marcas (altura de estipe exposto e diâmetro à altura do peito). Os resultados indicam que as plantas de Euterpe edulis formam agregados de vários tamanhos, distribuídos de forma regular sobre a área de estudo. Também, procurou-se estudar graficamente o efeito da perda de eventos sobre vários padrões de distribuição espacial simulados. Observou-se que o efeito da perda de eventos, depende principalmente da intensidade e do padrão de distribuição espacial. Por último, avaliou-se o efeito de uma simulação de exploração em regime de rendimento sustentável sobre o padrão de distribuição espacial do palmiteiro. Considerou-se apenas o caso univariado sem marcas. Concluiu-se que o sistema de manejo proposto não alterou o padrão de distribuição das plantas restantes. 


\title{
ANALYSIS OF SPATIAL POINT PATTERN OF THE PALMITEIRO (Euterpe edulis) USING RIPLEY'S K FUNCTION
}

\author{
Author: ADILSON DOS ANJOS \\ Adviser: Prof. Dr. HILTON THADEU ZARATE DO COUTO
}

\section{SUMMARY}

Many metodologies are used to analyse spatial point pattern. Great part are based in counts or distance methods. The Ripley's K function consider both of them. It was studied the spatial point pattern of the palmiteiro (Euterpe edulisMARTIUS) in a 5.44 ha plot of a Tropical Rain Forest in Blumenau - SC - Brazil, under low exploitation of valuable forest woods or heart of palm (palmito). It was employed the Ripley's K function considering bivariate and univariate cases, with and without marks (height and diameter at breast height). Results point out that E. edulis presents an aggregate pattern with several sizes, distributed regularly. It was intended to study graphically the effect of loosing events of the simulated spatial point pattern. As much as the intensity $(\lambda)$ increases, the effect of loosing events on spatial point pattern decreased. It was evaluated the effect of the sustainable yield management system on the spatial point pattern. It was considerated only univariate case without marks. The management proposed do not change the spatial point pattern of remainder plants of E. edulis. 


\section{CAPÍTULO 1}

\section{INTRODUÇÃO}

Um padrão espacial pontual pode ser definido como a presença de uma estrutura espacial repetida sobre a região de estudo (Newbery et al., 1986). O estudo de padrões espaciais é hoje, uma das ferramentas mais utilizadas para se entender melhor o comportamento de diversos fenômenos. Várias são as áreas do conhecimento que podem utilizar tal ferramenta. A medicina, em estudos epidemiológicos, as ciências sociais no estudo de distribuição de rendas, a meteorologia no estudo de fenômenos climáticos (como a distribuição de chuvas) e várias outras áreas.

Em ciências florestais, uma grande aplicação está no estudo da distribuição espacial de árvores, principalmente aquelas no ambiente natural. O conhecimento do padrão de distribuição espacial pode fornecer informações para melhorar técnicas de manejo, auxiliar em processos de amostragem ou simplesmente entender a estrutura espacial de uma espécie florestal.

Com a atual preocupação com a preservação do meio ambiente, a distribuição espacial representa uma ferramenta poderosa para monitorar espécies vegetais e animais em áreas conservadas (Unidades de conservação) e sob manejo. 
A distribuição espacial de animais e seus respectivos fluxos gênicos, dependem da ocupação que estes têm sobre o terreno, e avaliações consecutivas desta distribuição representam uma das melhores formas de diagnosticar o dinamismo de suas populações.

Existem inúmeras metodologias criadas ou desenvolvidas para se fazer a análise de um padrão de distribuição espacial. Os métodos baseados em contagens e em distâncias são os freqüentemente utilizados (Haase, 1995). A função $\mathrm{K}$ de Ripley (caso univariado) é um método baseado em contagem e em distância. Por sua vez, exige que se possuam as coordenadas $(\mathrm{x}, \mathrm{y})$ de cada ponto, tornando mais onerosa a sua utilização. A função $\mathrm{K}$ de Ripley permite que sejam feitas inferências sobre os valores associados à cada ponto: as marcas (caso univariado marcado). Desse modo, pode-se avaliar a correlação existente entre as marcas em um processo espacial, como por exemplo, a altura das árvores. Ainda, a função K de Ripley pode ser aplicada para avaliar a dependência espacial existente entre diferentes tipos de eventos, como por exemplo, diferentes espécies de árvores (caso bivariado). Também, pode-se associar a cada tipo de evento as marcas (caso bivariado marcado).

No terceiro capítulo deste trabalho, procura-se aplicar a função $K$ de Ripley a um conjunto de dados de locação de árvores de palmiteiro (Euterpe edulis) em um ambiente natural. Consideraram-se diferentes estádios existentes (caso univariado), a correlação existente entre as marcas: diâmetro à altura do peito (DAP) e altura das árvores (caso univariado marcado), a dependência espacial entre estádios (caso bivariado) e a correlação existente entre as marcas das diferentes classes fenológicas (caso bivariado marcado).

No quarto capítulo, foram simulados alguns padrões com diferentes intensidades, procurando-se fazer um estudo sobre o que acontece com um padrão espacial pontual, utilizando a função K de Ripley, quando ocorre a perda de eventos. 
No quinto capítulo, fez-se uma simulação de exploração de uma população de Euterpe edulis, avaliando-se os efeitos do sistema de manejo sobre o padrão de distribuição espacial da espécie, através da função K de Ripley, considerando o caso univariado. 


\section{CAPÍTULO 2}

\subsection{Processo Pontual}

Um conjunto de pontos, distribuído dentro de uma região do espaço é chamado um padrão espacial pontual e as locações dos pontos são chamadas de eventos (Andersen, 1992; Diggle, 1983). Por exemplo, neste trabalho, cada árvore de palmiteiro é um evento dentro da parcela estudada e o conjunto de locações destes pontos origina um padrão espacial pontual.

Um processo espacial pontual é um conjunto de $n$ pontos dentro de uma região $R \subset R^{2}$ (Venables \& Ripley, 1994), ou ainda, é algum processo estocástico que gera finitos números de eventos $(x, y)$ em uma região finita e plana. Todos os modelos de mecanismos que podem gerar padrões para cada tipo de dado são processos estocásticos (Ripley, 1981). Um processo espacial pontual é descrito por,

$$
\left\{Z\left(s_{i}\right): s_{i} \subset R^{2}\right\}
$$

onde $Z\left(\right.$.) é um conjunto (vetor) aleatório, $s_{i}$ é a locação do evento $i$. Quando $Z\left(s_{i}\right)$ é especificado, tem-se um processo pontual marcado (Cressie, 1993).

Uma das desvantagens dos métodos existentes para se avaliar o padrão de distribuição espacial é sua inabilidade para testar interações em diferentes escalas simultaneamente em testes de significância (Ripley, 1977). Um dos problemas do método da distância do vizinho mais próximo (Ripley, 1979), por exemplo, 
é que ele avalia somente pequenas escalas de padrão, ou seja, informações sobre grandes escalas são ignoradas, figura 2.1(a), (Bailey \& Gatrell, 1995; Kuuluvainen et al, 1996; Ripley, 1977). Além disso, métodos de distâncias não são apropriados para se fazer uma análise intensiva de um mapa (processo espacial pontual) (Ripley, 1977). Utilizando este método, há uma significativa perda de informação (Cressie, 1993; Kenkel, 1988).

Os métodos de contagem em parcelas também não consideram a estrutura dos eventos em uma parcela, ou melhor, a "estrutura fina" dos dados é perdida, figura 2.1(b), (Ripley, 1981). Índices de dispersão também não fornecem informação sobre o componente de segunda ordem, (Hill, 1973), que é a relação entre pares de eventos.

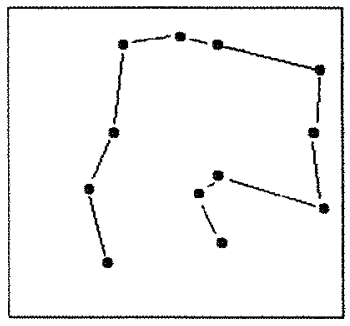

(a)

\begin{tabular}{|c|c|c|c|}
\hline 12 & 6 & 25 & 12 \\
\hline 8 & 13 & 23 & 23 \\
\hline 9 & 14 & 31 & 23 \\
\hline 11 & 19 & 34 & 17 \\
\hline
\end{tabular}

(b)

Figura 2.1: a) método do vizinho mais próximo e b) método de contagen sobre parcelas contínuas. 


\subsection{Completa Aleatoriedade Espacial}

A hipótese básica, que é testada em algum processo espacial pontual é a de completa aleatoriedade espacial, ou seja, que existe ausência de algum tipo de dependência entre eventos dentro de um processo espacial pontual (Batista, 1994). Esta hipótese atua como uma separação entre padrões, fazendo distinção entre um padrão classificado como regular ou agregado (Diggle, 1983).

A hipótese de completa aleatoriedade espacial corresponde a um Processo Homogêneo de Poisson no qual, segundo Diggle (1983), tem as seguintes propriedades:

1. o número de eventos em alguma região $\mathrm{R}$ com área $|R|$ segue uma distribuição de Poisson com média $\lambda|R|$ ( $\lambda$ é a intensidade ou número médio de eventos por unidade de área);

2. dados $n$ eventos $s_{i}$ em uma região $\mathrm{R}$, os $s_{i}$ 's são uma amostra aleatória independente de uma distribuição uniforme sobre R;

3. para duas regióes disjuntas $\mathrm{A}$ e $\mathrm{B}$, o número de eventos em $\mathrm{A}$ e em $\mathrm{B}$ são independentes;

Dessa forma, a idéia inicial, quando se realiza um teste sobre completa aleatoriedade espacial, é comparar o padrão observado com o padrão esperado sob completa aleatoriedade espacial, ou seja, um Processo Homogêneo de Poisson. Um teste de completa aleatoriedade espacial simplesmente indica qual a característica do padrão (aleatório, agregado ou regular) e não como reproduzi-lo. A modelagem de processos estocásticos não será enfocada neste trabalho, apenas a identificação do padrão de distribuição espacial. 


\subsection{A Função K de Ripley}

A função $K(h)$ é uma função de densidade que considera a variância de todas as distâncias entre todos os eventos (Haase, 1995; Moeur, 1993), ao contrário do método do vizinho mais próximo, que considera somente a distância entre o evento mais próximo. Basicamente, um círculo de raio $h$ é centrado em cada evento e o número de plantas dentro de cada círculo é contado.

Da mesma forma como em momentos de variáveis aleatórias, podese definir o primeiro e segundo momento em um processo espacial pontual. Assim, a intensidade de primeira ordem, ou a função de intensidade de um processo, $\lambda(x)$ é definida como:

$$
\lambda(x)=\lim _{|d x| \rightarrow 0}\left\{\frac{E[N(d x)]}{|d x|}\right\}
$$

onde:

$x$ é um ponto na região $R$;

$N(d x)$ é o número de eventos na região $d x$;

$d x$ é uma região infinitesimal que contém $x$;

$|d x|$ é a área desta região;

$E$ é o operador esperança.

Um processo espacial $\left\{Z\left(s_{i}\right): s_{i} \subset R^{2}\right\}$ é estacionário ou homogê$n e o$, se suas propriedades estatísticas são independentes da locação em $R$ (Bailey \& Gatrell, 1995), ou seja, que a intensidade $\lambda(x)$ seja constante sobre toda a região de estudo.

A função $K(h)$, supõe que exista isotropia, ou seja, que não exista 
efeito de direção entre dois eventos numa distância $h$. Assim, se a função $K(h)$ for usada quando existe anisotropia em uma grande escala, ela pode detectar alguma dependência espacial devido a falta de isotropia e não devido a alguma interação entre os eventos (Diggle, 1983).

Normalmente, assume-se "a priori" que estas suposições estejam satisfeitas. Elas podem ser testadas formalmente ou apenas se levar em conta a experiência que se tem sobre o fenômeno (Bailey \& Gstrell, 1995).

Se o processo é estacionário, $\lambda(x)$ assume um valor constante $\lambda$, que é o número médio de eventos por área, estimado por $\hat{\lambda}=\frac{n}{R}$, onde $n$ é o número de eventos dentro da região $R$ (Batista, 1994; Diggle, 1983).

As características de segunda ordem são aquelas que descrevem a relação existente entre pares de eventos (Cressie, 1993; Ripley, 1981).

Considere-se círculos infinitesimalmente pequenos, com áreas $|d x|$ e $|d y|$ com uma distância entre os centros $h$. Denotando por $P(h)$ a probabilidade de os dois círculos conterem um ponto do processo cada um, pode-se escrever

$$
P(h)=\lambda^{2} g(h) d x d y
$$

onde a função $g(h)$ é a função de correlação de pares que é uma função da distância $h$ entre os pontos.

A função de correlação de pares é um modo de caracterizar a função de intensidade de segunda ordem. Esta função é definida da seguinte forma, segundo Batista (1994) e Diggle (1983),

$$
g(h)=\frac{\lambda^{2}(h)}{\lambda^{2}}
$$


Se o processo é completamente aleatório, $g(h)=1$. Se o processo é agregado, $g(h)>1$ e se o processo é regular, $g(h)<1$ (Penttinen et al., 1992). A função $K(h)$ pode ser definida da seguinte forma, segundo Ripley (1977):

$$
K(h)=\int_{0}^{h} g(t) 2 \pi t d t, \quad h>0
$$

Um modo de caracterizar as propriedades da função de intensidade de segunda ordem de um processo espacial pontual é fazendo uso da função K de Ripley (1977).

A função $K(h)$, também pode ser definida intuitivamente da seguinte forma (Diggle, 1983; Haase, 1995; Ripley, 1979):

$$
K(h)=\lambda^{-1} E[N(h)]
$$

onde

$N(h)$ é o número de eventos até uma distância $h$ de um evento arbitrário; $\lambda^{-1}$ é a intensidade de primeira ordem;

A intensidade $\lambda$ é o número de eventos por unidade de área. Portanto, o número de eventos em $R$ é $\lambda|R|$ e o número de pares ordenados de eventos até uma distância não maior do que $h$ inclusive, com cada evento do par pertencente a região $R$ é dado por $\lambda^{2}|R| K(h)$ (Ripley, 1977). Dessa forma, pode-se escrever:

$$
\lambda^{2}|R| K(h)=E[N P(R)]
$$

onde

$\mathrm{E}[\mathrm{NP}(\mathrm{R})]=$ Esperança do número de pares ordenados de eventos até uma distância não maior do que $h$ inclusive. 
Denotando $\left(\mathrm{x}_{\mathbf{i}}-\mathrm{x}_{\mathbf{j}}\right)$ como a distância entre o i-ésimo e o j-ésimo evento em $R^{2}$ e definindo a função indicadora $I_{h}\left(\mathbf{x}_{\mathbf{i}}, \mathbf{x}_{\mathbf{j}}\right)$ como sendo 1 se $\left(\mathbf{x}_{\mathbf{i}}-\mathbf{x}_{\mathbf{j}}\right) \leq h$, e 0 caso contrário, então, o número de pares ordenados é dado por,

$$
\lambda^{2}|R| K(h)=\sum_{i=1}^{n} \sum_{j=1}^{n} I_{h}\left(\mathbf{x}_{\mathbf{i}}-\mathbf{x}_{\mathbf{j}}\right), \quad \text { para } \quad i \neq j \quad \text { e } \quad h>0
$$

A distância $h$ não possui uma regra para ser determinada; depende do fenômeno a ser estudado e geralmente é fornecida pelo pesquisador. A figura 2.2 fornece uma ilustração do uso da função K de Ripley.

Este somatório exclui todos aqueles eventos que estão fora de $R$ (eventos não observáveis), ou seja, a função será viesada devido ao efeito de borda. Fazendo então $\omega_{I}\left(\mathbf{x}_{\mathbf{i}}-\mathbf{x}_{\mathbf{j}}\right)$ a proporção da circuferência do círculo, com centro $\mathbf{x}_{\mathbf{i}} \mathrm{e}$ raio $h$, que pertence a região $R$ e escrevendo $\omega_{i j}$ para representar $\omega_{I}\left(\mathbf{x}_{\mathbf{i}}-\mathbf{x}_{\mathbf{j}}\right)$, e se o processo é estacionário e isotrópico, $\omega_{i j}$ é a probabilidade condicional de um evento ser observado, dado somente que ele está a uma distância $\left(\mathbf{x}_{\mathbf{i}}-\mathbf{x}_{\mathbf{j}}\right)$ do $i$-ésimo evento $x_{i}$, figura 2.2 . Em geral, $\omega_{i j} \neq \omega_{j i}$ (Diggle, 1983).

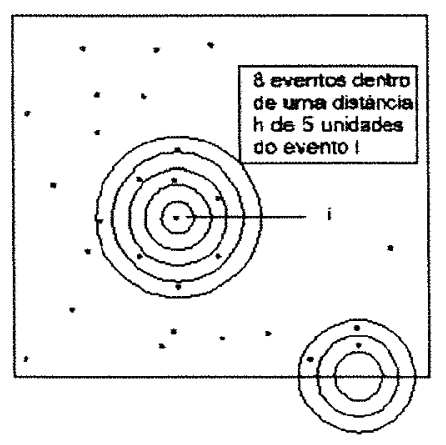

Figura 2.2: Caracterização gráfica do uso da função K de Ripley. Agora tem-se um estimador não viesado para $\lambda^{2}|R| K(h)$, 


$$
\lambda^{2}|R| K(h)=\sum_{i=1}^{n} \sum_{i=1}^{n} \omega_{i j}^{-1} I_{h}\left(\mathbf{x}_{\mathbf{i}}-\mathbf{x}_{\mathbf{j}}\right), \quad \text { para } \quad i \neq j \quad \text { e } \quad h>0
$$

Finalmente, substituindo a intensidade desconhecida $\lambda$ pela intensidade observada $\left(\hat{\lambda}=\frac{n}{|R|}\right)$, obtém-se o estimador de $K(h)$

$$
\hat{K}(h)=n^{-2}|R| \sum_{i=1}^{n} \sum_{i=1}^{n} \omega_{i j}^{-1} I_{h}\left(\mathbf{x}_{\mathbf{i}}-\mathbf{x}_{\mathbf{j}}\right), \quad \text { para } \quad i \neq j \quad \text { e } \quad h>0
$$

A fórmula para a proporção $\omega_{i j}\left(\mathbf{x}_{\mathbf{i}}-\mathbf{x}_{\mathbf{j}}\right)$ depende da forma da região $|R|$ (circular ou retangular) ${ }^{1}$. Considerando uma região retangular, de lados a e b e escrevendo $x=\left(x_{1}, x_{2}\right)$ e seja $d_{1}=\min \left(x_{1}, a-x_{1}\right)$, e $d_{2}=\min \left(x_{2}, b-x_{2}\right)$, onde $d_{1}$ e $d_{2}$ são as distâncias de $x$ em relação as bordas vertical e horizontal de $|R|$, respectivamente, o cálculo de $\omega_{i j}\left(\mathbf{x}_{\mathbf{i}}-\mathbf{x}_{\mathbf{j}}\right)$ é diferente para cada um dos casos abaixo:

i) se $\left(x_{i}-x_{j}\right) \leq d_{1}^{2}+d_{2}^{2}$,

$$
\begin{aligned}
& \omega_{i j}\left(\mathbf{x}_{\mathbf{i}}-\mathbf{x}_{\mathbf{j}}\right)=1-\pi^{-1}\left[\cos ^{-1}\right. \\
& \left.\left\{\min \left(d_{1}, x_{i}-x_{j}\right) / x_{i}-x_{j}\right\}+\cos ^{-1}\left\{\min \left(d_{2}, x_{i}-x_{j}\right) / x_{i}-x_{j}\right\}\right]
\end{aligned}
$$

ii) se $\left(x_{i}-x_{j}\right)>d_{1}^{2}+d_{2}^{2}$,

$$
\omega_{i j}\left(\mathbf{x}_{\mathbf{i}}-\mathbf{x}_{\mathbf{j}}\right)=\frac{3}{4}-(2 \pi)^{-1}\left\{\cos ^{-1}\left(d_{1} / x_{i}-x_{j}\right)+\cos ^{-1}\left(d_{2} / x_{i}-x_{j}\right)\right\}
$$

Quando $\left(x_{i}-x_{j}\right) \leq \min \left(d_{1}, d_{2}\right)$, então $\omega_{i j}\left(\mathbf{x}_{\mathbf{i}}-\mathbf{x}_{\mathbf{j}}\right)=1$. De outra forma, $\omega_{i j}\left(\mathbf{x}_{\mathbf{i}}-\mathbf{x}_{\mathbf{j}}\right)>1$ (Bailey \& Gatrell, 1995).

Ohser \& Stoyan (1981), sugerem um estimador para a função K, baseado na translação dos eventos para a correção de borda:

\footnotetext{
${ }^{1}$ Para maiores detalhes, veja Haase (1995).
} 


$$
\hat{K}_{2}(h)=\frac{1}{\hat{\lambda}^{2}} \sum_{i=1}^{n} \sum_{j=1}^{n} \frac{I_{h}\left(\left|x_{i}-x_{j}\right|\right)}{\omega_{S}\left(\left|x_{i}-x_{j}\right|\right)}, \quad i \neq j
$$

onde a função de correção de borda para uma parcela retangular

$$
\omega_{S}(x)=a b-x(2 a+2 b-x) / \pi
$$

é definida para $x \leq \min (a, b)$, onde $a$ e $b$ são os lados da área estudada. Este estimador permite que se façam inferências sobre grandes escalas de padrões e o processo computacional é simples porque a correção de borda é baseada apenas na distância entre os eventos (Batista, 1994).

Uma vez obtida $\hat{K}(h)$, pode-se visualizá-la em um gráfico para verificar a dependência espacial no processo pontual nas diferentes distâncias $(h)$.

Besag na discussão do artigo de Ripley, (1977), sugere uma transformação para a função $\mathrm{K}$, que produz uma linha simples,

$$
\hat{L}(h)=\sqrt{\frac{\hat{K}(h)}{\pi h^{2}}}, \quad h>0
$$

Graficamente, uma forma mais adequada de visualizar características de completa aleatoriedade espacial é:

$$
\hat{L}^{*}(h)=\sqrt{\frac{\hat{K}(h)}{\pi h^{2}}}-h, \quad h>0
$$

Pela definição da função $K$, pode-se esperar que em um processo sem dependência espacial, ou seja, se os eventos são aleatoriamente distribuídos, o valor esperado de $K(h)=\pi h^{2}$ (a área de um círculo de raio $h$ ) (Diggle, 1983; 
Haase, 1995). Sob a hipótese de completa aleatoriedade espacial, em uma região com área $C$, o número de eventos $N(C)$ segue uma distribuição de Poisson com média $\lambda C,\left(\lambda\right.$ é a intensidade estimada, dada por $\left.\hat{\lambda}=\frac{n}{|R|}\right)$. Tem-se então que a distribuição de probabilidade de $N(C)$,

$$
P_{n}(C)=\frac{e^{-\lambda C}(\lambda C)^{2}}{n !} \quad n=1,2,3, \ldots
$$

onde

$P_{n}(C)=$ é a probabilidade de existirem $n$ eventos independentes dentro da região $C$ (neste caso, $C=\pi h^{2}$ ).

E aplicando-se o operador esperança, pode-se verificar que:

$$
E\left[P_{n}(C)\right]=\lambda C=\lambda \pi h^{2}
$$

Como $\lambda K(h)=\lambda \pi h^{2}$, verifica-se que $\mathrm{E}[K(h)]=\pi h^{2}$

Para $\hat{L}^{*}(h)=\sqrt{\hat{K} / \pi h^{2}}-h$ o valor esperado é 0 . Para valores menores do que 0 tem-se uma distribuição regular (inibição) e para valores maiores do que 0 tem-se uma distribuição agregada (atração) (Batista, 1994; Diggle, 1983; Haase, 1995).

Em um gráfico, picos positivos indicam agregamento e picos negativos indicam regularidade (Bailey \& Gatrell, 1995). Para uma avaliação formal da significância destes "picos" observados, precisa-se saber qual a distribuição de $\hat{L}(h)$, sob completa aleatoriedade espacial. Como esta distribuição é desconhecida e complexa, devido as correções de borda isso torna-se muito difícil. Assim, uma forma de se avaliar a significância destes picos é construir um envelope de confiança ou envelopes de simulação,

$$
\begin{aligned}
\mathcal{U}(h) & =\max _{i=1 \cdots m}\left\{\hat{L}_{i}(h)\right\} \\
\mathcal{L}(h) & =\min _{i=1 \cdots m}\left\{\hat{L}_{i}(h)\right\}
\end{aligned}
$$


por simulação de $m$ processos aleatórios com $n$ eventos. Besag, também na discussão do artigo de Ripley (1977), recomenda o uso de $m=99$ simulações para se ter uma confiança razoável nos envelopes. Feito isso, "plota-se" o envelope juntamente com $\hat{L}(h)$, considerando que:

$$
P(\hat{L}(h)>\mathcal{U}(h))=P(\hat{L}(h)<\mathcal{L}(h))=\frac{1}{(m+1)}
$$

Se $\hat{L}_{i}(h)$ cai fora do envelope de confiança, rejeita-se a hipótese de nulidade com um nível de confiança $\frac{1}{(m+1)}$.

\subsection{Processo Pontual Marcado}

Um processo pontual marcado é um modelo matemático de um sistema aleatório de pontos marcados $\left\{Z\left(s_{i}\right): s_{i} \subset R^{2}\right\}$, onde os $s$ 's são pontos no plano cartesiano e os $Z\left(s_{i}\right)$ 's são as marcas (Cressie, 1991; Penttinen et al., 1992). Neste trabalho, por exemplo, a localização das plantas de palmiteiro são os $s_{i}^{\prime} s$ e os DAP's (Diâmetro à altura do peito - $1,30 \mathrm{~m}$ ) são as marcas. Para um processo pontual marcado também assume-se que ocorram estacionariedade e isotropia.

Num processo pontual marcado, tem-se também as características de primeira ordem que são a densidade $\lambda$ e a média das marcas $\mu$. Considerando as árvores de palmiteiro, a densidade $\lambda$ é o número médio de eventos na parcela e $\mu$ é a média dos diâmetros.

Considere-se agora as marcas no processo. Denota-se por $M(h)$ a média do produto das marcas em dois círculos infinitesimalmente pequenos, com áreas $|d x|$ e $|d y|$ com uma distância $h$ entre os centros. Observe que este produto 
desaparece quando um dos círculos não contém o ponto. Pode-se então escrever $M(h)$ da seguinte forma:

$$
M(h)=\lambda^{2} g(h) k_{m m}(h) d x d y
$$

onde a função $k_{m m}$ descreve a relação entre as marcas e é chamada de função de correlação de marcas. Valores de $k_{m m}$ maiores do que $\mu^{2}$ indicam que as marcas dos dois membros do par de pontos numa distância $h$ variam juntos na mesma direção, indicando uma correlação positiva. Penttinen (1992), sugere o uso de $\rho_{m m}$, definida como

$$
\rho_{m m}(h)=\frac{k_{m m}(h)}{\mu^{2}}
$$

Assim, valores pequenos, comparados com o valor 1 , indicam correlação negativa ou inibição entre as marcas numa distância $h$. Grandes valores indicam uma correlação positiva ou atração. Quando a variável é espacialmente não correlacionada, $\rho_{m m}(h)=1$.

A função pode então ser definida como

$$
K_{m m}(h)=\int_{0}^{h} g(t) \rho_{m m}(t) 2 \pi t d t, \quad h>0
$$

Pode-se da mesma forma, fazer a transformação

$$
L_{m m}(h)=\sqrt{\frac{\rho_{m m}(h)}{\left(\pi \mu^{2}\right)}}, \quad h>0
$$

Os estimador da função de correlação de marcas é dado da seguinte forma

$$
\hat{K}_{m m}(h)=\frac{1}{\hat{\lambda}^{2}} \sum_{i=1}^{n} \sum_{j=1}^{n} w_{S} I_{h}\left(x_{1 i}-x_{2 j}\right) m_{1 i} m_{2 j}
$$

Para a representação gráfica usa-se 


$$
\hat{L}_{m m}(h)=\sqrt{\frac{\hat{K}_{m m}(h)}{\pi \hat{\mu}^{2}}}-h, \quad h>0
$$

Para a avaliação da significância dos valores gerados pela função $\mathrm{K}$, pode-se construir envelopes de confiança por simulação. Para um processo univariado marcado, mantém-se fixa as posições e distribui-se aleatoriamente as marcas sobre estes eventos.

Se os valores da função K permanecem dentro dos envelopes, significa que os eventos são não correlacionados. Se eles ultrapassam o envelope superior, significa que existe uma correlação positiva entre as marcas dos eventos. Se ultrapassam o evelope inferior, significa que existe correlação negativa entre as marcas dos eventos (Penttinen et. al, 1992). No caso do palmiteiro, por exemplo, quando ocorre uma correlação positiva entre as marcas (por exemplo, altura), significa que estas variam na mesma direção, ou seja, na distância $h$ considerada, espera-se encontrar plantas com a mesma altura. Se a correlação for negativa, significa que as marcas variam em direção oposta, ou seja, espera-se encontrar árvores baixas ou altas. Se não há correlação, na distância $h$ considerada, devem ocorrer tanto árvores baixas quanto árvores altas.

\subsection{Processo Pontual Bivariado}

Um padrão espacial bivariado é aquele produzido por dois tipos de eventos diferentes ou distinguíveis (Batista, 1994; Diggle, 1983). Por exemplo, classes de diâmetro de árvores, espécies diferentes, estádios, fenologias, idades etc, podem ser avaliadas quanto ao padrão de distribuição espacial. A função $\mathrm{K}$ de Ripley pode ser aplicada nesta situação, como uma extensão do caso univariado. 
No caso bivariado, a independência de cada um dos diferentes tipos de eventos é avaliada, ou seja, se o padrão de distribuição espacial de um tipo de evento é independente do outro tipo de evento. Isto não significa necessariamente que o padrão de distribuição tenha que ser aleatório, pois dois padrões espaciais que sejam considerados como agregados, podem ser independentes (Bailey \& Gatrell, 1995).

Para um processo espacial pontual, valem as mesmas suposições para o caso univariado, que são a isotropia e estacionariedade (Diggle, 1983).

Da mesma forma, como no caso univariado, pode-se definir as funções de intensidade de primeira e segunda ordens. A função de primeira ordem é definida segundo (Diggle, 1993) como:

$$
\lambda_{l}=\lim _{|d x| \rightarrow 0}\left\{\frac{E\left[N_{l}(d x)\right]}{|d x|}\right\} l=1,2 .
$$

e a função de segunda ordem por:

$$
\lambda_{12}(h)=\lim _{|d x||d y| \rightarrow 0}\left\{\frac{E\left[N_{1}(d x) N_{2}(d y)\right]}{|d x||d y|}\right\}
$$

A função K de Ripley para um processo bivariado, analogamente é definida da seguinte forma:

$$
K_{12}(h)=\frac{2 \pi}{\lambda_{1} \lambda_{2}} \int_{0}^{h} \lambda_{12}(t) t d t
$$

e $K_{12}=K_{21}$. Da mesma forma, $K_{11}$ e $K_{22}$ correspondem à função $K(h)$ no caso univariado (Batista, 1994; Diggle, 1983).

A função $K(h)$, para o caso bivariado, pode ser interpretada da seguinte forma: 


$$
\lambda_{2} K_{12}(h)=E(d)
$$

onde

$E(d)$ é a esperança do número de eventos do tipo 2 entre uma distância $h$ inclusive de um evento do tipo. 1.

Basicamente, a função $K(h)$, para o caso bivariado, mede a relação espacial entre dois tipos de eventos diferentes (Batista, 1994).

A função $K(h)$ pode ser estimada segundo Batista (1994) e Ohser \& Stoyan (1981) através de:

$$
\hat{K}_{12}(h)=\frac{1}{\hat{\lambda}_{1} \hat{\lambda}_{2}} \sum_{i=1}^{n_{1}} \sum_{j=1}^{n_{2}} \frac{I_{h}\left(\left|x_{1 i}-x_{2 j}\right|<h\right)}{w_{S}\left(\left|x_{1 i}-x_{2 j}\right|\right)}
$$

Como $\hat{K}_{12}=\hat{K}_{21}$, o estimador sugerido por Lotwick \& Silverman (1982) é dado da seguinte forma:

$$
\tilde{K}_{12}(h)=\frac{n_{1} \hat{K}_{12}+n_{2} \hat{K}_{21}}{n_{1}+n_{2}}
$$

Da mesma forma, como no caso univariado, para um processo pontual bivariado, os envelopes de confiança podem ser calculados. A hipótese nula é que os eventos de diferentes tipos não se "atraem" ou se "inibem" (Batista, 1994). A hipótese de nulidade é simulada através de permutação aleatória entre todos os tipos de eventos observados, assegurando-se que o número de eventos para cada tipo permaneça constante e igual ao número observado (Batista, 1994).

Assim, as envelopes podem ser "plotados" juntamente com a função $\tilde{K}_{12}(h)$, contra $h$. Dessa forma, valores maiores do que o envelope superior, indicam atração entre os eventos, valores menores do que o envelope inferior indicam inibição e valores contidos nos envelopes indicam completa independência espacial. 
Para um processo espacial bivariado, sob completa independência espacial, o valor esperado de $\hat{K}_{12}(h)$ é $\pi h^{2}$, ou seja, que não existe nenhuma relação entre os diferentes tipos de eventos ou que eles não são correlacionados (Batista, 1994). Pode-se dizer ainda que os eventos são positivamente ou negativamente correlacionados na distância $(h)$ (Diggle, 1983).

Para um processo espacial bivariado, pode-se visualizar melhor a função K de Ripley graficamente através da forma transformada,

$$
\hat{L}(h)=\sqrt{\frac{\hat{K}_{12}(h)}{\pi \hat{h}^{2}}}-h, \quad h>0
$$

Para a avaliação da significância dos valores gerados pela função $\mathrm{K}$, pode-se construir envelopes de confiança por simulação. Para um processo bivariado, mantém-se fixa as posições e distribui-se aleatoriamente os eventos sobre estes pontos, garantindo que cada tipo de evento continue com o mesmo número de pontos.

Se os valores da função $\mathrm{K}$ permanecem dentro dos envelopes, significa que os eventos são independentes. Se eles ultrapassam o envelope superior, significa que existe uma atração entre os eventos. Se ultrapassam o evelope inferior, significa que existe inibição entre os eventos (Batista, 1994). No caso do palmiteiro, quando ocorre atração entre as plantas, significa que um tipo de planta está mais próxima do outro tipo de planta e vice-versa. Quando ocorre inibição, significa que um tipo de planta está a uma distância mínima de outro tipo de planta. Quando ocorre independência, significa que a posição de um tipo de planta não depende da posição de outro tipo de planta. 


\subsection{Processo Pontual Marcado Bivariado}

Como no caso univariado, também pode-se associar marcas a um processo espacial bivariado. O objetivo deste tipo de análise é avaliar a correlação ou a dependência existente entre as marcas de um processo (por exemplo, altura de plantas, diâmetro etc) de dois tipos de pontos (espécies, estádios, fenologias, idades etc). A questão básica é, dado o padrão individual de dois tipos de pontos, existe alguma dependência espacial entre uma e outra marca?

Como exemplo, pode-se ter dois tipos de pontos como sendo plantas reprodutivas e plantas não reprodutivas e como marcas, pode-se ter a altura. Neste caso, deseja-se saber se a altura de um tipo de evento é independente da altura do outro tipo de evento.

A função K de Ripley pode ser estimada como:

$$
\hat{K}_{m_{1} m_{2}}(h)=\frac{1}{\hat{\lambda}_{1} \hat{\lambda}_{2}} \sum_{i=1}^{n_{1}} \sum_{j=1}^{n_{2}} w_{S} I_{h}\left(x_{1 i}-x_{2 j}\right) m_{1 i} m_{2 j}
$$

Graficamente, pode-se visualizar a função $\mathrm{K}$ através da seguinte transformação:

$$
\hat{L}(h)=\sqrt{\frac{\hat{K}_{m_{1} m_{2}}(h)}{\pi \mu^{2}}}-h, \quad h>0
$$

Para testar a hipótese de independência das marcas, um envelope de confiança pode ser calculado. Mantém-se fixo o padrão dos dois tipos de eventos e distribui-se as marcas por permutação aleatória nestes pontos. 
Se os valores da função K permanecem dentro dos envelopes de confiança, significa que as marcas dos eventos são espacialmente não correlacionadas. Se os valores ultrapassam o envelope superior, as marcas são positivamente correlacionadas e se os valores da função $\mathrm{K}$ ultrapassam o envelope inferior, significa que as marcas são negativamente correlacionadas (Batista, 1994). No caso do palmiteiro, quando ocorre uma correlação positiva entre as marcas (por exemplo, altura) de dois tipos de plantas, significa que estas variam na mesma direção, ou seja, na distância $h$ considerada, espera-se encontrar plantas do tipo 1 com a mesma altura de plantas do tipo 2. Se a correlação for negativa, significa que as marcas variam em direção oposta, ou seja, na distância $h$ considerada, espera-se encontrar árvores baixas do tipo 1 e árvores altas do tipo 2 e vice versa. Se não há correlação, na distância $h$ considerada, devem ocorrer tanto árvores baixas e altas do tipo 1 quanto árvores baixas e altas do tipo 2 .

\subsection{Perda de Eventos}

$\mathrm{Na}$ análise do padrão de distribuição espacial, supõe-se, segundo Diggle (1983) e Ripley (1977), que um mapa completo está disponível, com as coordenadas. Em situações específicas, pode ocorrer a perda de alguma informação no conjunto de dados mapeados. Árvores podem ser de difícil mensuração ou acesso. Dados podem ser registrados de maneira errada e assim por diante. Em tais situações, qual a confiabilidade dos resultados gerados sem estes pontos? Quanto e como os resultados finais são perturbados, em relação a um mapa completo? Quais as implicações para diferentes padrões de distribuição espacial: aleatório, agregado ou regular?

Por outro lado, considerando uma população natural, onde preten- 
de-se desenvolver um sistema de manejo de rendimento sustentado, como é o caso do palmiteiro (E. edulis), procura-se minimizar o efeito da exploração na alteração do padrão natural de distribuição espacial desta espécie. Em tais casos, é ideal que numa mesma escala, o padrão de distribuição permaneça inalterado.

Uma alteração do padrão espacial de uma espécie dentro de um ecossistema complexo e frágil, como a floresta tropical atlântica, pode causar danos irreparáveis, além de frustrar qualquer tentativa de um aproveitamento futuro de produtos florestais. Por exemplo, se o padrão de distribuição de plantas matrizes for alterado, é possível que a regeneração não ocorra de forma eficiente, afetando a reposição de novas plantas.

A probabilidade dos dispersores, principalmente aves (Reis, 1996) encontrarem as plantas matrizes pode diminuir, conseqüentemente diminuindo o número de sementes que poderiam estar germinando no solo da floresta e certamente, mantendo o padrão de distribuição espacial natural da espécie. 


\section{CAPÍTULO 3}

\section{Análise do Padrão de Distribuição Espacial do Palmiteiro (Euterpe edulis) Utilizando a Função K de Ripley}

\subsection{Introdução}

Segundo Andersen (1992), Sterner et al. (1986) e Thomson (1986), a detecção de padrões espaciais tem sido uma das questões bastante estudadas há vários anos por ecologistas. O padrão espacial de plantas em uma comunidade pode revelar alguns aspectos de interesse para ecologistas, principalmente com relação à dinâmica populacional e competição intra e interespecífica (Andersen, 1992; Haase, 1995).

A análise do padrão espacial é uma ferramenta para interpretar processos de desenvolvimento anteriores e interações competitivas em uma floresta (Moeur, 1993). O conhecimento do padrão de distribuição espacial caracteriza a variação da localização das árvores (Penttinem et al., 1992), que é uma característica que pode revelar qual o melhor método de amostragem que pode ser utilizado (Diggle, 1983). Por exemplo, se for detectado que o padrão de distribuição é agregado, pode-se utilizar um método de amostragem adequado para esta situação.

Existem várias vantagens em conhecer os padrões espaciais em comunidades de plantas. Algumas inferências que podem ser feitas são citadas por Hill (1973): 
- relacionar diferenças no ambiente local com diferenças na vegetação. É possível identificar áreas onde a ocorrência de uma determinada espécie é maior e áreas onde a ocorrência é menor e determinar o que está interferindo ou causando este padrão: clareiras, dispersores, condições edáficas etc.

- sugerir ou confirmar teorias sobre a competição e estabelecimento de plantas na comunidade. Pode-se inferir sobre quais os fatores que atuam sobre a diversidade de espécies num ambiente de floresta, por exemplo.

- determinar uma escala aproximada do mosaico da vegetação. Descritivamente, é possível determinar quais as dimensões da estrutura de uma população, ou melhor, em que escala existe algum padrão, ou em que escala um padrão está ausente.

O conhecimento do padrão espacial parece ser a chave para entender as causas, modos e taxas de processos de dispersão (Reis, 1995; Rosso et al., 1994). Além disso, o objetivo de ecologistas, principalmente em formações florestais, é explicar como uma grande quantidade de espécies de árvores estão aparentemente aptas para coexistirem num mesmo local (Newbery et al., 1986). Também, a inclusão da informação sobre o padrão de distribuição espacial pode melhorar manejos tradicionais, orientar pesquisadores na elaboração de modelos de exploração (Levin, 1992; Moeur, 1993) e subsidiar estratégias de conservação de ecossistemas naturais (Reis,1996).

O padrão de distribuição de uma população é uma característica fundamental, mas é de difícil descrição em termos precisos e significativos (Clark \& Evans, 1954). Existem vários métodos utilizados na análise do padrão de distribuição espacial, que tentam descrever o máximo possível a estrutura do fenômeno ao qual estão sendo aplicados, e que, comumente utilizam medidas de distâncias entre indivíduos ou contagem em parcelas (Heltshe \& Ritchey, 1984). Esta estrutura pode ser definida através do tamanho e do arranjamento espacial das árvores e o 
conhecimento destes fatores pode informar as condições ou o nível de distúrbio de uma floresta (Kuuluvainen et al., 1996). É necessário, obviamente, para que esta comparação possa ser feita, que exista um conhecimento "a priori" da estrutura natural ou primitiva da espécie que se está estudando.

O palmiteiro (Euterpe edulis - MARTIUS,) é uma palmeira encontrada na Mata Atlântica, estendendo-se desde o sul da Bahia $\left(15^{\circ} \mathrm{S}\right)$ até o norte do Rio Grande do Sul $\left(30^{\circ} \mathrm{S}\right)$ no litoral, adentrando, no sul, até o leste do Paraguai e norte da Argentina $\left(57^{\circ} \mathrm{W}\right)$ (Reis, 1996).

Esta palmeira é uma das principais fornecedoras de "palmito", que é um alimento formado basicamente do meristema apical e de folhas jovens, das quais, as principais partes consumidas são as bainhas (Reis, 1995).

Devido a sua importância econômica, muitas pesquisas tem sido realizadas, caracterizando esta espécie como uma das plantas mais estudadas quanto a sua ecologia dentro da Mata Atlântica (Fantini, 1992; Fantini, 1997; Reis, 1995; Reis, 1996; ). Por outro lado, alguns trabalhos (Monteiro \& César, 1995; Reis, 1995) analisam a distribuição espacial, mas utilizam métodos baseados apenas em contagens ou distâncias separadamente.

Esta espécie vem sendo explorada de forma extrativista indiscriminada. Devido a isso, as populações naturais encontram-se alteradas em sua estrutura (Reis, 1995). Em vista disso, tem-se procurado conciliar à exploração do palmito com a conservação das florestas, através de sistemas de manejo em regime de rendimento sustentado.

Esta espécie apresenta algumas características favoráveis a este tipo de manejo, que são, segundo Reis (1995):

- possui uma distribuição geográfica ampla; 
- ocupa o estrato médio da floresta;

- ocorre com alta freqüência e grandes densidades;

- possui alto valor econômico;

- é fácil de ser explorada e industrializada;

- tem produção de sementes abundante;

- tem uma forte interação com a fauna.

Ainda, é possível o retorno econômico com a conservação da floresta pois, como o palmiteiro ocupa o estrato médio, existe a necessidade de conservação das mesmas, sem as quais, não é possivel a perpetuação da exploração.

O estudo sobre a estrutura de populações desta espécie é de fundamental importância, não só para poder explorá-la racionalmente, como para a preservação das florestas as quais pertence (Reis, 1995). O padrão de distribuição espacial é uma característica que pode fornecer informações sobre a sucessão de plantas (Budowski, 1965), além de fornecer informações para orientar modelos de manejo.

Neste sentido, o estudo de tais populações, em locais com pouca ou nenhuma intervenção do homem, é essencial para que possa ser feita uma comparação, em relação à dinâmica populacional da espécie, em áreas manejadas, sob processo de extrativismo ou em fase de colonização em estádios iniciais de sucessão (Reis, 1995).

Desta forma, os objetivos deste capítulo são descrever o padrão de distribuição espacial do palmiteiro, considerando os diferentes estádios e número total de plantas, utilizando a função K de Ripley, no caso univariado e bivariado, com e sem marcas (Diâmetro a altura do peito (DAP) e altura da estipe). 


\subsection{Material e Métodos}

\section{Dados}

Os dados de distribuição espacial do palmiteiro (E. edulis), foram coletados na Fazenda Faxinal, localizada no município de Blumenau, SC, entre os paralelos $27^{\circ} 04^{\prime}$ e $27^{\circ} 05^{\prime}$ sul e os meridianos $49^{\circ} 05^{\prime}$ e $49^{\circ} 10^{\prime}$ a oeste de Greenwich. A área possui uma cobertura vegetal de Mata Atlântica com pouca ou nenhuma exploração de madeira ou palmito (Reis, 1995). Dentro desta região foi demarcada uma área de 5,44 hectares $(160 \times 340 \mathrm{~m})$, onde foram registradas as posições de todas as plantas de palmiteiro que apresentavam estipe exposto. Estas plantas foram classificadas em três estádios:

- Imaturos 1 - Plantas com altura de estipe exposto inferior a 1,30 m;

- Imaturos 2 - Plantas com altura de estipe exposto maior ou igual a 1,30 m mas, sem evidências de emissão de inflorescências;

- Adultos - Plantas com altura de estipe exposto maior ou igual a $1,30 \mathrm{~m}$ e com sinais de reprodução (cachos secos, cicatrizes) ou em reprodução. 
Análise estatística

Analisou-se o padrão de distribuição das plantas de palmiteiro de todas os estádios. Consideraram-se os casos univariado e bivariado, com e sem marcas, da função K de Ripley. A distância $h$ foi definida em $1 \mathrm{~m}$, ou seja, a função $\mathrm{K}$ de Ripley avalia a relação existente entre pares de eventos a cada $1 \mathrm{~m}$, até o $\min (a, b)$, onde $a$ e b são os lados da parcela estudada, neste caso $\min (a, b)=160 \mathrm{~m}$.

Para visualização gráfica, utilizou-se a forma transformada da função $K(h)$ dada por:

$$
\hat{L}(h)=\sqrt{\frac{K(h)}{\pi h^{2}}}-h, \quad h>0
$$

Para um padrão com distribuição aleatória, o valor esperado de $L(h)=0$. Para um padrão agregado, $L(h)>0$ e para um padrão regular, $L(h)<0$. Para a avaliação da significância do padrão observado, construiram-se envelopes de confiança ao nível de $1 \%$ de probabilidade (99 simulações).

Consideraram-se como marcas as alturas de estipe exposto e o DAP (Diâmetro à altura do peito) de cada palmeira. 


\subsection{Resultados e Discussão}

\subsubsection{Caso Univariado}

Imaturos 1: As plantas do estádio imaturos 1 (figura 3.3a), mapeadas dentro da parcela de $340 \times 160 \mathrm{~m}$, apresentaram um padrão de distribuição agregado até uma distância de $120 \mathrm{~m}$, passando para aleatório até $145 \mathrm{~m}$ e depois tornando-se regular. A figura $3.3 \mathrm{~b}$ mostra que estas plantas apresentam agregados de diferentes tamanhos, distribuídos regularmente dentro da área.

Considerando-se as alturas (figura $3.4 \mathrm{a}$ ), a figura $3.4 \mathrm{~b}$ indica que não há nenhuma correlação entre as alturas das palmeiras na escala estudada, ou seja, as alturas deste estádio estão distribuídas de forma independente na área.

Imaturos 2: As plantas do estádio imaturos 2 (figura 3.5a) apresentaram um padrão muito semelhante ao das plantas do estádio imaturos 1 . Há um padrão agregado até uma distância de $100 \mathrm{~m}$, passando para aleatório até $130 \mathrm{~m}$ e depois tornando-se regular (figura 3.5b). Este padrão também indica que as plantas deste estádio formam agregados de diferentes tamanhos e estes agregados são distribuídos de maneira regular na área estudada.

Considerando-se as alturas (figura 3.6a), a figura 3.6b mostra que não existe correlação entre as alturas das plantas de palmiteiro do estádio imaturos 2 na escala estudada, ou seja, as alturas deste estádio também são distribuídas 


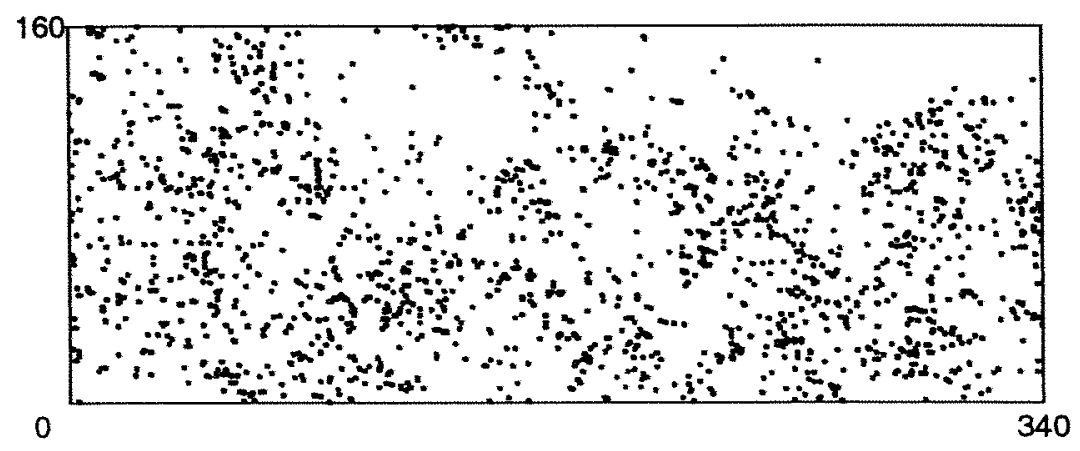

a

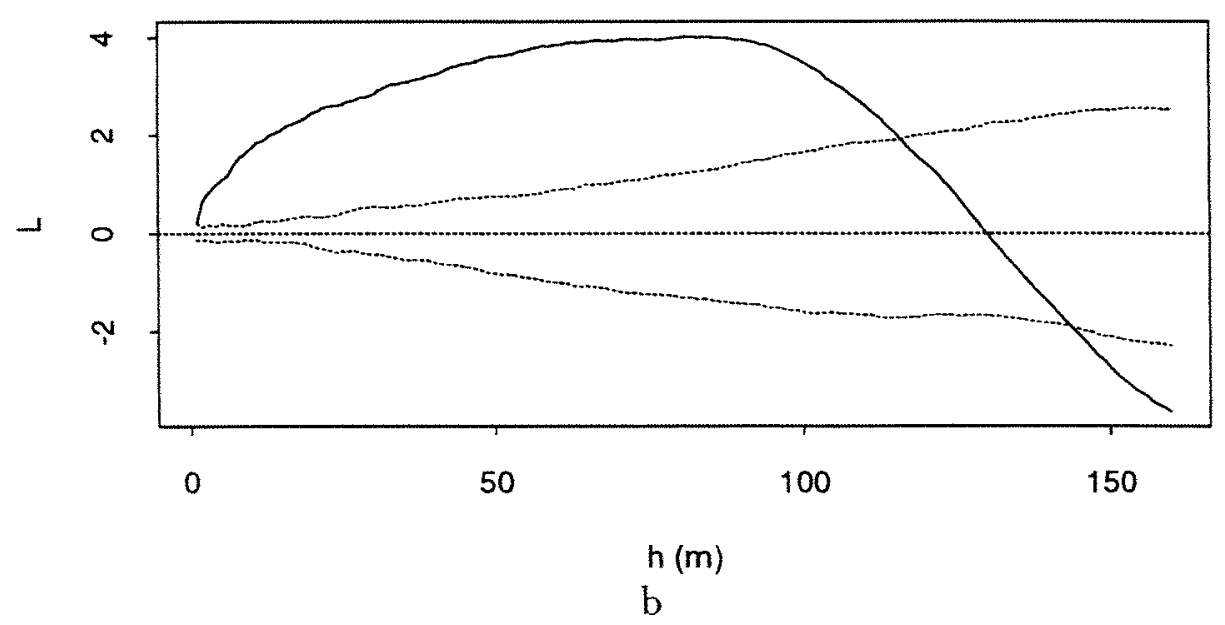

Figura 3.3: a) Plantas de palmiteiro do estádio imaturos $1(n=1598)$, mapeadas dentro da parcela de $340 \times 160 \mathrm{~m}$; b) análise do padrão de distribuição espacial através da função $\mathrm{K}$ de Ripley. Linhas pontilhadas representam envelopes de confiança construídos com 99 simulações. 


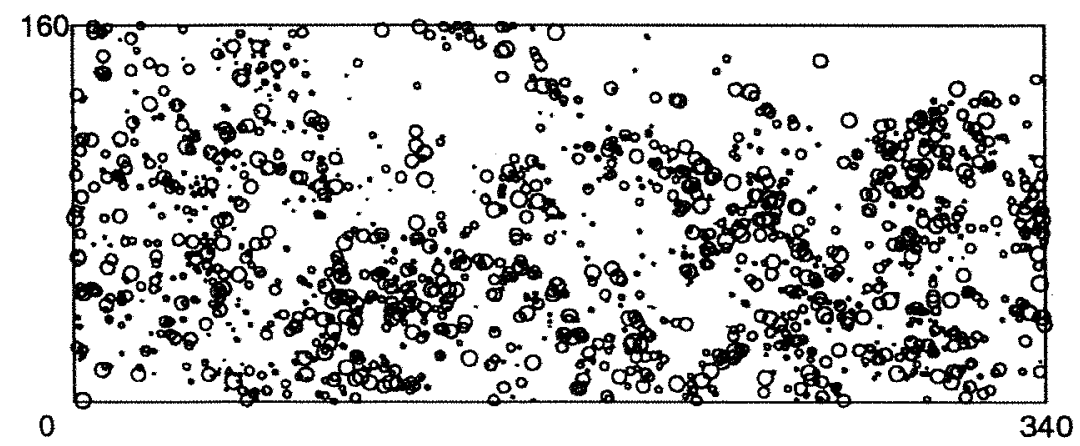

a

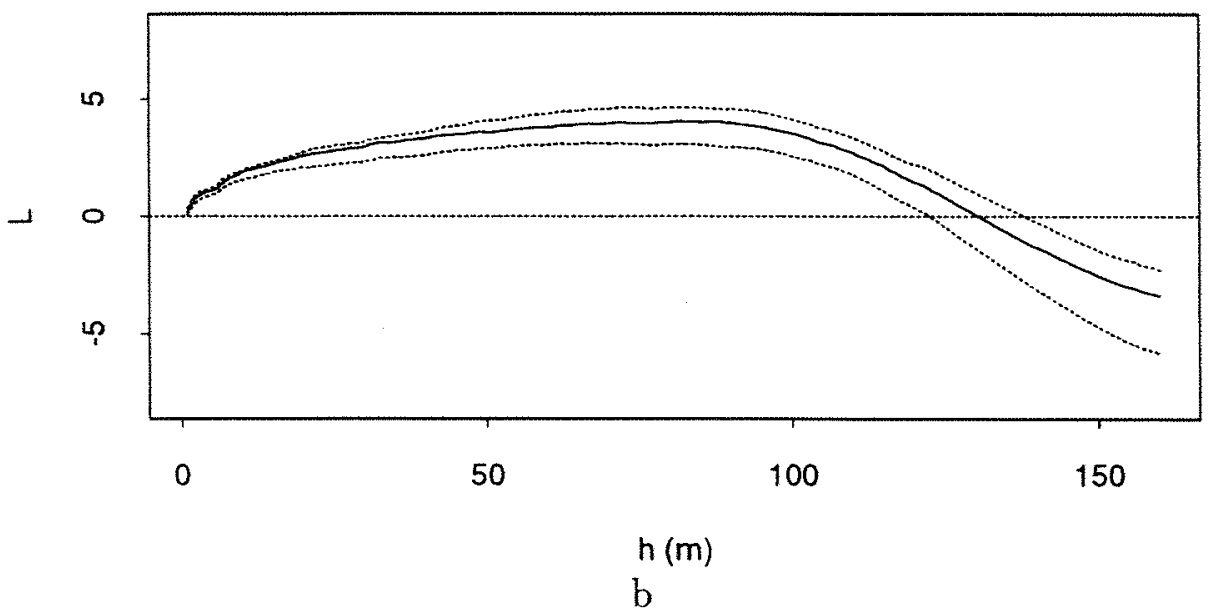

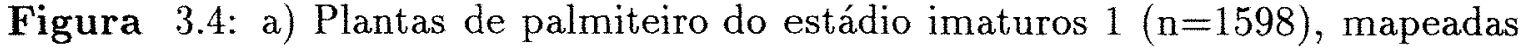
dentro da parcela de $340 \times 160 \mathrm{~m}$; b) análise da correlação entre as alturas, através da função K de Ripley. Linhas pontilhadas representam envelopes de confiança construídos com 99 simulações. 


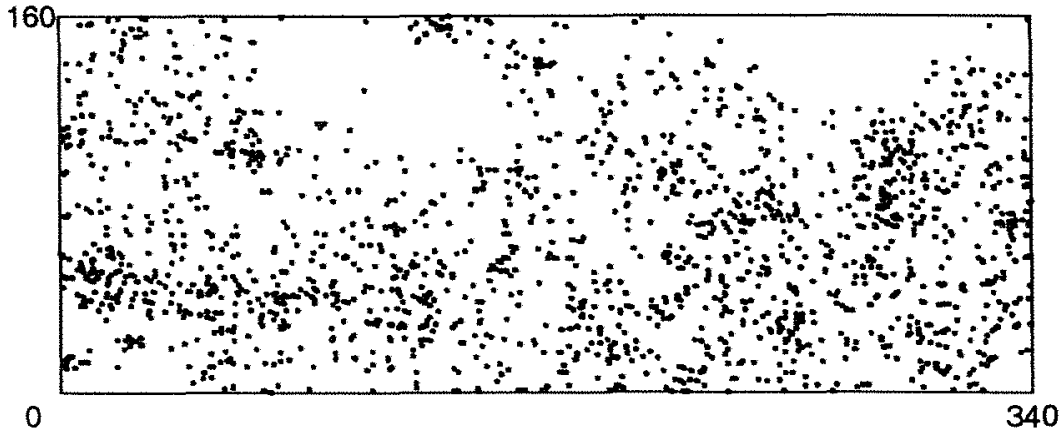

a

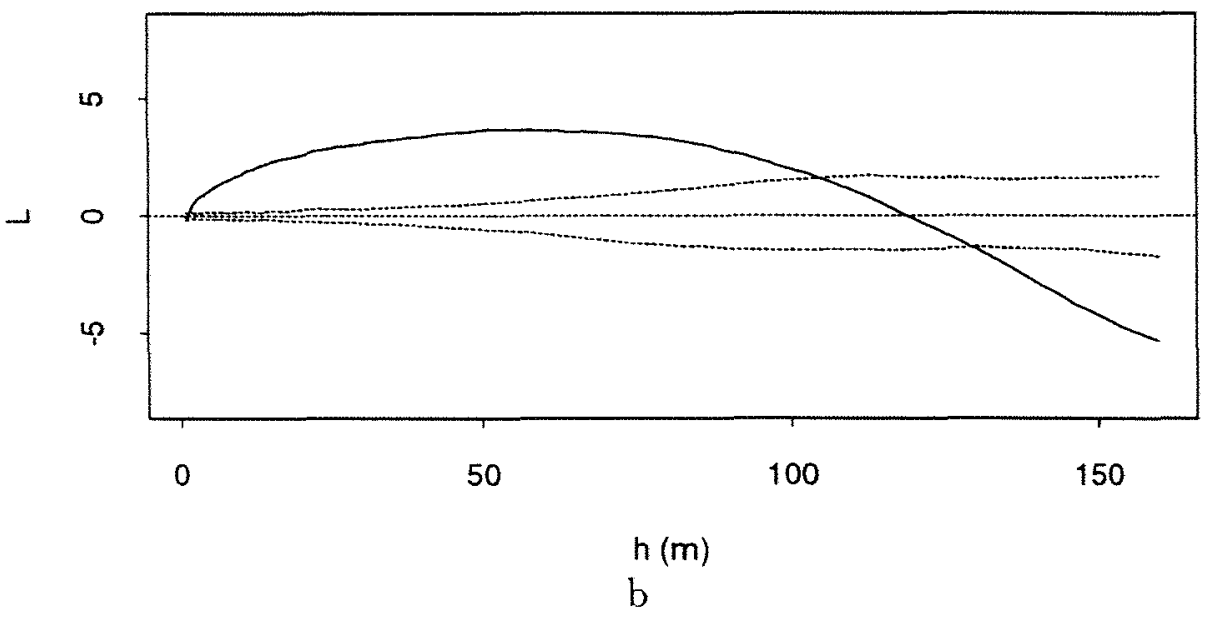

Figura 3.5: a) Plantas de palmiteiro do estádio imaturos $2(\mathrm{n}=1680)$, mapeadas dentro da parcela de $340 \times 160 \mathrm{~m}$; b) análise do padrão de distribuição espacial através da função K de Ripley. Linhas pontilhadas representam envelopes de confiança construídos com 99 simulações. 
independentemente na área.

Quando consideraram-se os diâmetros (figura 3.7a), observa-se que existe uma correlação positiva, a uma distância que varia de 60 a $90 \mathrm{~m}$ (figura 3.7b). Espera-se encontrar, em média, indivíduos maiores a esta distância.

Adultos: As plantas de palmiteiro do estádio adulto (figura 3.8a), também apresentaram um padrão de distribuição agregado, muito semelhante ao encontrado para as plantas dos estádios imaturos 1 e 2. As plantas adultas apresentam um padrão aleatório até uma distância de $5 \mathrm{~m}$ e acima de $130 \mathrm{~m}$. Entre 5 e $130 \mathrm{~m}$, o padrão é agregado (figura $3.8 \mathrm{~b}$ ). Neste caso, os agregados estão distribuídos de forma aleatória sobre a área. As plantas dentro de cada agregado têm uma distribuição aleatória até $5 \mathrm{~m}$ de distância ou de raio.

Quando consideraram-se as alturas das plantas do estádio adulto (figura 3.9a), observa-se que existe uma correlação positiva entre 25 e $50 \mathrm{~m}$ (figura 3.9b). Fora destas distâncias, observou-se que não há nenhuma dependência espacial entre as árvores adultas de palmiteiro dentro da área.

Quando consideraram-se os diâmetros (figura 3.10a) das plantas de palmiteiro do estádio adulto, observa-se que não há nenhuma dependência espacial entre as árvores de palmiteiro (figura 3.10a). Isto mostra que o diâmetro de uma árvore de palmiteiro, é independente do diâmetro de qualquer outra planta desta espécie na mesma área.

Imaturos 1, Imaturos 2 e Adultos: Considerando-se toda a população medida na área (figura 3.11a), através da função K de Ripley (figura 3.11b), pode-se verificar, como já era esperado, que o padrão de distribuição das plantas é do tipo agregado, até uma distância de $120 \mathrm{~m}$, passando a aleatório até uma distância de $140 \mathrm{~m}$ e depois torna-se regular. Assim, as plantas de palmiteiro formam agregados de vários tamanhos, distribuídos de forma regular sobre a parcela. 


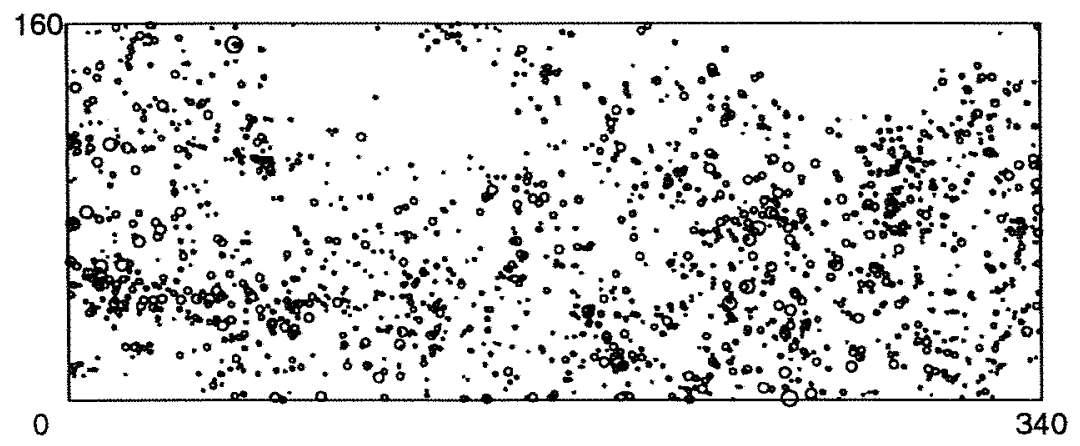

a

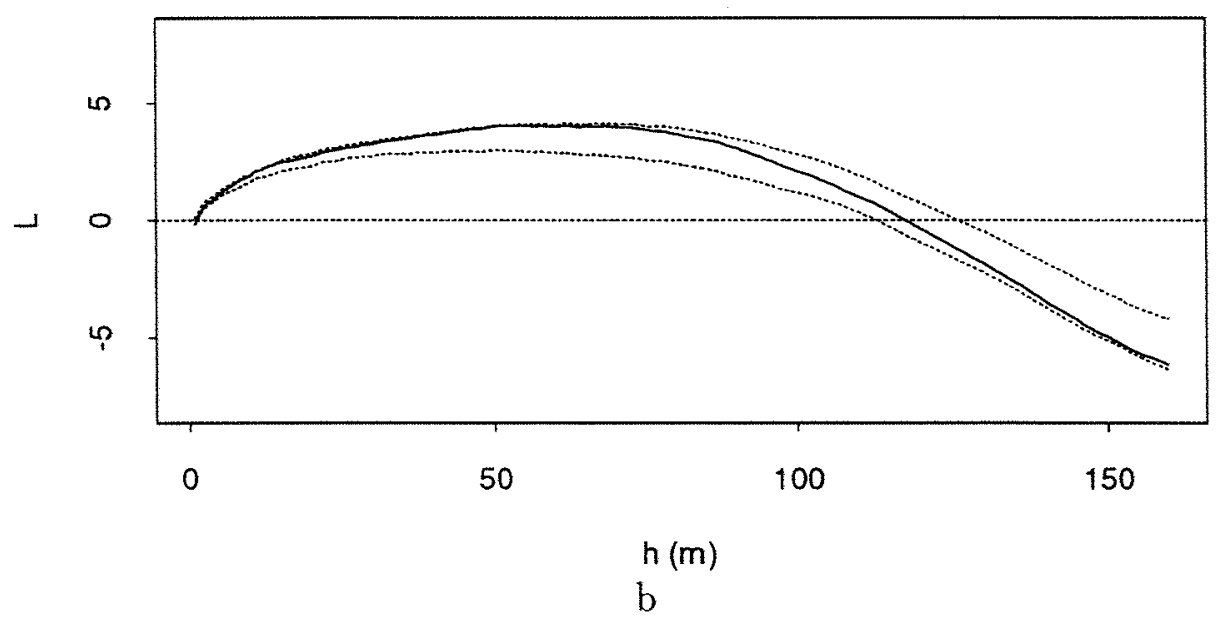

Figura 3.6: a) Plantas de palmiteiro do estádio imaturos $2(n=1680)$, mapeadas dentro da parcela de $340 \times 160 \mathrm{~m}$; b) análise da correlação entre as alturas, através da função K de Ripley. Linhas pontilhadas representam envelopes de confiança construídos com 99 simulações. 


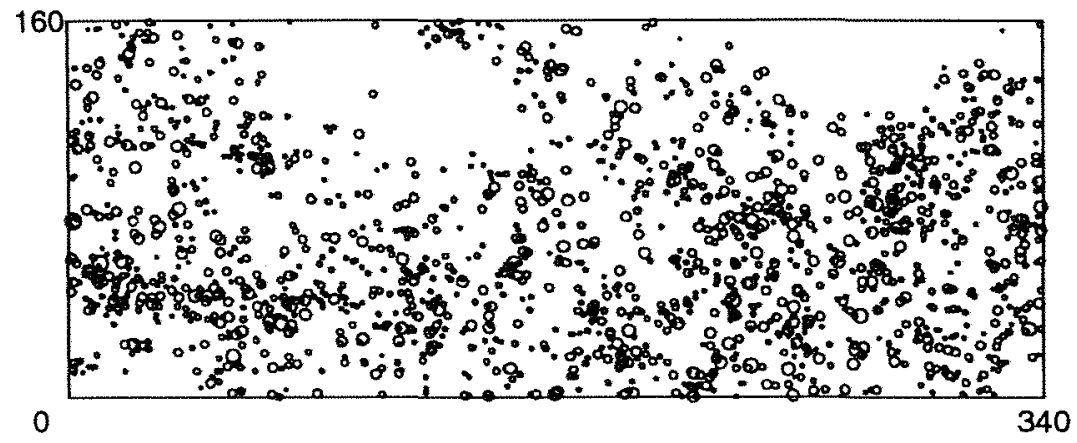

a

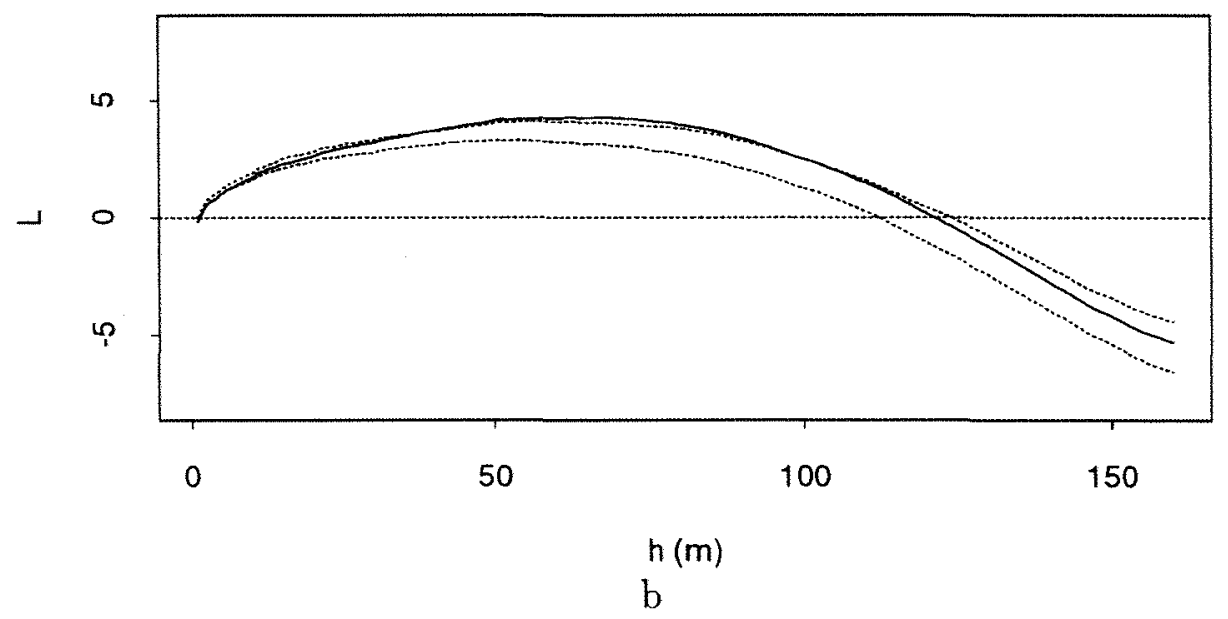

Figura 3.7: a) Plantas de palmiteiro do estádio imaturos $2(n=1680)$, mapeadas dentro da parcela de $340 \times 160 \mathrm{~m}$; b) análise da correlação entre os diâmetros, através da função K de Ripley. Linhas pontilhadas representam envelopes de confiança construídos com 99 simulações. 


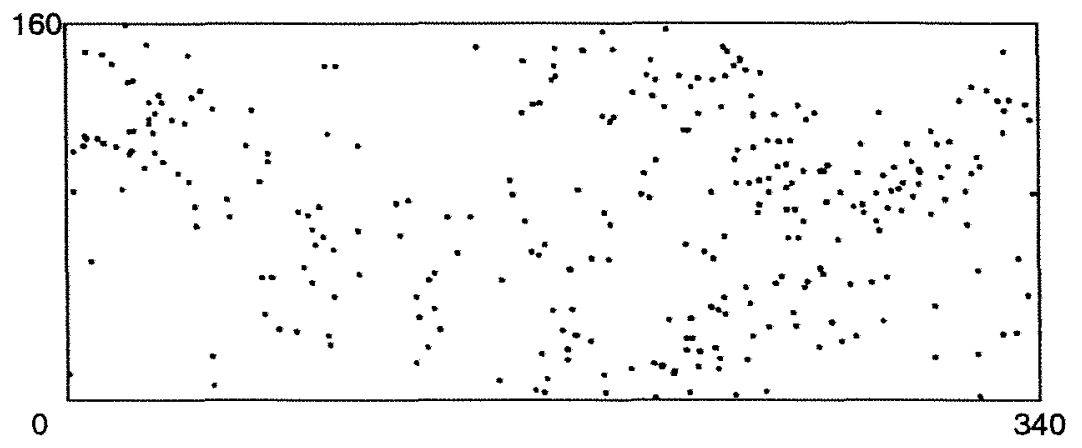

a

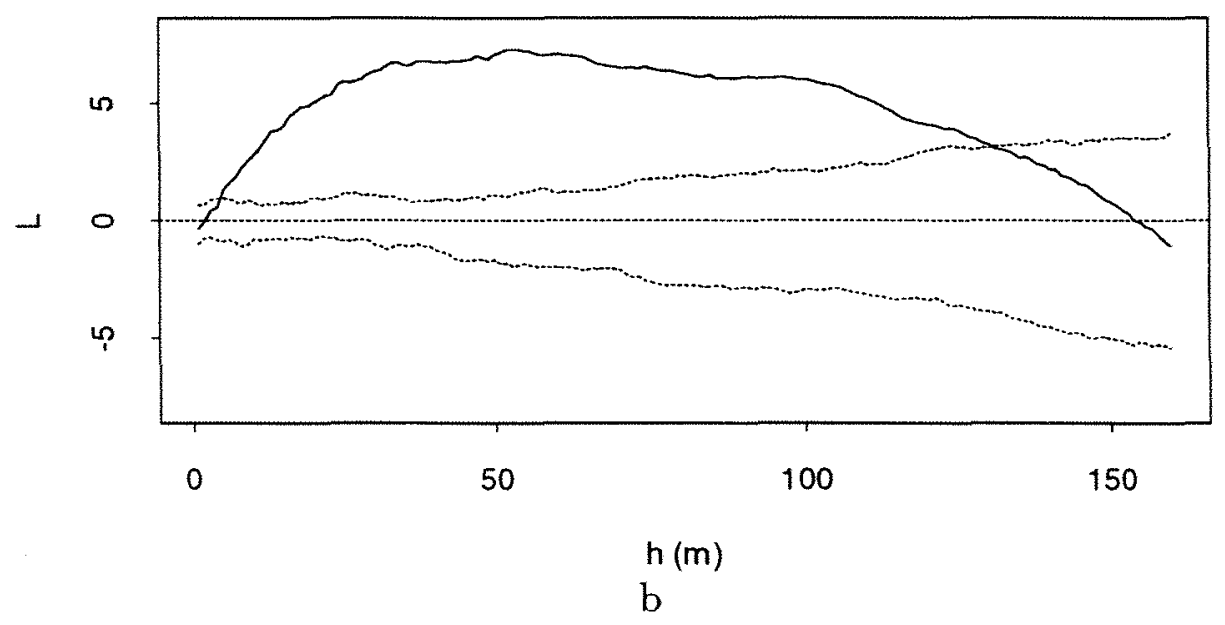

Figura 3.8: a) Plantas de palmiteiro do estádio adulto $(\mathrm{n}=297)$, mapeadas dentro da parcela de $340 \times 160 \mathrm{~m}$; b) análise do padrão de distribuição espacial através da função $\mathrm{K}$ de Ripley. Linhas pontilhadas representam envelopes de confiança construídos com 99 simulações. 


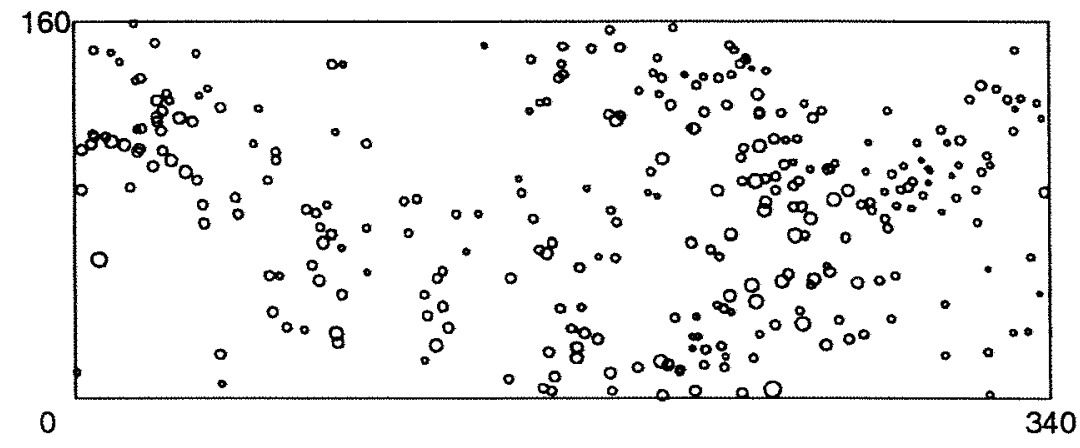

a

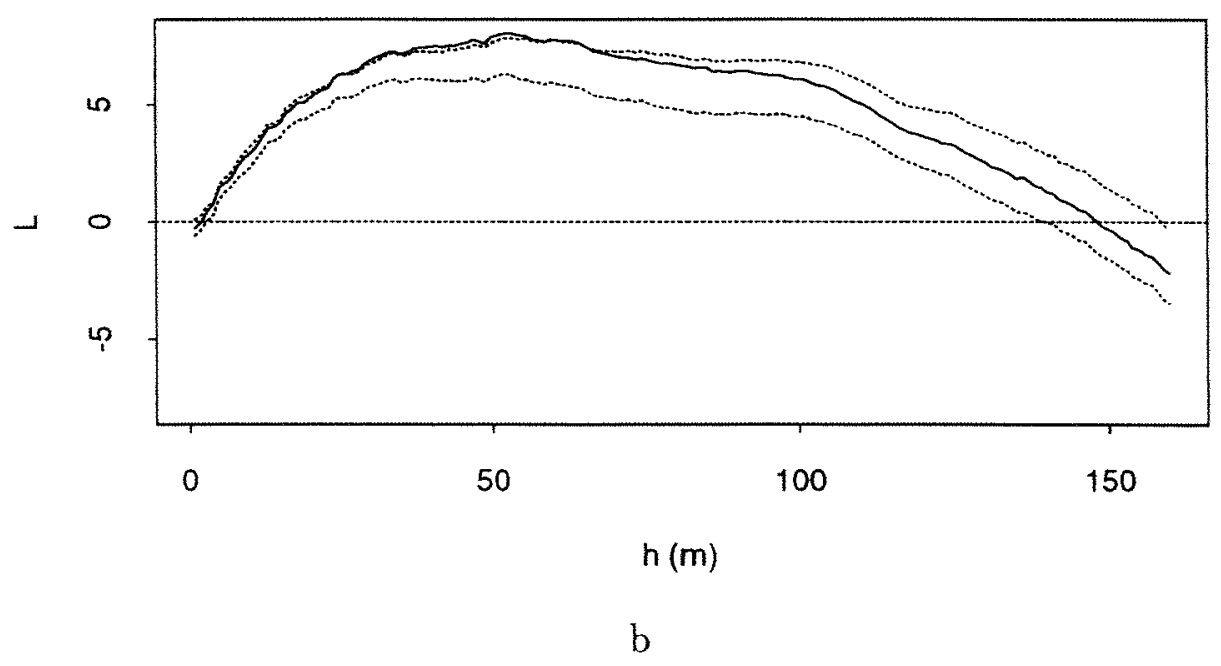

Figura 3.9: a) Plantas de palmiteiro do estádio adulto $(\mathrm{n}=297)$, mapeadas dentro da parcela de $340 \times 160 \mathrm{~m}$; b) análise da correlação entre as alturas, através da função K de Ripley. Linhas pontilhadas representam envelopes de confiança construídos com 99 simulações. 


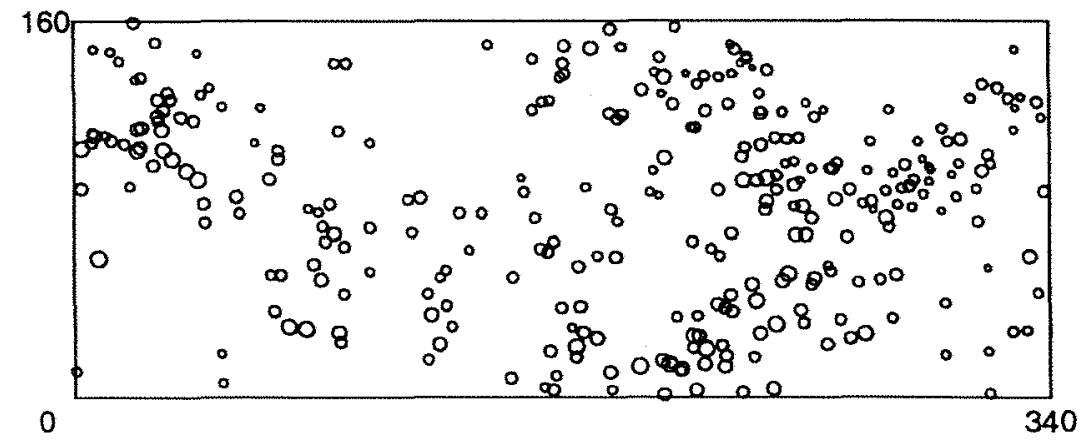

a

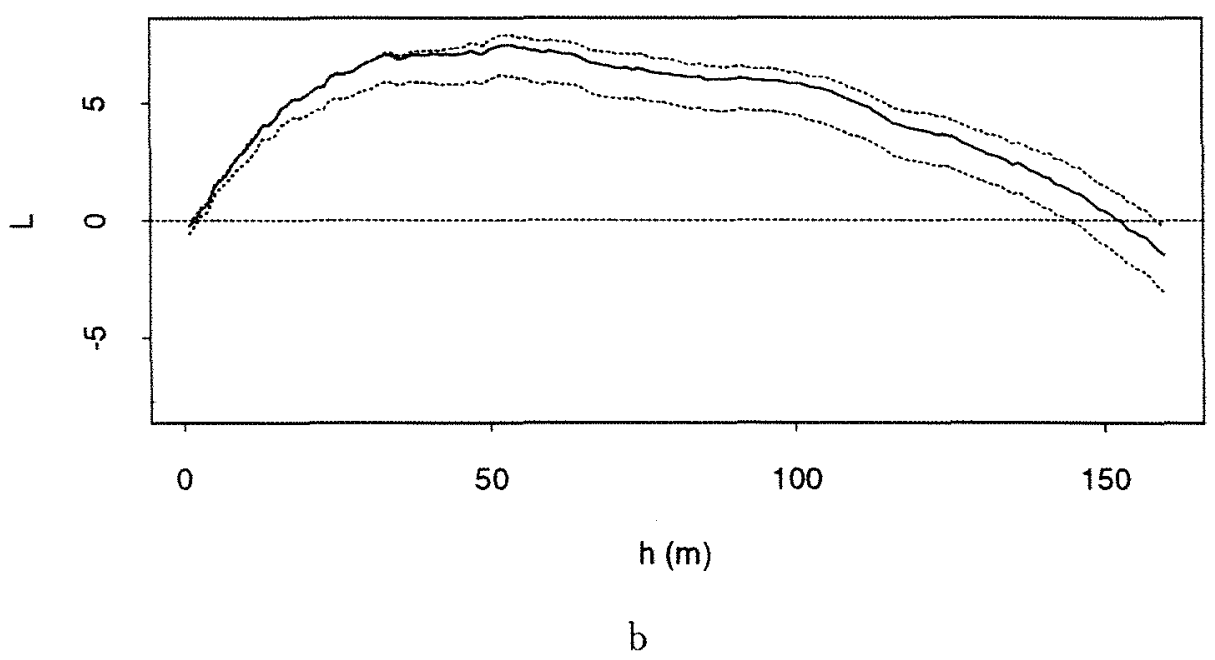

Figura 3.10: a) Plantas de palmiteiro do estádio adulto $(\mathrm{n}=297)$, mapeadas dentro da parcela de $340 \times 160 \mathrm{~m}$; b) análise da correlação entre os diâmetros, através da função $\mathrm{K}$ de Ripley. Linhas pontilhadas representam envelopes de confiança construídos com 99 simulações. 


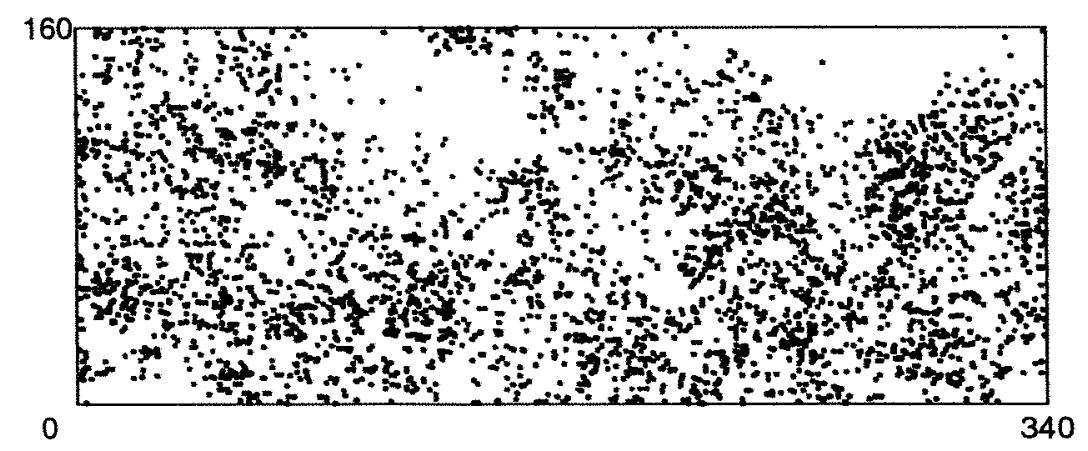

a

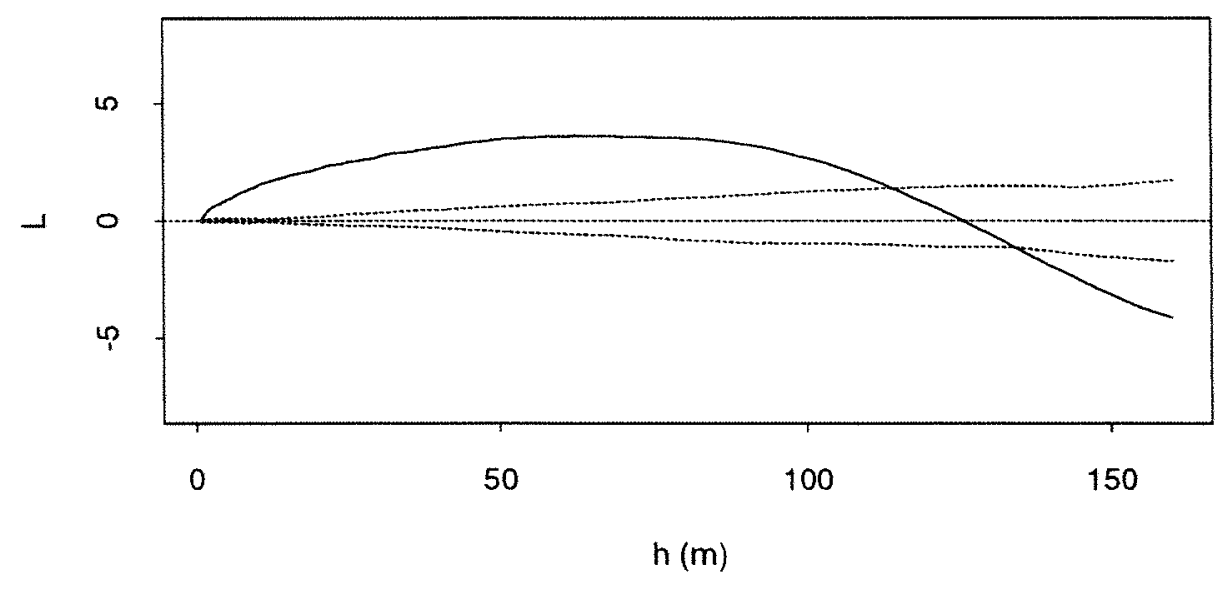

$\mathrm{b}$

Figura 3.11: a) Plantas de palmiteiro dos estádios imaturos $1(\mathrm{n}=1598), 2(\mathrm{n}=1680)$ e adultos $(\mathrm{n}=297)$, mapeadas dentro da parcela de $340 \times 160 \mathrm{~m}$; b) análise do padrão de distribuição espacial através da função K de Ripley. Linhas pontilhadas representam envelopes de confiança construídos com 99 simulações. 
Quando consideraram-se as alturas de todas as plantas (figura 3.12a), observa-se que também não há dependência espacial entre as árvores de palmiteiro, para esta variável (figura 3.12b). Portanto, a altura da estipe de uma planta não depende da altura de outras plantas vizinhas.

Imaturos 2 e Adultos: Considerando-se as plantas dos estádios 2 e adultas juntas (figura 3.13a), o padrão de distribuição destas plantas segue o mesmo padrão encontrado para toda a população (figura $3.13 \mathrm{~b}$ ).

Quando consideraram-se as alturas (figura 3.14a) e também os diâmetros (figura 3.15a), verifica-se que não existe correlação entre as plantas de palmiteiro destes estádios (figura $3.14 \mathrm{~b}$ e figura 3.15b). Portanto, tanto a distribuição das alturas de estipe, quanto a dos diâmetros, estão distribuídas na área de forma independente. 


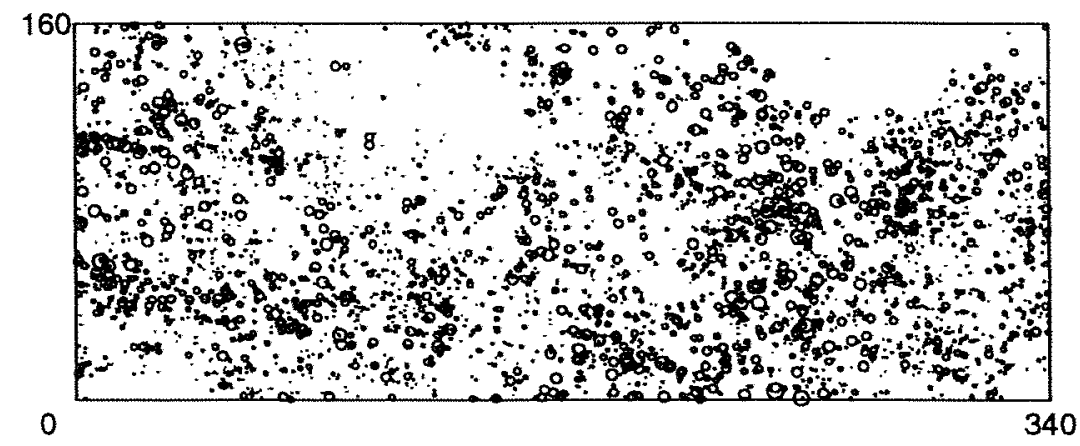

a

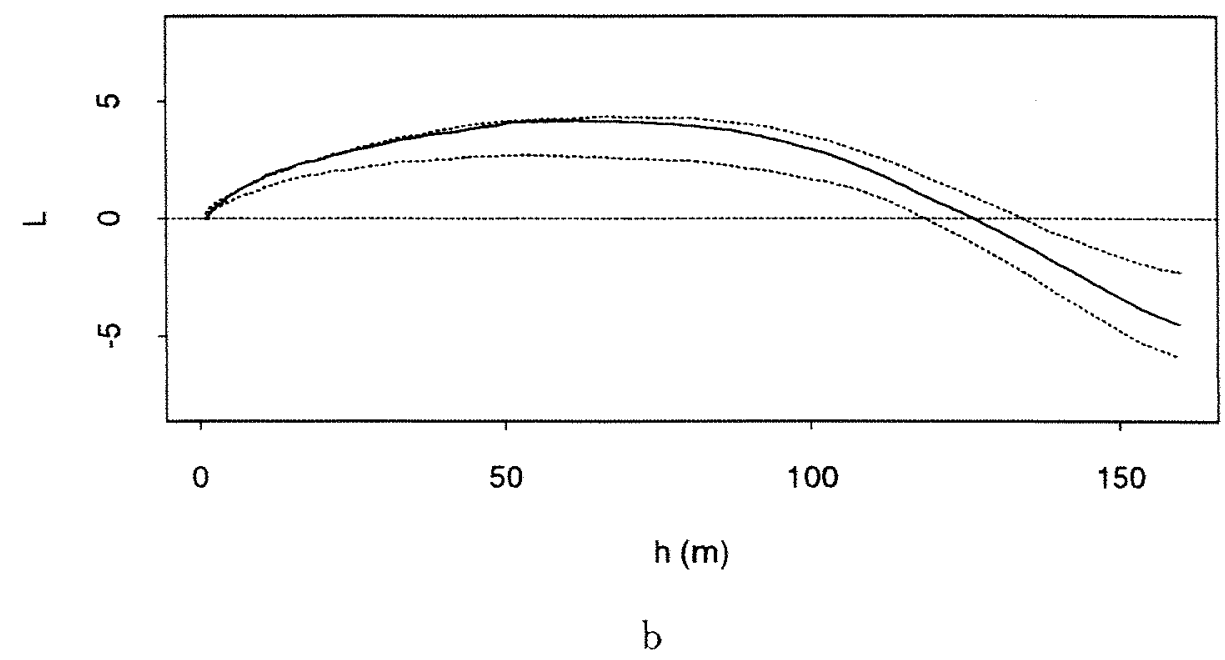

Figura 3.12: a) Plantas de palmiteiro dos estádios imaturos $1(\mathrm{n}=1598), 2(\mathrm{n}=1680)$ e adultas $(n=297)$, mapeadas dentro da parcela de $340 \times 160 \mathrm{~m}$; b) análise da correlação entre as alturas, através da função K de Ripley. Linhas pontilhadas representam envelopes de confiança construídos com 99 simulações. 


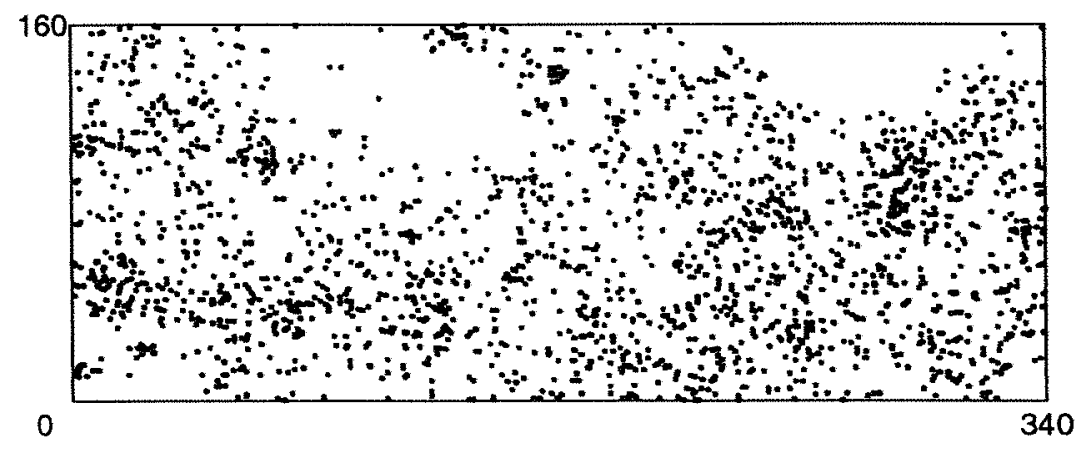

$a$

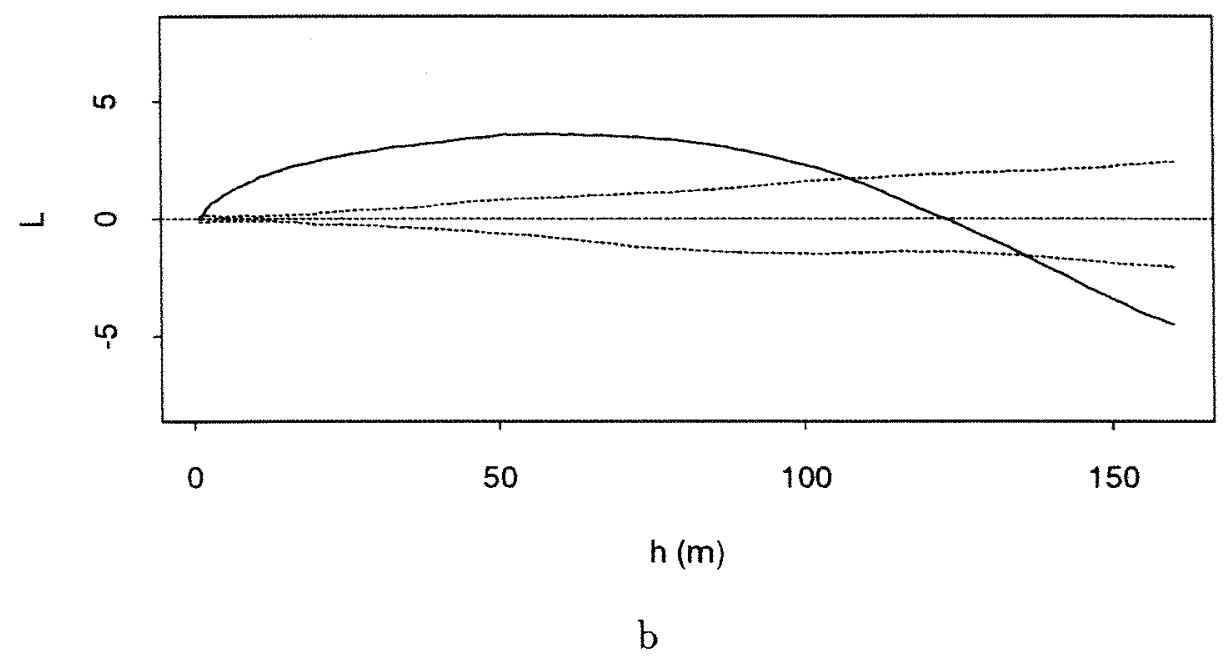

Figura 3.13: a) Plantas de palmiteiro dos estádios imaturos $2(\mathrm{n}=1680)$ e adultas $(\mathrm{n}=297)$, mapeadas dentro da parcela de $340 \times 160 \mathrm{~m}$; b) análise do padrão de distribuição espacial através da função $\mathrm{K}$ de Ripley. Linhas pontilhadas representam envelopes de confiança construídos com 99 simulações. 


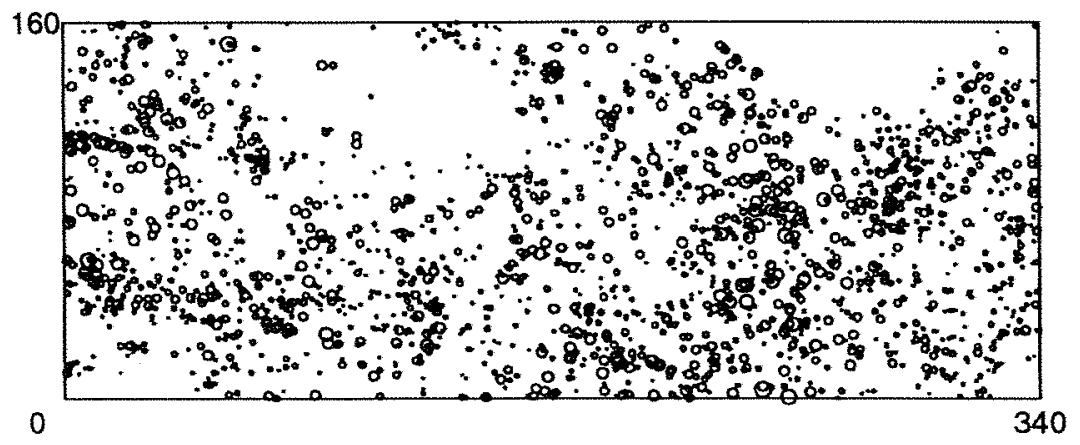

a

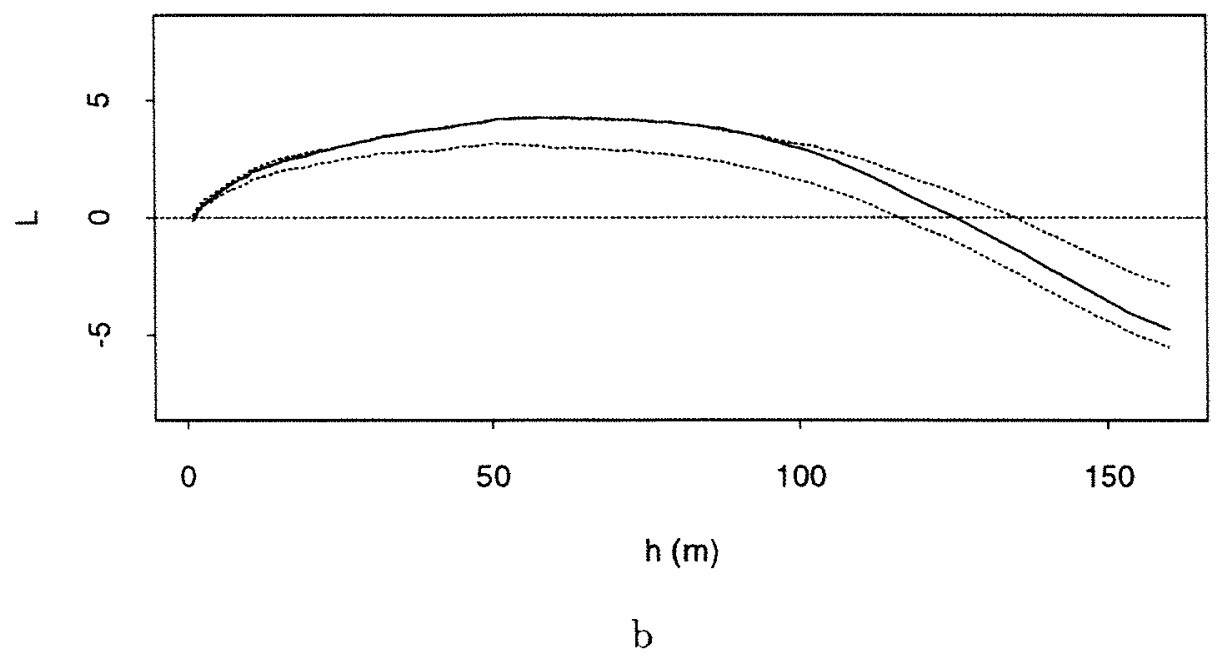

Figura 3.14: a) Plantas de palmiteiro dos estádios imaturos $2(\mathrm{n}=1680)$ e adultas $(\mathrm{n}=297)$, mapeadas dentro da parcela de $340 \times 160 \mathrm{~m} ; \mathrm{b})$ análise da correlação entre as alturas, através da funçăo K de Ripley. Linhas pontilhadas representam envelopes de confiança construídos com 99 simulações. 


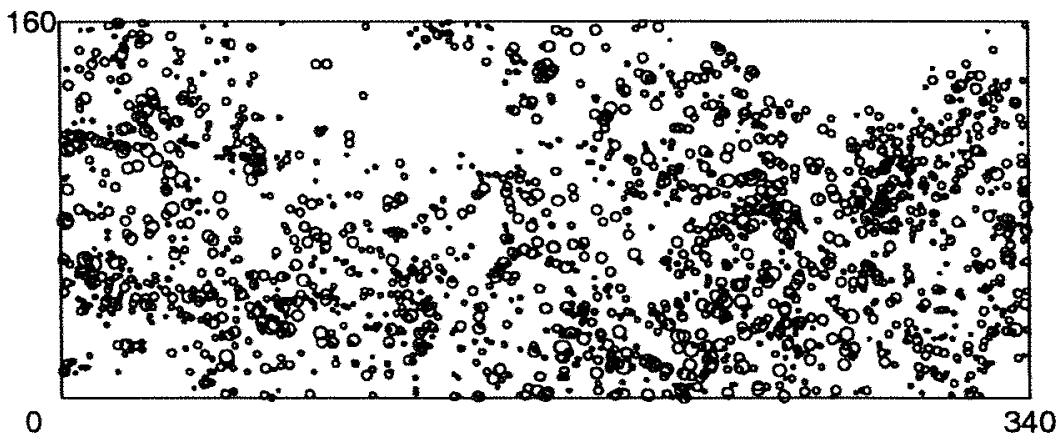

$a$

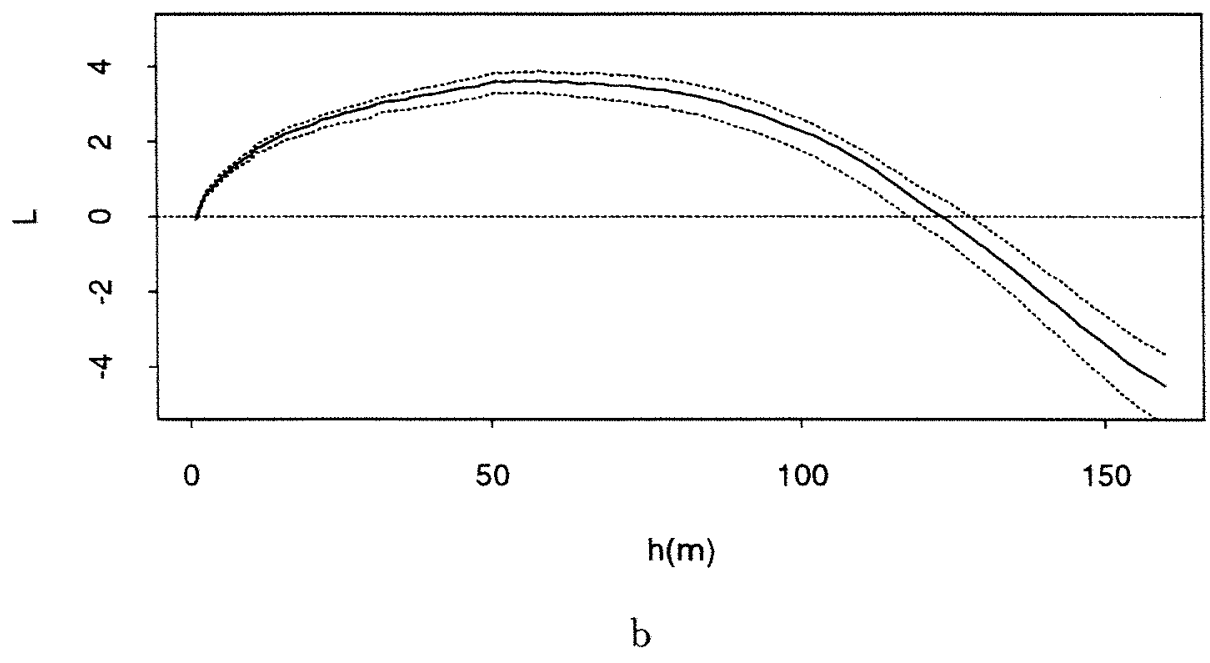

Figura 3.15: a) Plantas de palmiteiro dos estádios imaturos $2(\mathrm{n}=1680)$ e adultas $(\mathrm{n}=297)$, mapeadas dentro da parcela de $340 \times 160 \mathrm{~m}$; b) análise da correlação entre os diâmetros, através da função K de Ripley. Linhas pontilhadas representam envelopes de confiança construídos com 99 simulações. 


\subsubsection{Caso Bivariado}

Imaturos 1 x Imaturos 2: Considerando-se a dependência espacial entre estádios diferentes de plantas), observa-se que a distribuição das árvores de palmiteiro não apresentam nem atração, nem inibição (figura 3.16b). As plantas deste estádio estão distribuídas independentemente na área da parcela estudada.

Quando consideraram-se as alturas destes estádios, verifica-se também que não existe correlação entre as plantas dos diferentes estádios, com relação a esta variável (figura 3.17). Portanto, as alturas das palmeiras do estádio imaturos 1 são independentes das alturas das palmeiras do estádio imaturos 2 e vice-versa.

Imaturos 1 x Adultos: Os estádios imaturos $1 \mathrm{e}$ adultos (figura 3.18a) apresentam atração numa distância de aproximadamente $5 \mathrm{~m}$ e também uma atração na distância de 100 a 140 m (figura 3.18b). Nas outras distâncias consideradas, o padrão de distribuição destes estádios é independente. Esse padrão torna-se claro, uma vez que no campo, observa-se uma grande quantidade de plantas do estádio imaturos 1 ao redor das plantas adultas (Reis, 1995).

Quando consideraram-se as alturas no processo, há uma correlação positiva em toda a escala estudada, 1-150 m (figura 3.19). Isto pode indicar porque as plantas dos diferentes estádios apresentam um padrão agregado, ou melhor, plantas altas tendem a se concentrar ao redor de plantas altas ou plantas baixas tendem a concentrar-se ao redor de plantas baixas. Talvez seja devido a algum fator físico, como por exemplo luminosidade ou tipo de solo. 


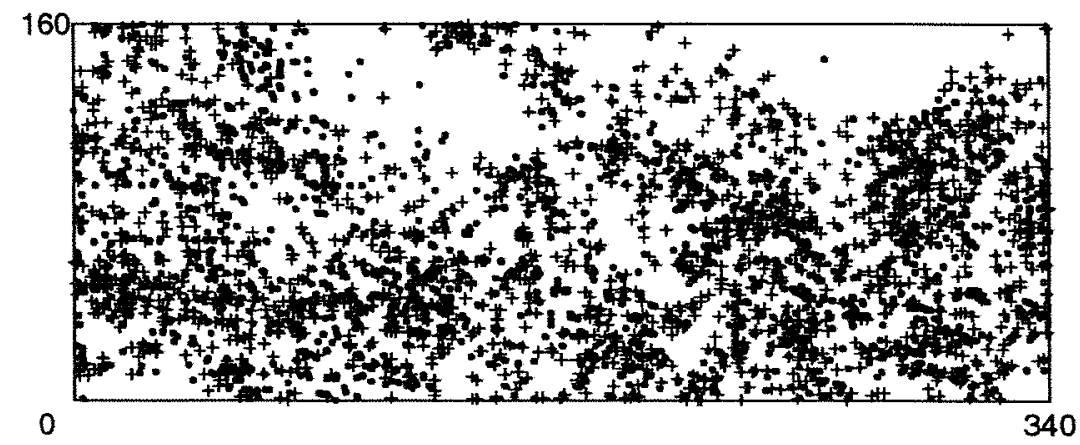

a

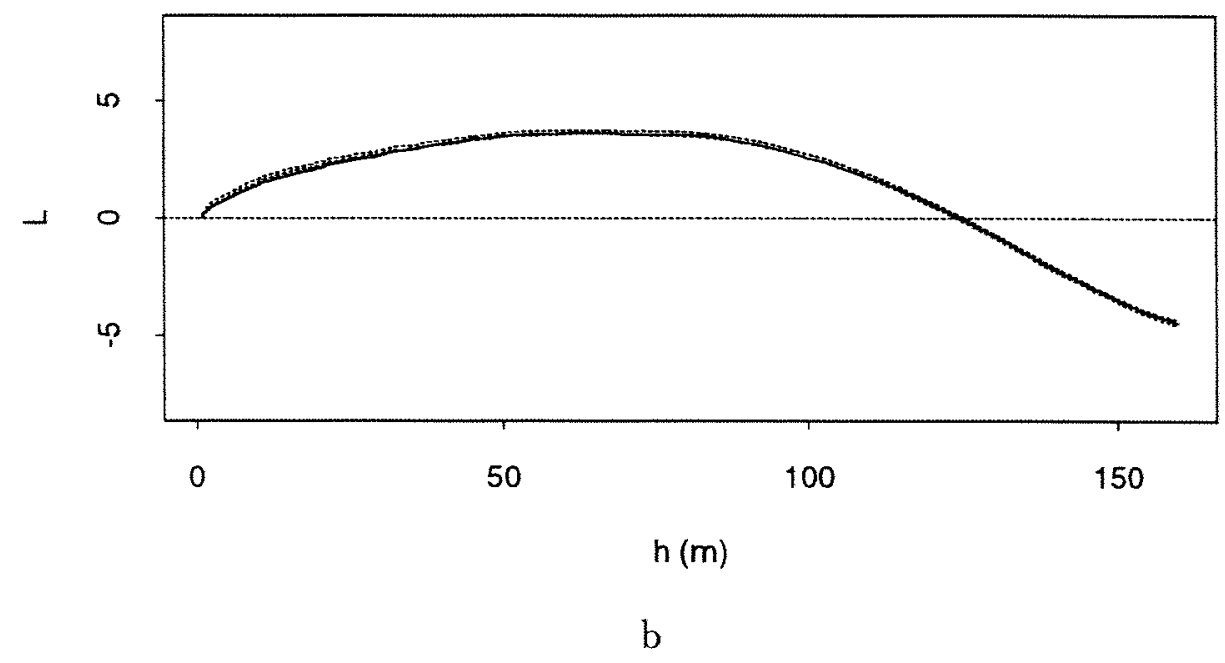

Figura 3.16: a) Plantas de palmiteiro dos estádios imaturos $1(\cdot)(\mathrm{n}=1598)$ e imaturos $2(+)(n=1680)$, mapeadas dentro da parcela de $340 \times 160 \mathrm{~m} ; \mathrm{b})$ análise da dependência espacial através da função K de Ripley. Linhas pontilhadas representam envelopes de confiança construídos com 99 simulações. 


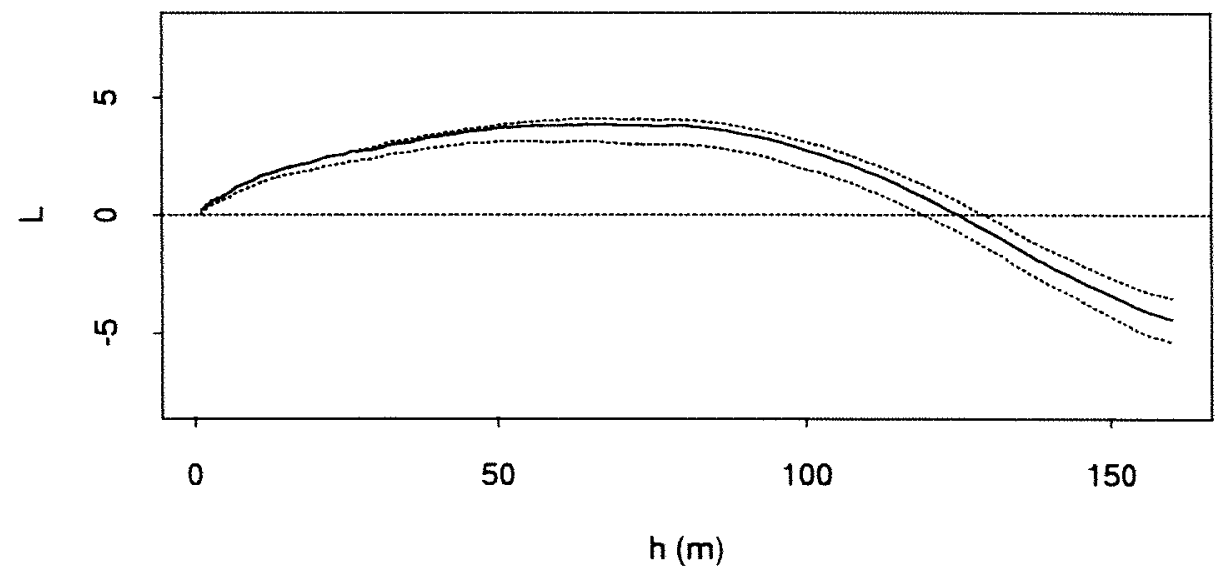

Figura 3.17: Análise da correlação entre as alturas dos estádios imaturos 1 e imaturos 2, através da função $\mathrm{K}$ de Ripley. Linhas pontilhadas representam envelopes de confiança construídos com 99 simulações.

Imaturos 2 x Adultos: As plantas dos estádios 2 e adultos (figura $3.20 \mathrm{a}$ ), apresentam uma inibição em uma distância de até $30 \mathrm{~m}$, indicando que espera-se encontrar poucos indivíduos próximos, destes dois estádios, nesse intervalo (figura $3.20 \mathrm{~b}$ ). De 30 até $130 \mathrm{~m}$, a distribuição das plantas se dá de forma independente na área estudada. Já, a partir de $130 \mathrm{~m}$, há uma atração destas plantas, ou seja, espera-se encontrar mais indivíduos do estádio imaturos 2 próximo às plantas adultas e vice-versa.

Considerando-se as alturas (figura 3.21), detectou-se uma correlação positiva na distância de 25 até $110 \mathrm{~m}$, e independência fora destes limites. Com relação aos diâmetros, ocorre também uma correlação positiva até a distância de $140 \mathrm{~m}$ (figura 3.22 ). Acima de $140 \mathrm{~m}$ não há correlação entre os diâmetros dos estádios imaturos 2 e adultos.

Monteiro \& César (1995), investigando populações de E. edulis em 


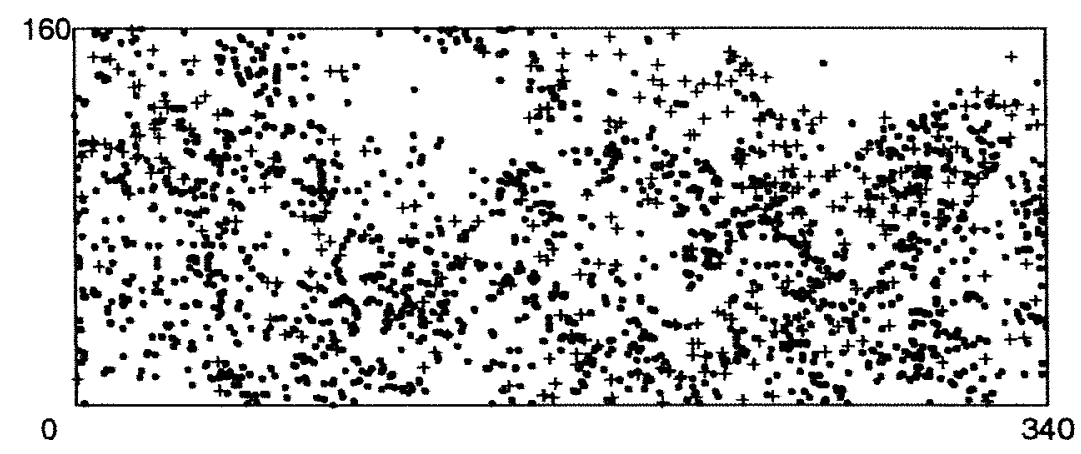

a

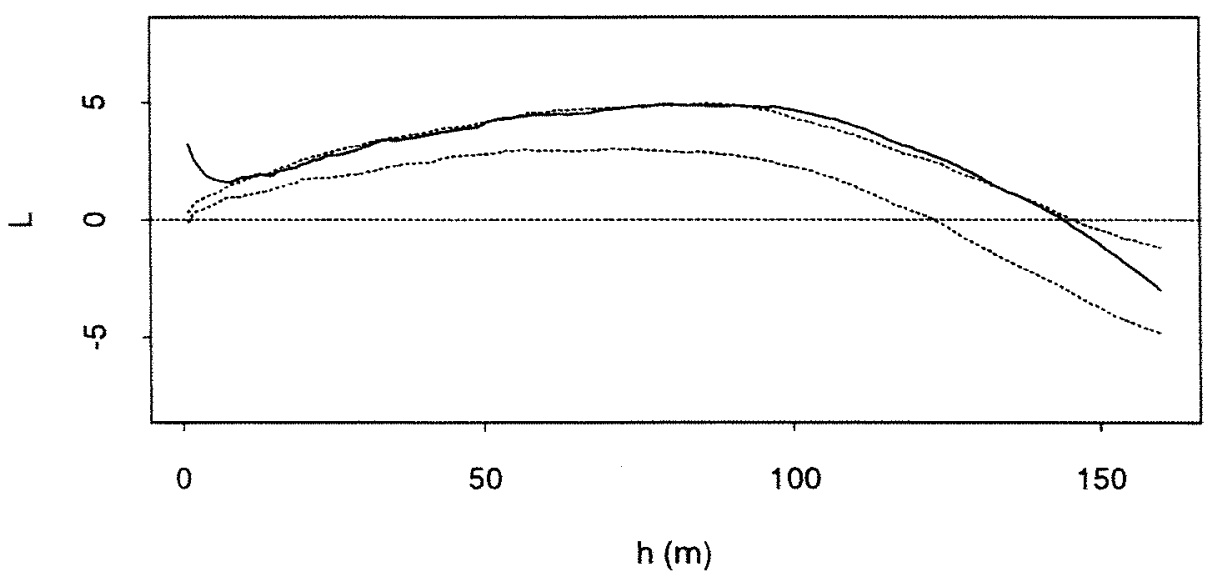

$\mathrm{b}$

Figura 3.18: a) Plantas de palmiteiro do estádio imaturos $1(\cdot)(n=1598)$ e adultas $3(+)(n=297)$, mapeadas dentro da parcela de $340 \times 160 \mathrm{~m} ; \mathrm{b})$ análise da dependência espacial, através da função K de Ripley. Linhas pontilhadas representam envelopes de confiança construídos com 99 simulações. 


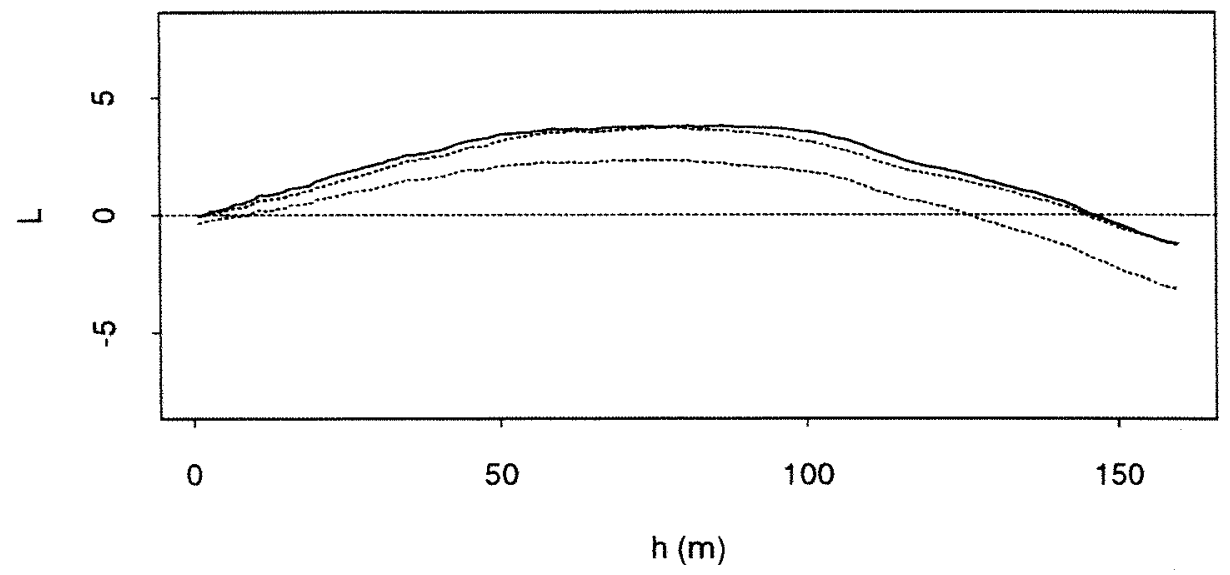

Figura 3.19: Análise da correlação entre as alturas dos estádios imaturos $1 \mathrm{e}$ adultas, através da função $\mathrm{K}$ de Ripley. Linhas pontilhadas representam envelopes de confiança construídos com 99 simulações. 


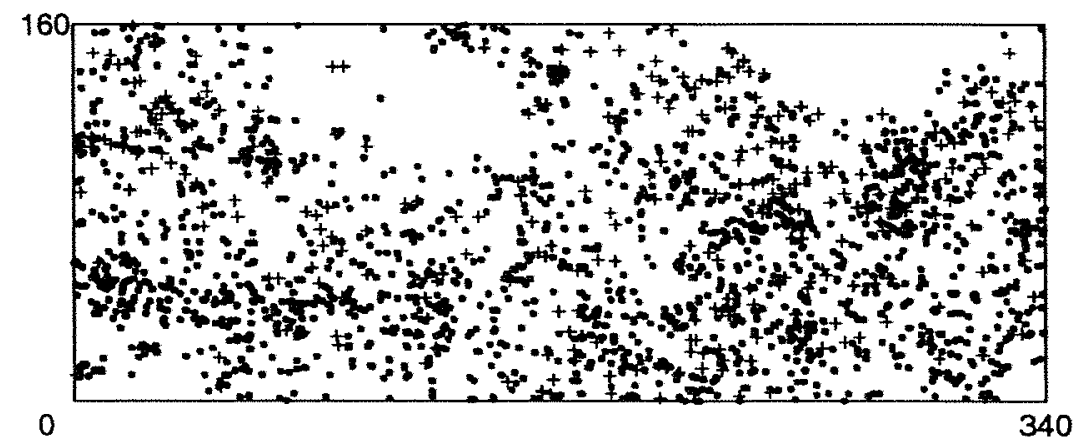

a

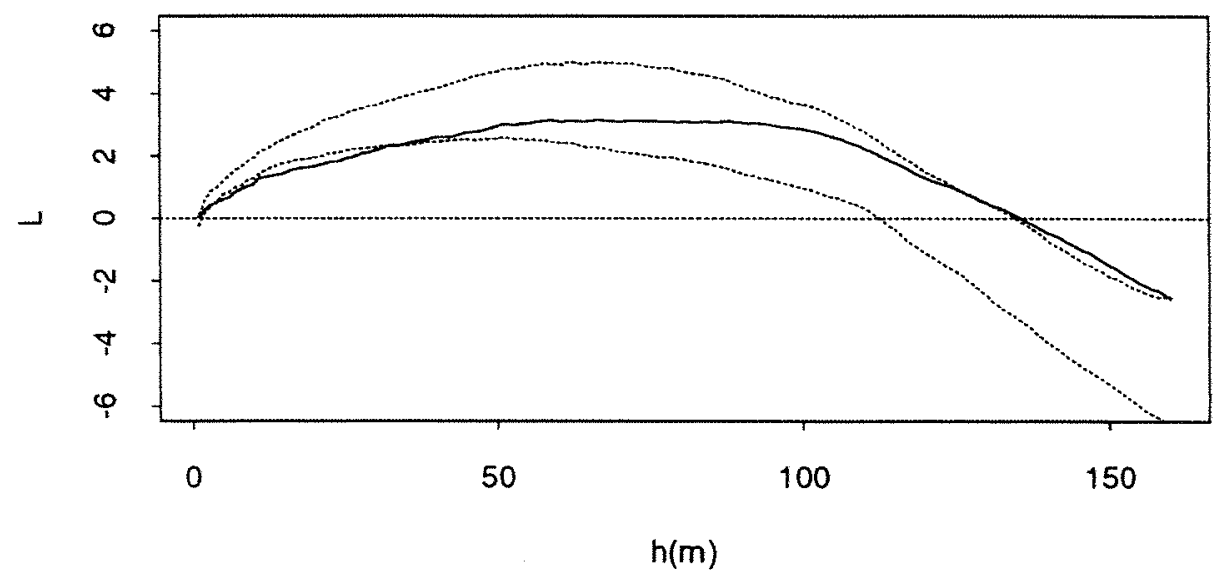

b

Figura 3.20: a) Plantas de palmiteiro do estádio imaturos $2(\cdot)(\mathrm{n}=1680)$ e adultas $(+)(\mathrm{n}=297)$, mapeadas dentro da parcela de $340 \times 160 \mathrm{~m} ; \mathrm{b})$ análise da dependência espacial, através da função K de Ripley. Linhas pontilhadas representam envelopes de confiança construídos com 99 simulações. 


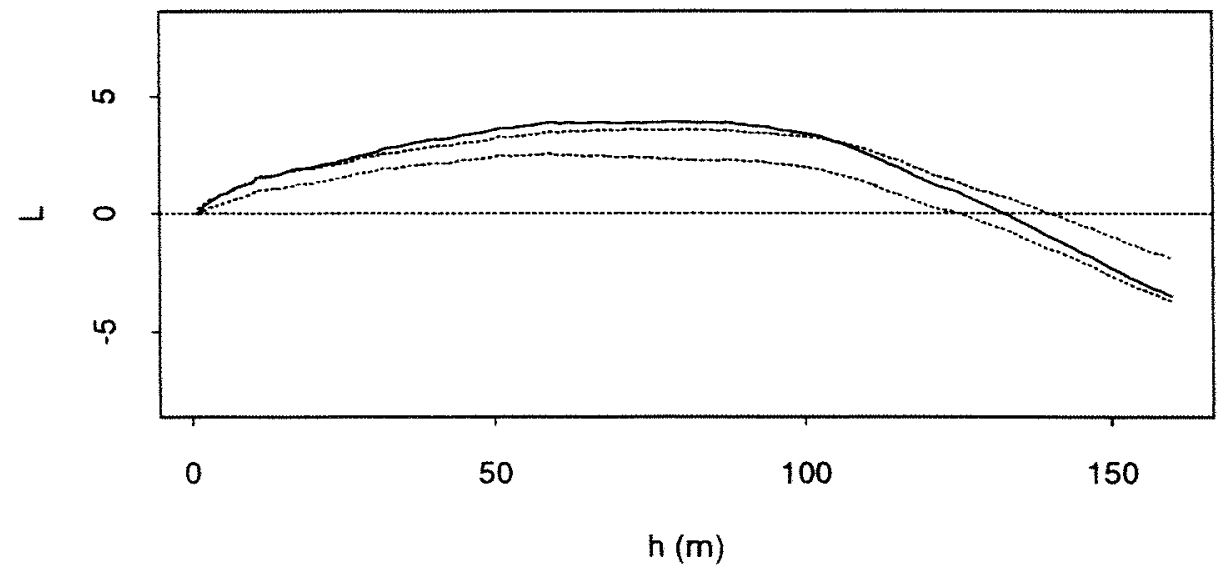

Figura 3.21: Análise da correlação entre as alturas dos estádios imaturos $2 \mathrm{e}$ adultos, através da função $\mathrm{K}$ de Ripley. Linhas pontilhadas representam envelopes de confiança construídos com 99 simulações.

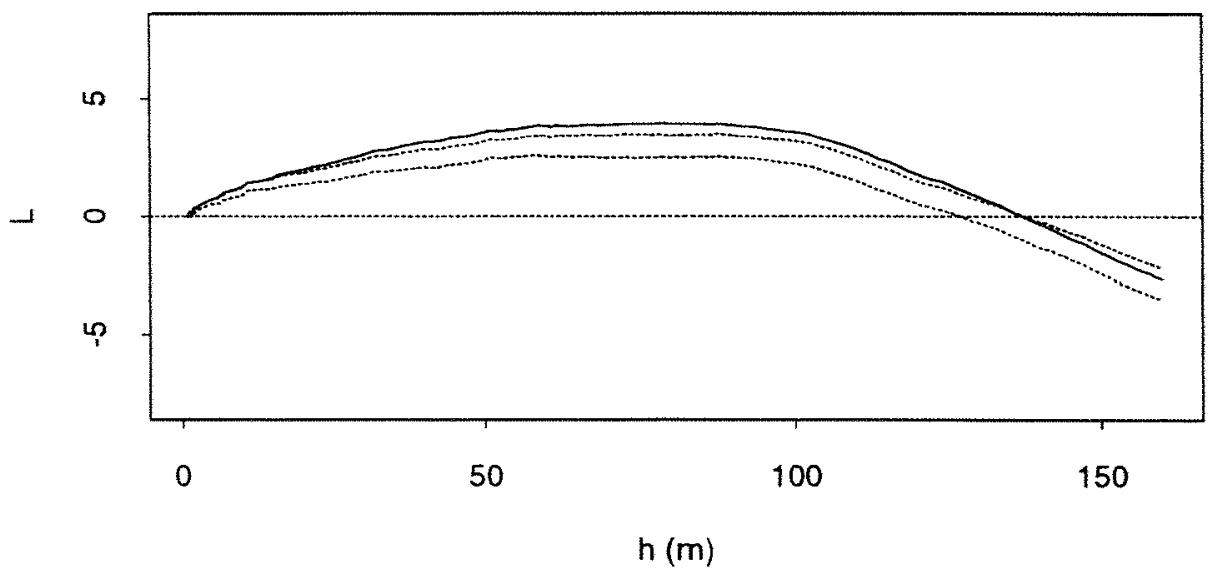

Figura 3.22: Análise da correlação entre os diâmetros dos estádios imaturos $2 \mathrm{e}$ adultos, através da função $K$ de Ripley. Linhas pontilhadas representam envelopes de confiança construídos com 99 simulações. 
uma região litorânea do estado de São Paulo, encontraram, utilizando metodologias baseadas no método de contagem em parcelas, que esta espécie apresenta "uma forte tendência" ao padrão agregado, considerando apenas plantas com DAP $>4,77 \mathrm{~cm}$. Estes mesmos autores verificaram que entre várias outras espécies pesquisadas (Alchornea triplinervia, Eugenia brasiliensis, Pera glabrata, entre outras), E. edulis foi a única que apresentou exclusivamente esta tendência. Outras espécies apresentaram variações nos padrões, variando entre regular e/ou agregado e/ou aleatório.

Reis (1995) encontrou um padrão aleatório para todos os estádios estudados (Imaturos 1, Imaturos 2 e adulto), utilizando o índice de Morizita, que também é baseado em contagem em parcelas. Neste caso, foram utilizadas parcelas com 100 e $1600 \mathrm{~m}^{2}$. Neste mesmo trabalho, Reis (1995), trabalhando com plantas sem estipe exposto, (1024 parcelas com $0,5 \mathrm{~m}^{2}$ ), concluiu que o padrão destas plantas é agregado. A maior concentração ocorreu entre 1 e $6 \mathrm{~m}$ da planta parental mais provável.

Como as plantas apresentaram, através da função $\mathrm{K}$, um padrão caracterizado por agregados de vários tamanhos, o teste de Morizita pode não ter sido eficiente para detectar esse tipo de variação. Este fato evidencia a capacidade da função $K$ de Ripley em detectar a variabilidade espacial ao longo de toda a janela amostral. Uma das principais vantagens é que as inferências não são feitas apenas sobre uma única escala. Cabe ressaltar, que este é um estudo que não leva em conta a variação espaço-temporal. É apenas um estudo do comportamento da espécie em um momento. É evidente, que esta espécie, como um organismo vivo, pode apresentar ao longo de um escala de tempo uma variação espacial.

Como a proposta de manejo feita por Fantini et al. (1992) prevê que a exploração seja feita de forma cíclica e contínua, convém que estudos de natureza espaço-temporal sejam contemplados na avaliação da estrutura populacional do palmiteiro. $\mathrm{O}$ conhecimento da variação espacial ao longo de um processo de ex- 
ploração pode corrigir falhas no plano de manejo bem como, garantir a perpetuação da espécie.

Fantini et al. (1992), afirma que a completa compreensão do comportamento da floresta é um dos requisitos indispensáveis para o sucesso do sistema de manejo em regime de rendimento sustentável.

A análise do padrão de distribuição espacial, principalmente utilizando a função K de Ripley, permite que se façam inferências sobre grandes escalas, tanto no caso univariado quanto no caso bivariado. É uma ferramenta poderosa para o entendimento de fatores responsáveis pela distribuição espacial de plantas, tais como condições climáticas, edáficas, processos de dispersão etc. Ainda, a função $\mathrm{K}$ de Ripley pode avaliar a relação entre plantas, considerando as variáveis medidas no ponto (processos pontuais marcados). 


\subsection{Conclusões}

Caso univariado

Os resultados encontrados para a população de palmiteiro e escala estudadas, indicam que existe um padrão de agregados com vários tamanhos, distribuídos com regularidade e que não há correlação entre as alturas de estipe.

Quando consideraram-se os estádios isoladamente, os padrões de distribuição também apresentam uma distribuição agregada. Para os estádios imaturos 1 e 2, observou-se que não há correlação na escala estudada. Já para plantas adultas, observou-se que há uma correlação positiva entre alturas a uma distância de 25 a $30 \mathrm{~m}$.

Considerando os diâmetros, observa-se que existe uma correlação positiva entre as árvores do estádio 2 entre 60 e $90 \mathrm{~m}$, e que não existe correlação entre os diâmetros das plantas adultas.

Caso bivariado

Observou-se entre as plantas dos estádios imaturos 1 e adultos, que existe uma atração na distância de até $5 \mathrm{~m}$, portanto espera-se encontrar um maior número de plantas do estádio imaturos 1 próximo de plantas adultas nesta distância. Com relação as alturas, observou-se que há uma correlação positiva em toda a escala estudada, ou seja, plantas altas do estádio imaturos 1 tendem a concentrar-se 
próximas de plantas altas adultas e vice-versa.

As plantas dos estádios imaturos 2 e adultas apresentaram inibição em uma distância de até $30 \mathrm{~m}$, ou seja, espera-se encontrar poucos indivíduos destes dois estádios próximas uma das outras nesta escala, e atração a uma distância de 130 até $150 \mathrm{~m}$.

Quando consideraram-se as alturas, observou-se uma correlação positiva na distância de 25 até $110 \mathrm{~m}$. Espera-se portanto, que árvores altas ocorram com maior frequência neste intervalo entre estes estádios ou que ocorram árvores baixas. Observou-se também entre estes estádios, que, com relação ao diâmetro, existe uma correlação positiva até uma distância de $140 \mathrm{~m}$. Portanto, espera-se encontrar indivíduos com diâmetros maiores neste intervalo. 


\section{CAPÍTULO 4}

\section{Análise do Padrão de Distribuição Espacial, Utilizando a Função K de Ripley, Quando há Perda de Eventos}

\subsection{Introdução}

$\mathrm{Na}$ análise do padrão de distribuição espacial, supõe-se, segundo Diggle (1983) e Ripley (1977), que um mapa completo está disponível, com as coordenadas. Em situações específicas, pode ocorrer a perda de alguma informação no conjunto de dados mapeados. Árvores podem ser de difícil mensuração ou acesso. Dados podem ser registrados de maneira errada e assim por diante. Em tais situações, qual a confiabilidade dos resultados gerados sem estes pontos? Quanto e como os resultados finais são perturbados, em relação a um mapa completo? Quais as implicações para diferentes padrões de distribuição espacial: aleatório, agregado ou regular?

Por outro lado, considerando uma população natural, onde pretende-se desenvolver um manejo de rendimento sustentado, como é o caso do palmiteiro (E. edulis), procura-se minimizar o efeito da exploração na alteração do padrão natural de distribuição espacial desta espécie. Em tais casos, é ideal que numa mesma escala, o padrão de distribuição permaneça inalterado.

Uma alteração do padrão espacial de uma espécie dentro de um ecossistema complexo e frágil como a Mata Atlântica (Reis, 1995), pode causar danos 
irreparáveis, além de frustrar qualquer tentativa de um aproveitamento futuro de produtos florestais. Por exemplo, se o padrão de distribuição de plantas matrizes for alterado, é possível que a regeneração não ocorra de forma eficiente, afetando a reposição de novas plantas.

A chance dos dispersores, principalmente aves (Reis, 1996) encontrarem as plantas matrizes pode diminuir, conseqüentemente diminuindo o número de sementes que poderiam estar germinando no solo da floresta e certamente, mantendo o padrão de distribuição espacial natural da espécie.

O objetivo deste trabalho é avaliar o comportamento da função $K$ de Ripley em vários padrões de dados simulados com diferentes densidades em uma mesma escala, com relação a alteração do padrão de distribuição espacial destes pontos. 


\title{
4.2 Material e Métodos
}

\author{
Simulação de dados
}

Foram simulados três tipos de padrões, com diferentes densidades:

- aleatório, com n=50, 100 e 200 eventos (figura 4.23).

- regular, com $\mathrm{n}=50,100$ e 200 eventos(figura 4.24).

- agregado, com as densidades variando em função do número e da intensidade $\lambda$, de pontos dentro dos agregados, conforme a tabela 4.1 abaixo.

\section{Padrão Regular}

O padrão de distribuição regular foi simulado utilizando a opção "Strauss" do módulo de estatística espacial do Software "S-plus" (Kaluzny et al. 1996). Este procedimento gera um padrão pontual com uma distância mínima entre os pontos. Gerou-se para um padrão regular, um padrão pontual de Strauss com raio de $5 \mathrm{~m}$ de inibição e parâmetro de inibição de 0.5 .

Para simulação dos padrões, utilizou-se as funções programadas por Batista (1994).

As simulações foram feitas utilizando o "software" S-plus sobre PC-586-133Hz. 
Tabela 4.1: Número de pontos para cada padrão de agregado simulado, variando o número de agregados e a intensidade $\lambda$.

\begin{tabular}{c|ccc}
\hline \multirow{2}{*}{ num. agregados } & \multicolumn{3}{|c}{$\lambda$} \\
\cline { 2 - 4 } & 3 & 7 & 10 \\
\hline 10 & 46 & 60 & 103 \\
15 & 40 & 108 & 129 \\
20 & 59 & 132 & 176 \\
\hline
\end{tabular}

As figuras 4.254 .26 e 4.27 , mostram os padrões espaciais de agregados simulados.

Foram considerados os valores de $p$ (pontos perdidos): $1,5,10,20$, 30,40 (este último número pode variar em função do número de eventos simulados em cada padrão). Para cada número de eventos perdidos $(p)$, foram simuladas aleatoriamente e independentemente 100 amostras de tamanho $(p)$. Quando $\mathrm{p}=1$, e o número de eventos do padrão simulado for menor do que 100, o número de amostras estará limitado ao número de eventos. A função K de Ripley (caso univariado) foi aplicada a cada conjunto de dados gerado. Para gerar a função $\bar{K}_{p}(h)$, foi tomada a média em cada $h$ da função $K(h)$ calculada para cada amostra com $p$ pontos perdidas.

Para todos os $\bar{K}_{p}(h)$ 's, também foi tomado o mínimo e o máximo de cada $K_{p}(h)$. Os valores gerados foram comparados graficamente com um envelope com 1\% de significância (99 simulações), calculado a partir do conjunto original de dados. Dessa forma, foi possível determinar em qual número de eventos perdidos ocorreu alteração no padrão de distribuição espacial e em qual escala.

A figura 4.28 mostra o fluxograma de cálculo. 


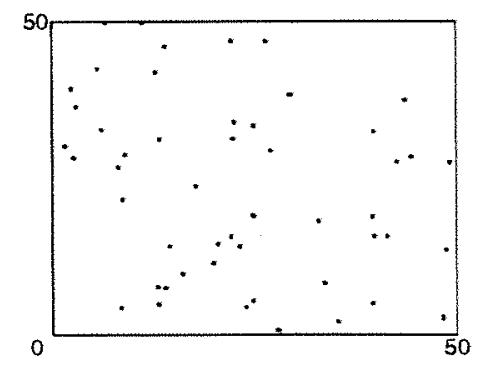

(a)

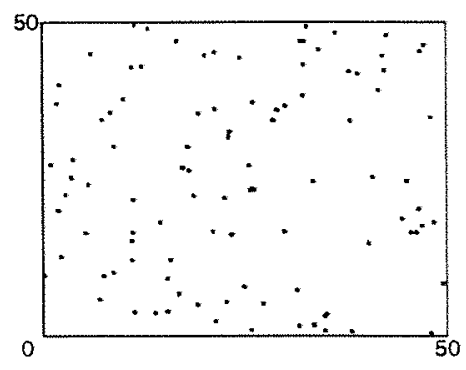

(b)

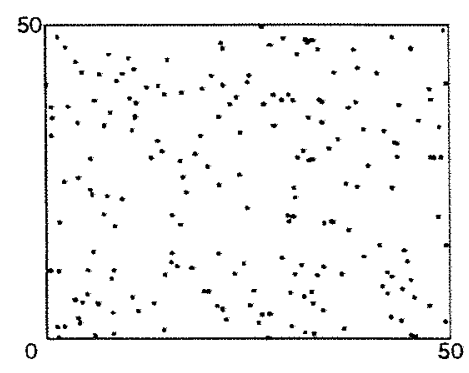

(c)

Figura 4.23: Padrões aleatórios simulados com n eventos: a) $n=50$, b) $n=100$ e c) $\mathrm{n}=200$. 


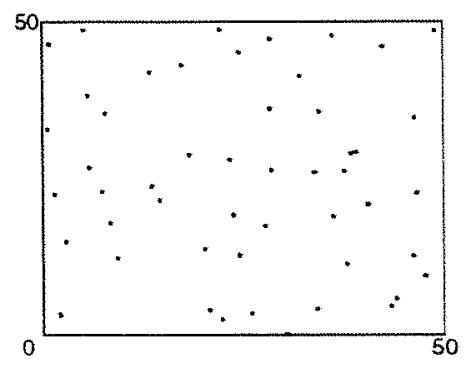

(a)

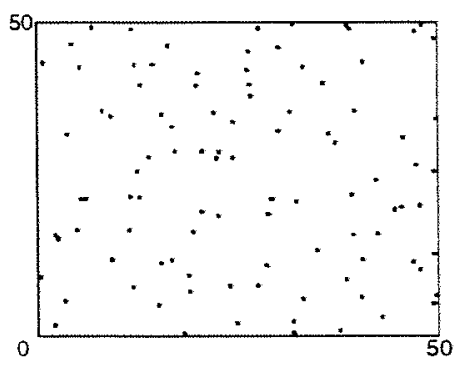

(b)

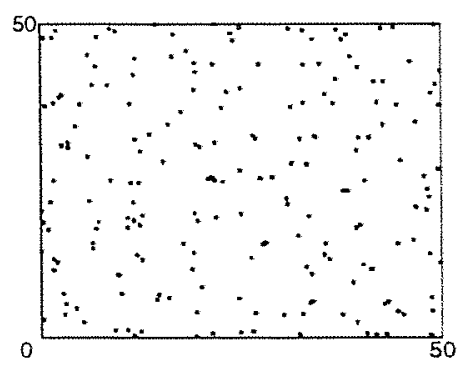

(c)

Figura 4.24: Padrões regulares simulados com $n$ eventos: a) $n=50$, b) $n=100$ e c) $n=200$. 


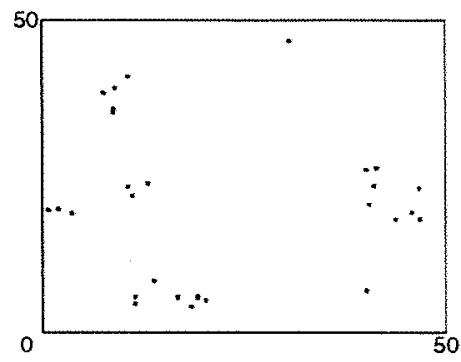

(a)

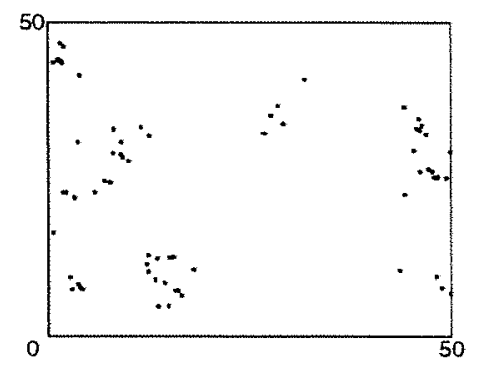

(b)

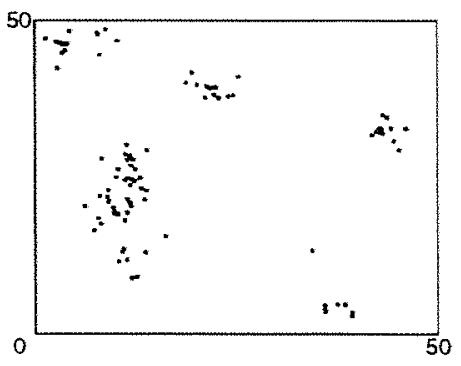

(c)

Figura 4.25: Padrões agregados simulados ( $\lambda$ =intensidade de cada agregado): a) agregados $=10, \lambda=3$ (num. de eventos $=46$ ); b) agregados $=10, \lambda=7$ (num. de eventos $=60) ; c$ ) agregados $=10, \lambda=10$ (num. de eventos $=103$ ). 


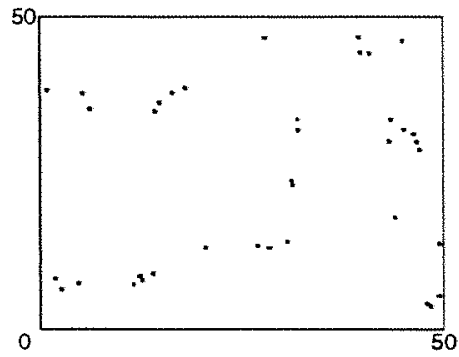

(a)

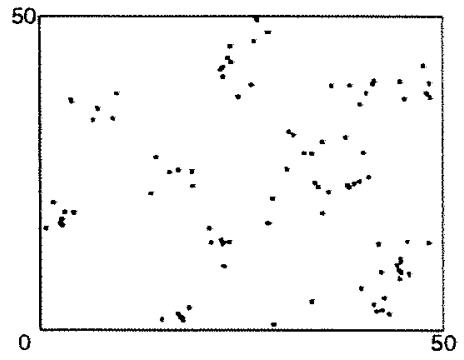

(b)

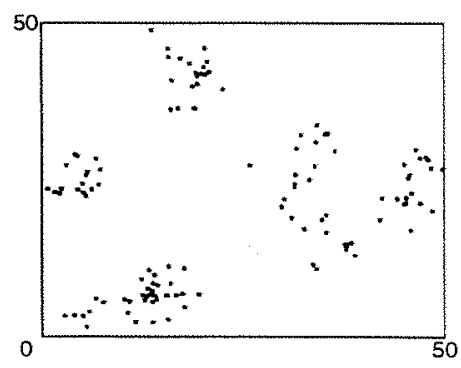

(c)

Figura 4.26: Padrões agregados simulados ( $\lambda$ =intensidade de cada agregado): a) agregados $=15, \lambda=3$ (num. de eventos $=40$ ); a) agregados $=15, \lambda=7$ (num. de eventos $=108$ ); a) agregados $=15, \lambda=7$ (num. de eventos $=129$ ). 


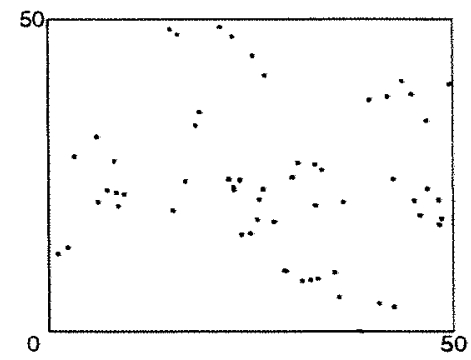

(a)

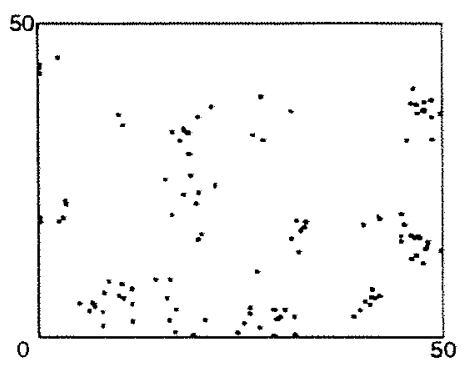

(b)

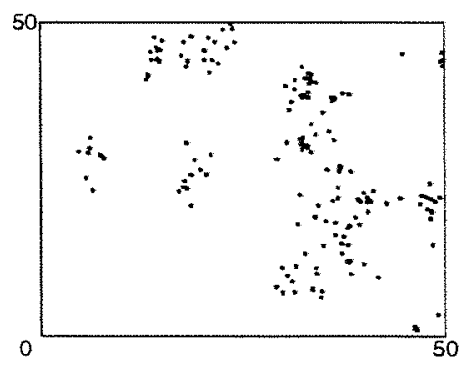

(c)

Figura 4.27: Padrões agregados simulados ( $\lambda=$ intensidade de cada agregado): a) agregados $=20, \lambda=3$ (num. de eventos $=59$ ); b) agregados $=20, \lambda=7$ (num. de eventos $=132$ ); c) agregados $=20, \lambda=10$ (num. de eventos $=176$ ). 


\section{Fluxograma de Cálculo}

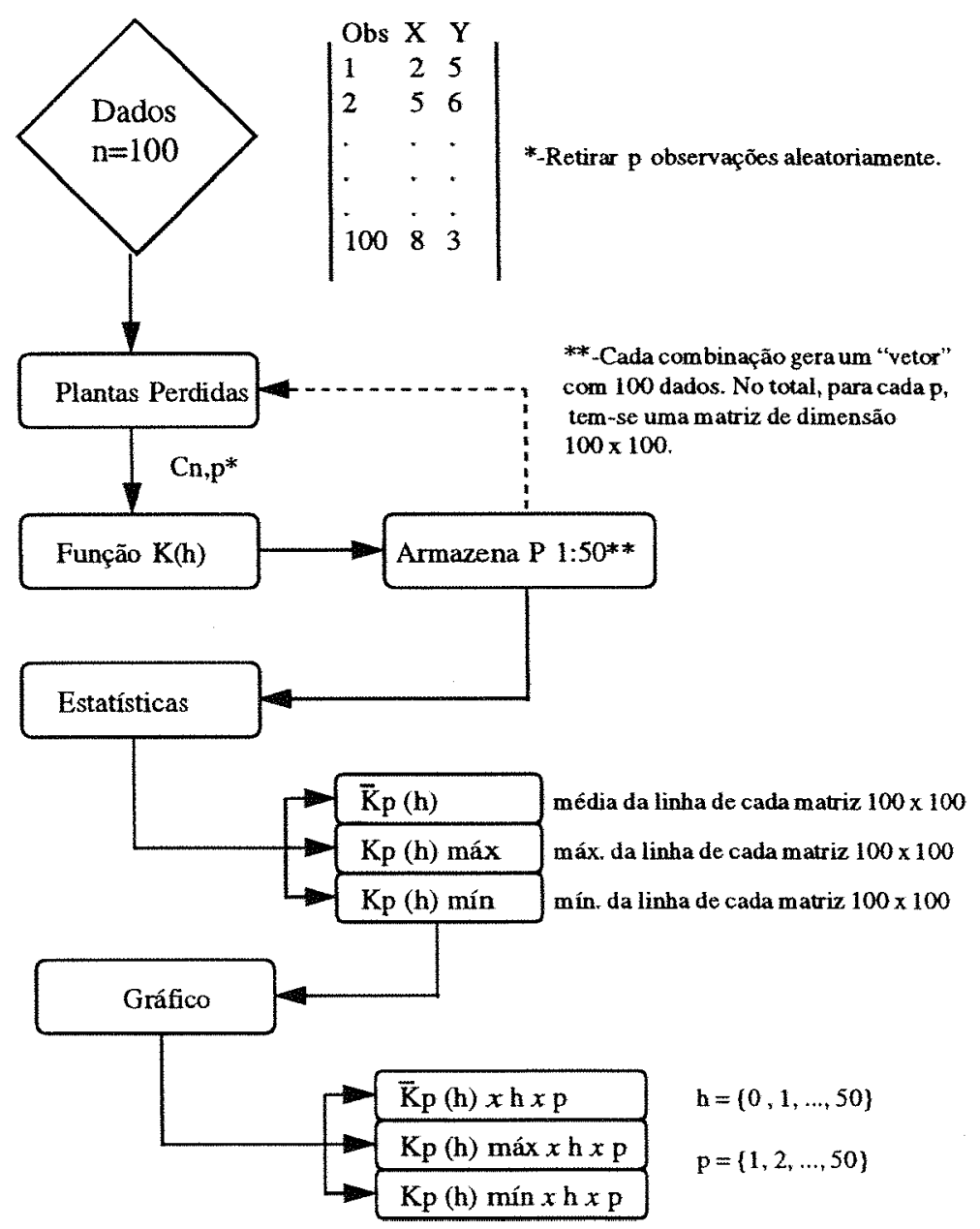

Figura 4.28: Fluxograma de avaliação da simulação do efeito de perda de eventos em um padrão espacial pontual. 


\subsection{Resultados e Discussão}

A figura 4.29 mostra a função $\mathrm{K}$ de Ripley, aplicada aos padrões espaciais aleatórios simulados com $n=50,100$ e 200 eventos, respectivamente. Podese observar que à medida que a intensidade de cada padrão simulado aumenta, a variação da função $\mathrm{K}$ diminui. Os envelopes de confiança foram construídos com 99 simulações (1\% de significância).

A figura 4.30 mostra a função $\mathrm{K}$ de Ripley aplicada aos padrões espaciais regulares simulados com $n=50,100$ e 200 eventos, respectivamente. Para estes padrões, simulou-se uma inibição a uma distância de $5 \mathrm{~m}$, ou seja, a função $\mathrm{K}$ de Ripley ultrapassa o envelope inferior na distância $h=5$. Os envelopes de confiança foram construídos com 99 simulações (1\% de significância).

A função K de Ripley, calculada para os diferentes padrões de agregados simulados com diferentes números de agregados e intensidades $(\lambda)$, podem ser vistas na figura 4.31 , figura 4.32 e figura 4.33 . Em cada uma destas figuras, observase que foram simulados agregados de vários tamanhos em cada área ou parcela de $50 \times 50 \mathrm{~m}$. Os envelopes de confiança foram construídos com 99 simulações (1\% de significância). 


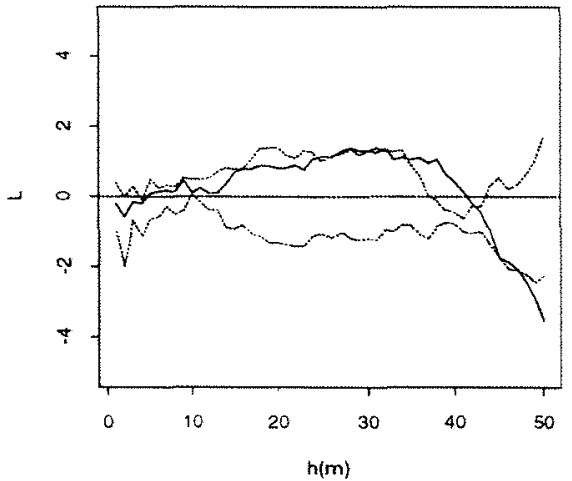

(a)

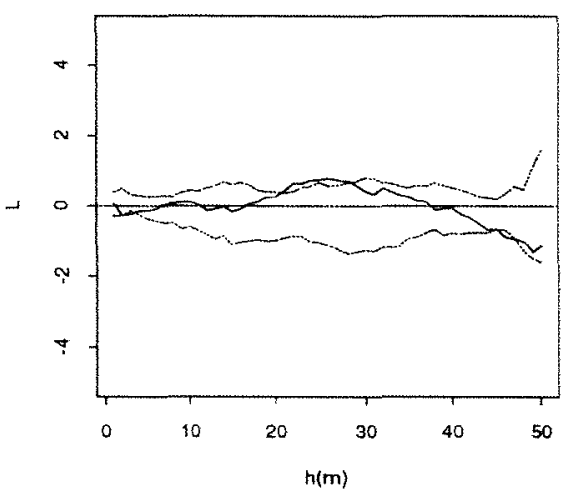

(b)

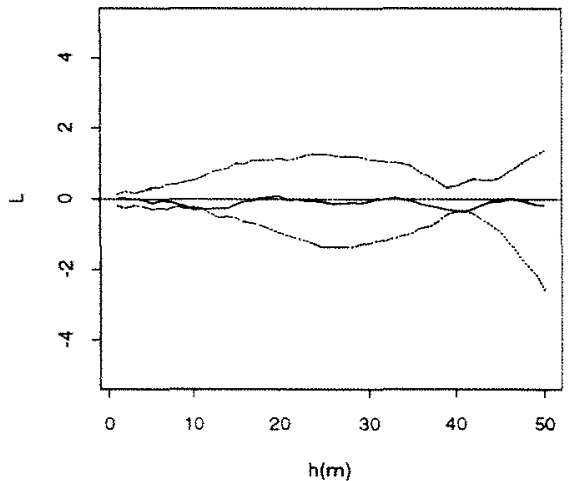

(c)

Figura 4.29: Função K para padròes aleatórios simulados com n eventos: a) n=50, b) $n=100$ e c) $n=200$. Linhas pontilhadas representam envelopes de confiança construídos com 99 simulaçòes. 


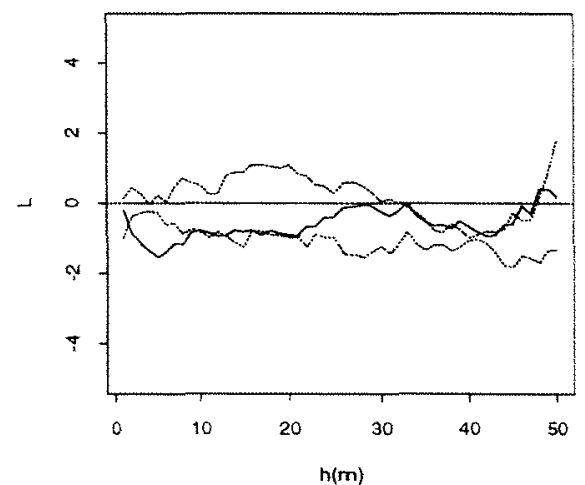

(a)

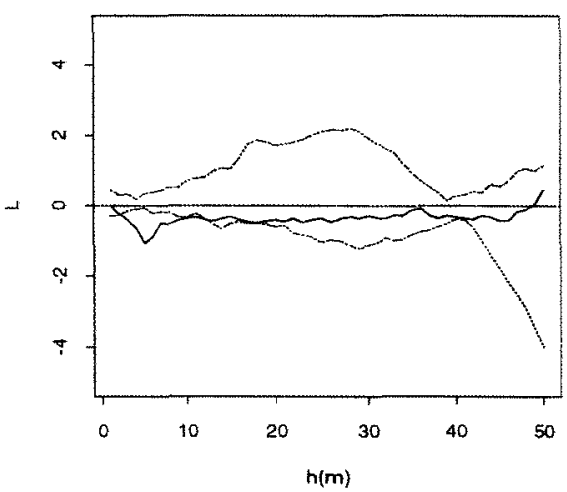

(b)

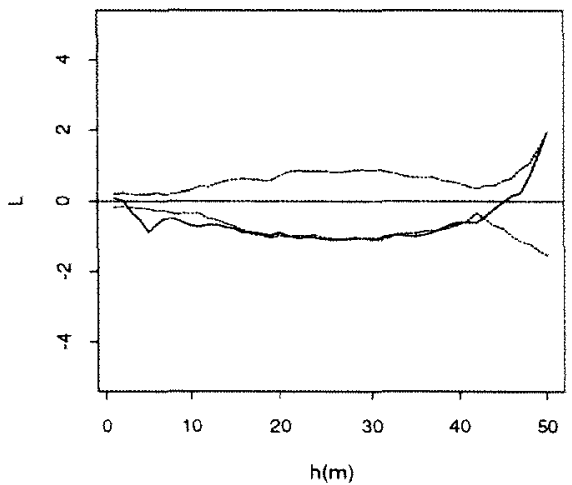

(c)

Figura 4.30: Função $\mathrm{K}$ para padrões regulares simulados com n eventos: a) $n=50$, b) $n=100$ e c) $n=200$. Linhas pontilhadas representam envelopes de confiança construídos com 99 simulaçòes. 


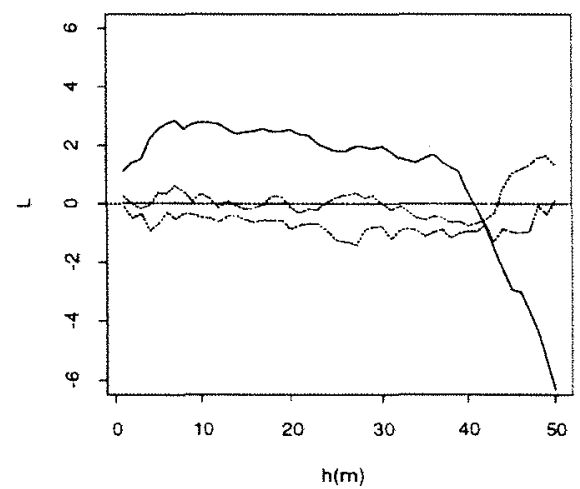

(a)

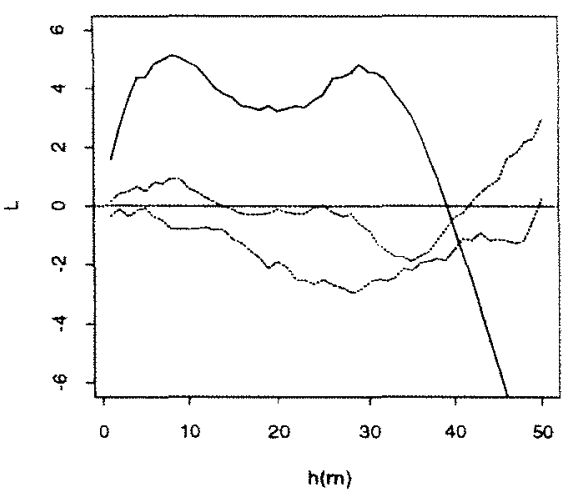

(b)

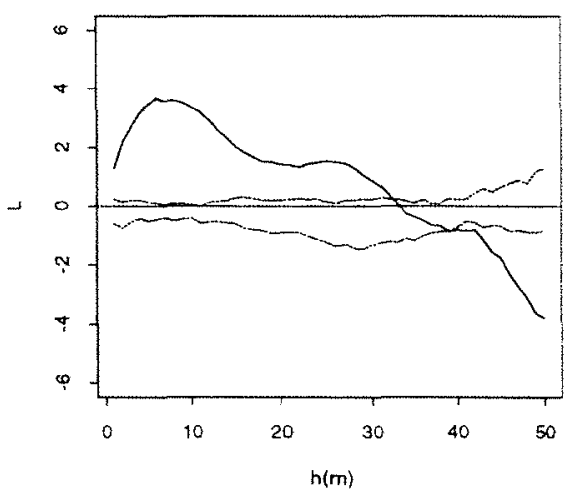

(c)

Figura 4.31: Função $K$ para padrões agregados simulados $(\lambda=$ intensidade de eventos por agregado): a) agregados $=10, \lambda=3(n=46) ; b)$ agregados $=10, \lambda=7 \quad(n=60)$; c) agregados $=10, \lambda=10(\mathrm{n}=103)$. Linhas pontilhadas representam envelopes de confiança construídos com 99 simulações. 


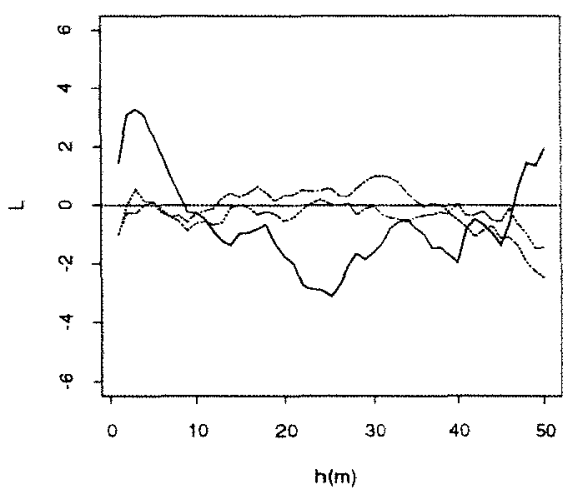

(a)

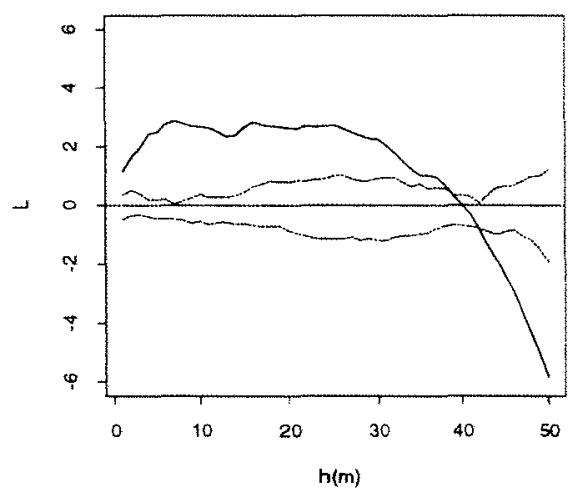

(b)

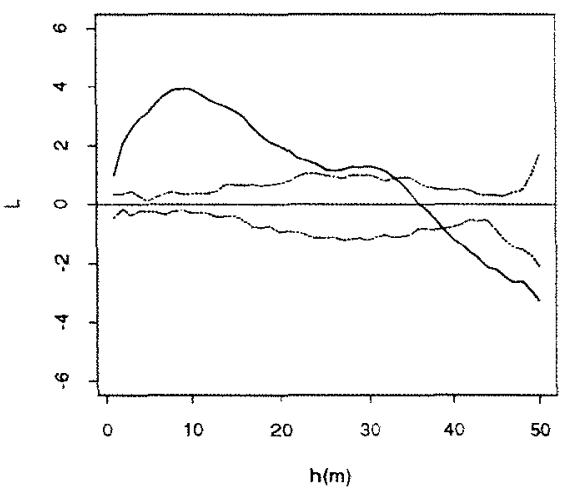

(c)

Figura 4.32: Função K para padrões agregados simulados $(\lambda=$ intensidade de eventos por agregado): a) agregados $=15, \lambda=3(n=40) ; b)$ agregados $=15, \lambda=7(n=108)$; c) agregados $=15, \lambda=7 \quad(n=129)$. Linhas pontilhadas representam envelopes de confiança construídos com 99 simulações. 


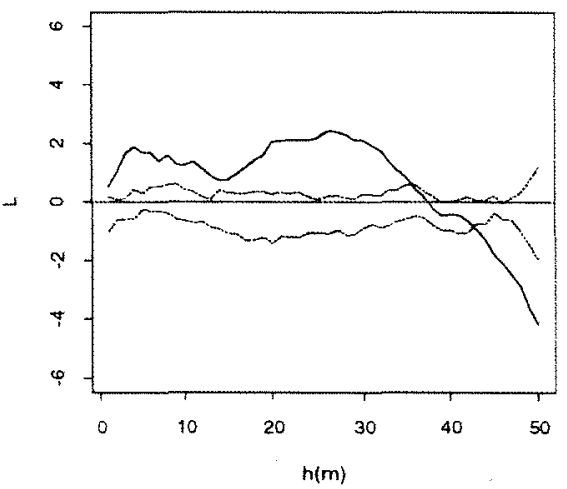

(a)

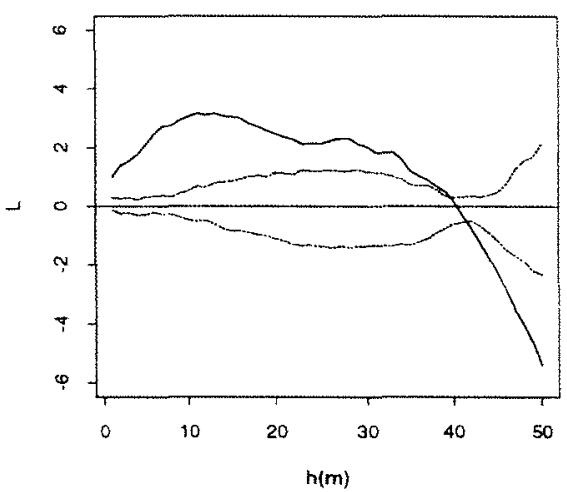

(b)

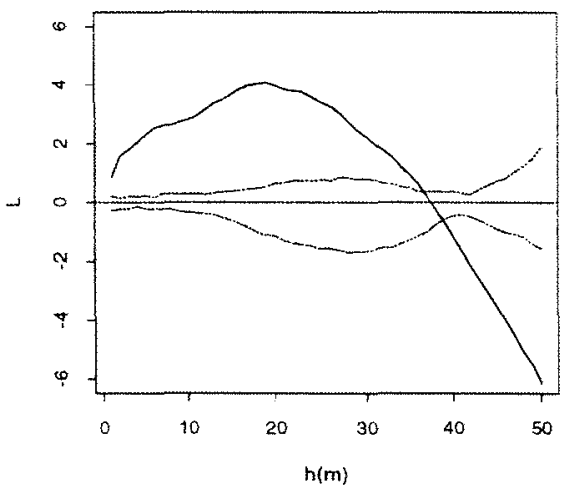

(c)

Figura 4.33: Função K para padrôes agregados simulados $(\lambda=$ intensidade de eventos por agregado): a) agregados $=20, \lambda=3(n=59) ; b)$ agregados $=20, \lambda=7 \quad(n=132)$; c) agregados $=20, \lambda=10(n=176)$. Linhas pontilhadas representam envelopes de confiança construídos com 99 simulações. 


\subsubsection{Padrão Aleatório}

Observando-se a figura $4.34 \mathrm{a}$, pode-se perceber que o padrão de distribuição ou a posição dos valores gerados pela função $L$, praticamente não se alteram quando ocorre a perda de 1 evento. Mas, quando ocorre a perda de 5, $10,20,30,40$ eventos (figura 4.34b, 4.34c, 4.34d, 4.34e, 4.34f), os valores de LMax e de LMin ultrapassam os envelopes de confiança, podendo gerar padrões muito diferentes do original simulado com 50 eventos. Em média, pode-se esperar neste caso, qual a função L não se altere quando ocorre perda de eventos, com um padrão simulado com 50 eventos, numa região de $50 \times 50 \mathrm{~m}$.

$\mathrm{Na}$ figura 4.35a, observa-se também que, para um padrão aleatório simulado com $n=100$ eventos, pode-se esperar que quando há perda de 1 evento, não ocorra alteração no padrão de distribuição espacial. Para $p=5$ e $p=10$ eventos perdidos (figura $4.35 \mathrm{~b}$ e figura $4.35 \mathrm{c}$ ), valores de LMax ultrapassam os envelopes de confiança superiores ao redor de $25 \mathrm{~m}$ e valores de LMin ultrapassam os envelopes de confiança inferiores ao redor de $42 \mathrm{~m}$, enquanto que a função Lmed praticamente não muda em relação à função L original. Para valores de $p=20,30$ e 40, os valores de LMax e LMin ultrapassam em vários pontos os envelopes de confiança, alterando as conclusões ou o padrão de distribuição original. Mas, a função Lmed, também, praticamente não altera-se, em relação a função $L$ original.

Quando o número de eventos aumenta para $n=200$, observa-se pela figura $4.36 \mathrm{a}$, figura $4.36 \mathrm{~b}$, figura $4.36 \mathrm{c}$, que não ocorre alteração do padrão de distribuição. No entanto, quando ocorre perda de 20, 30 e 40 eventos (figura 4.36d, figura $4.36 \mathrm{e}$, figura $4.36 \mathrm{f}$ ), observou-se apenas uma tendência a regularidade a uma distância ao redor de $40 \mathrm{~m}$. 


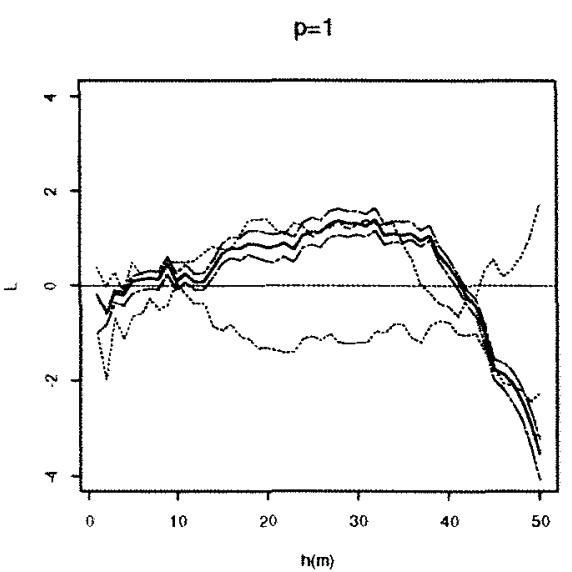

a.

$p=10$

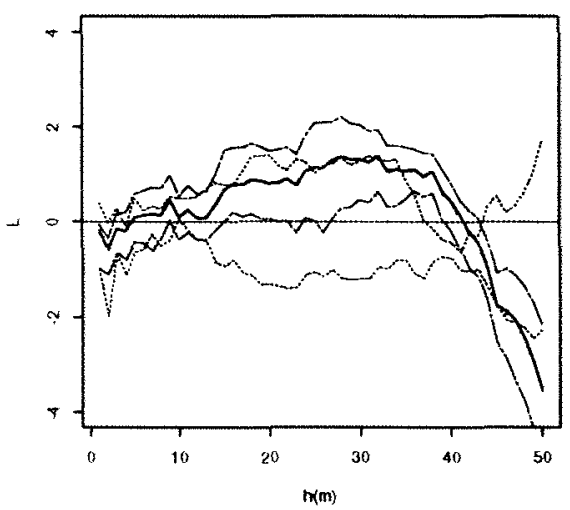

C

$p=30$

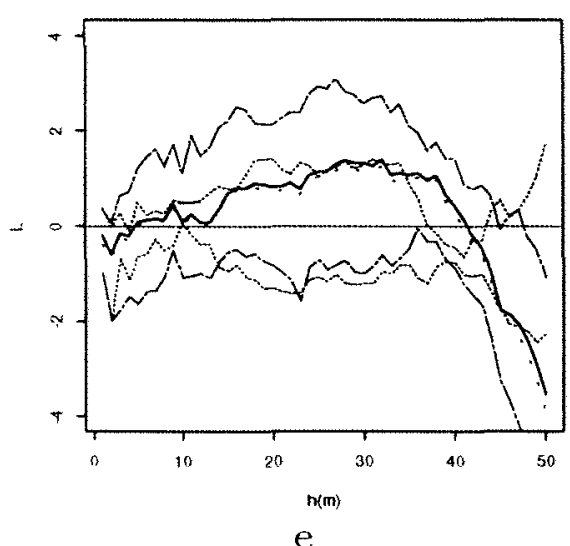

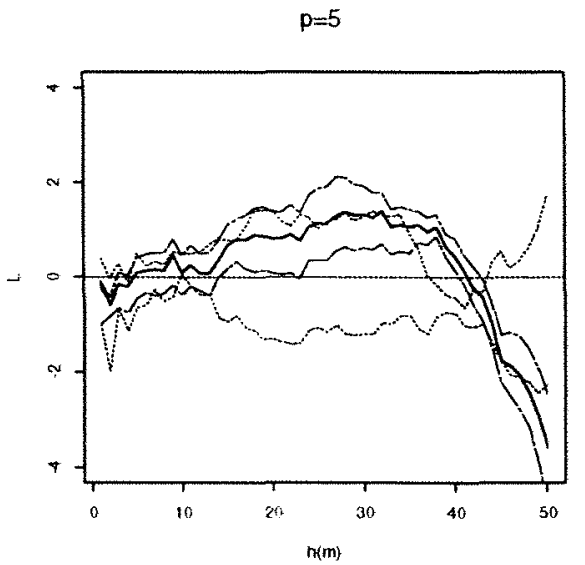

b

$p=20$

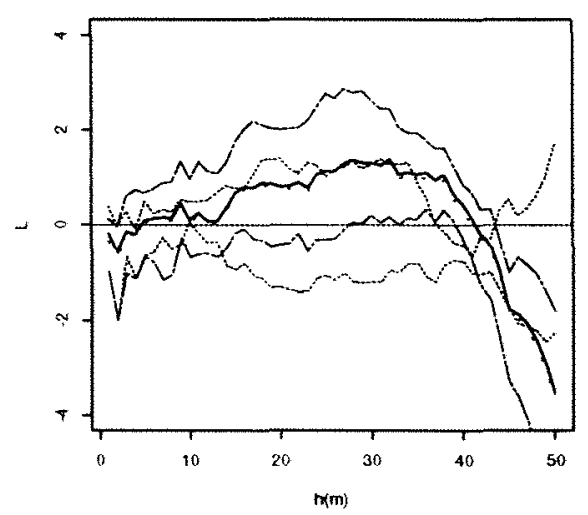

d

$p=40$

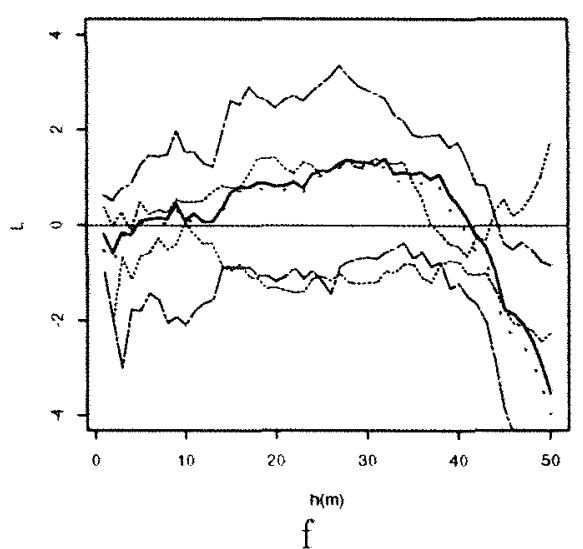

Figura 4.34: Efeito da perda de eventos (p) em um padrão aleatório simulado com

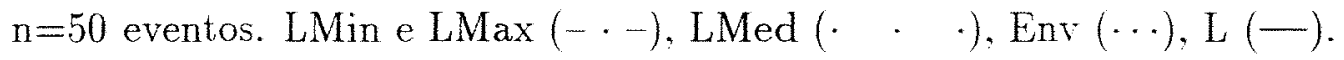




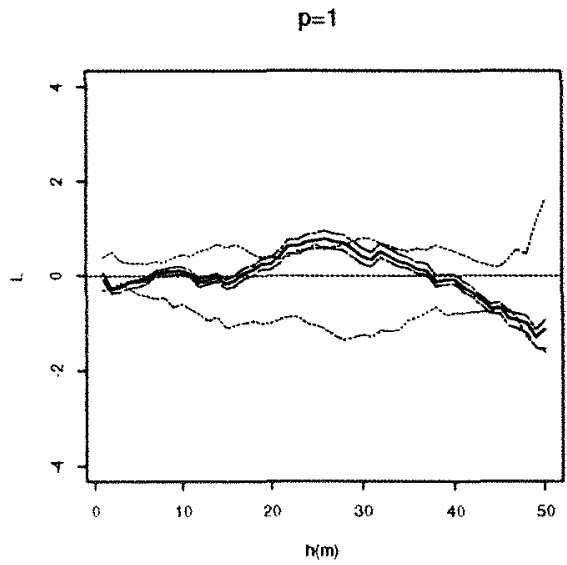

a

$p=10$

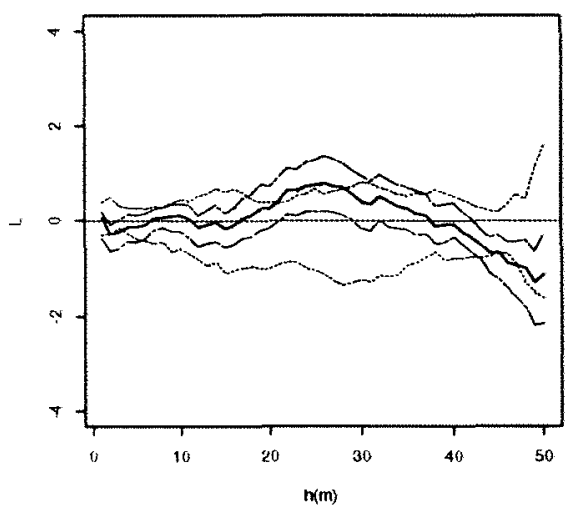

C

$p=30$

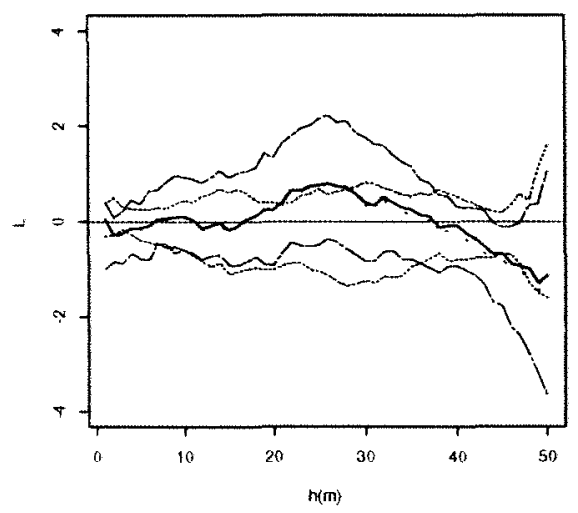

$e$

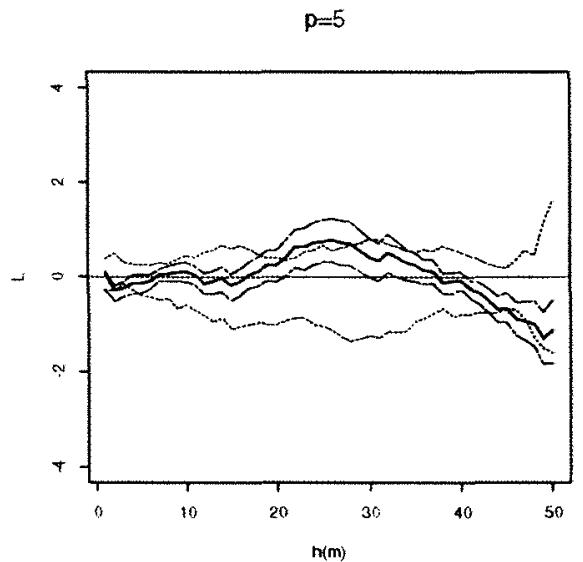

b

$p=20$

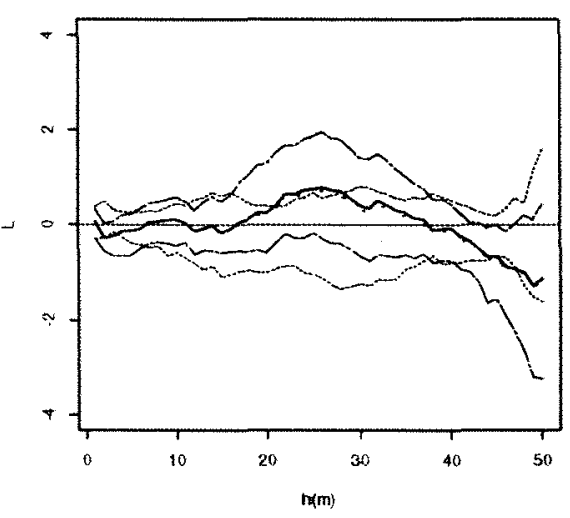

d

$p=40$

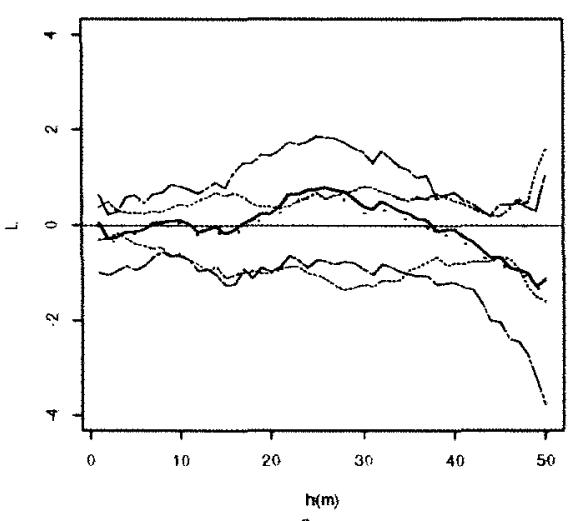

f

Figura 4.35: Efeito da perda de eventos (p) em um padrão aleatório simulado com

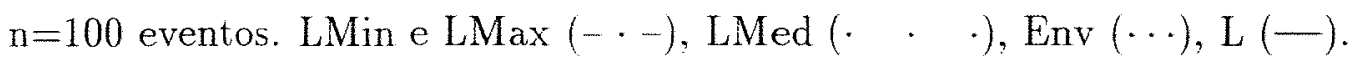




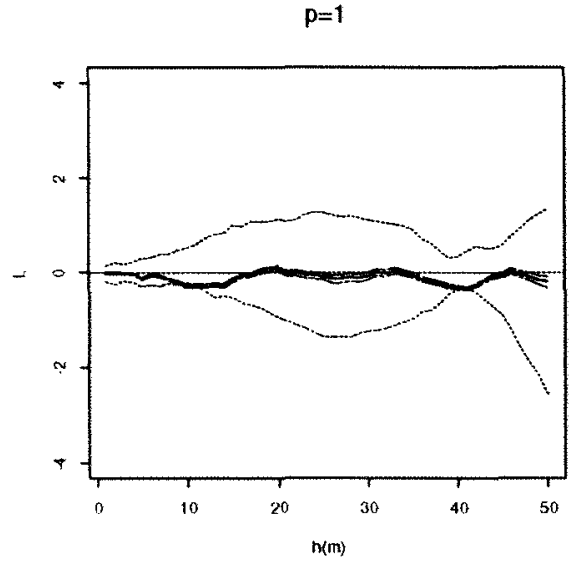

a

$p=10$

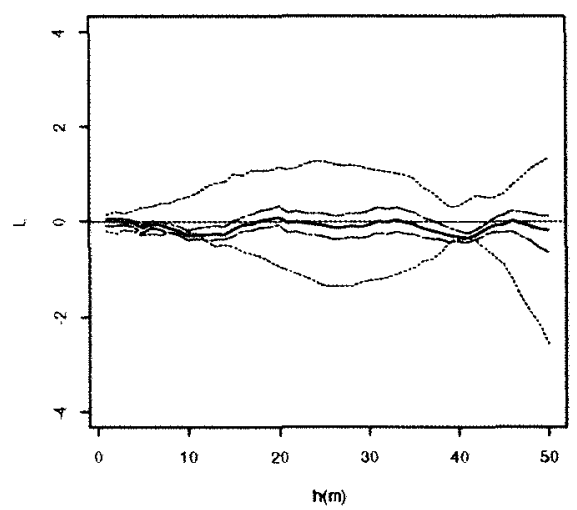

c.

$p=30$

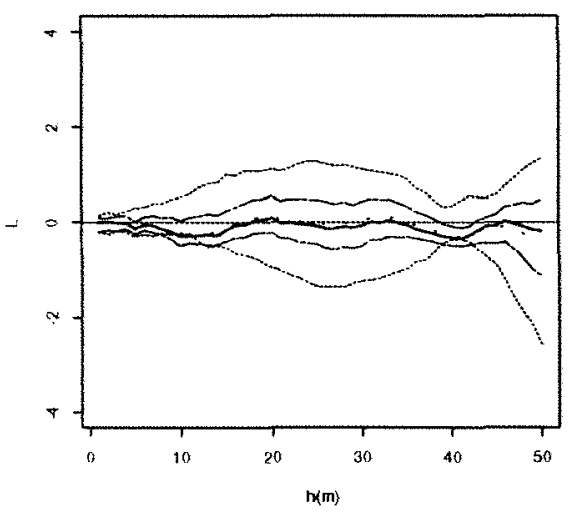

e

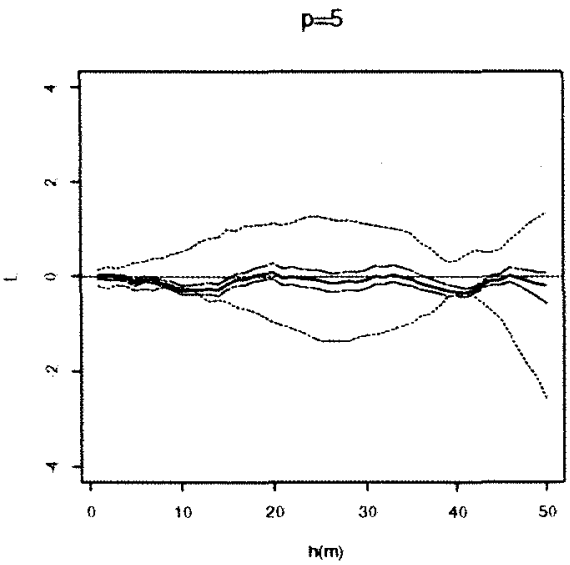

b

$p=20$

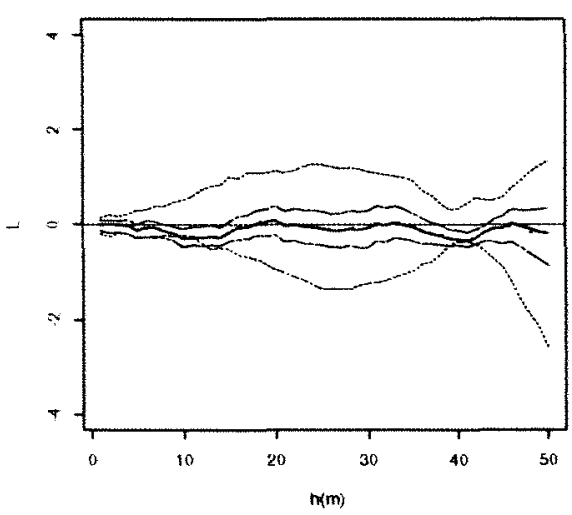

d

$p=40$

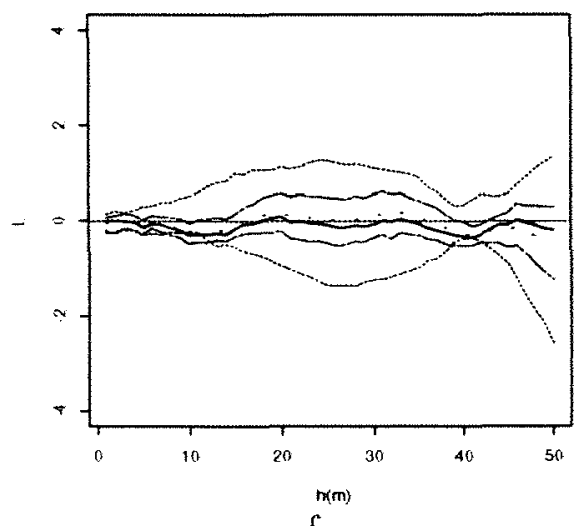

f

Figura 4.36: Efeito da perda de eventos (p) em um padrão aleatório simulado com $\mathrm{n}=200$ eventos. LMin e LMax $(-\cdot-)$, LMed $(\cdot \cdot \cdot \cdot)$, Env $(\cdots), L(-)$. 


\subsubsection{Padrão Regular}

Observando a figura $4.37 \mathrm{a}$, verifica-se que com apenas um evento perdido $(p=1)$, não se alteram significativamente a ponto de alterar as conclusões sobre o padrão de distribuição simulado. Para $\mathrm{p}=5,10,20,30$ e 40 (figura 4.37b, figura $4.37 \mathrm{c}$, figura $4.37 \mathrm{~d}$, figura $4.37 \mathrm{e}$ e figura $4.37 \mathrm{f}$, respectivamente). os valores máximos e mínimos ultrapassam os envelopes de confiança tanto os superiores, quanto inferiores, principalmente quando há um grande número perdido de eventos.

Para $n=100$, os resultados são semelhantes aos encontrados para um padrão regular, simulado com $n=50$. Para $\mathrm{p}=1$ (figura $4.38 \mathrm{a}$ ), não ocorrem mudanças nas conclusões sobre o padrão de distribuição espacial em nenhuma parte do gráfico. Para outros valores de p (figura 4.38b, figura 4.38c, figura 4.38d, figura 4.38e e figura 4.38f), existe uma forte tendência dos valores de LMin ultrapassarem o envelope de confiança inferior, levando a concluir que o padrão é regular em várias escalas.

No caso de um padrão regular simulado com 200 eventos, os efeitos de perda de eventos são menos acentuados. Para $\mathrm{p}=1$ (figura 4.39a), os valores de LMax, LMin e L, praticamente sobrepõe-se, não alterando-se as conclusões do padrão de distribuição espacial. Para outros valores de p (figura $4.39 \mathrm{~b}$. figura $4.39 \mathrm{c}$, figura $4.39 \mathrm{~d}$, figura $4.39 \mathrm{e}$ e figura 4.39f), os valores de LMin também ultrapassam o envelope de confiança inferior, levando a concluir que o padrão é regular em várias escalas. 


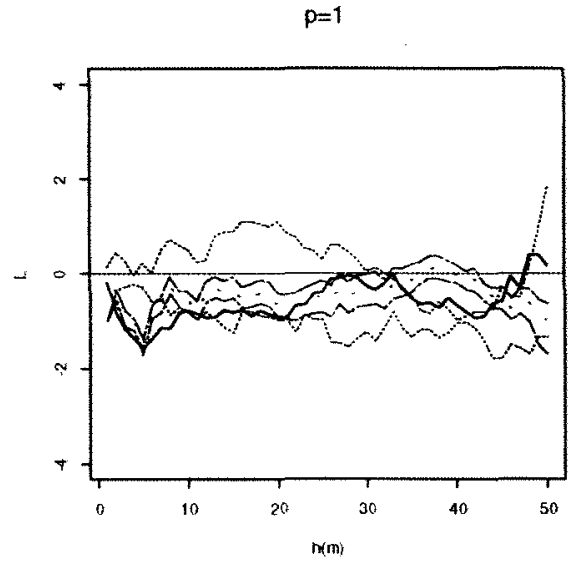

a

$p=10$

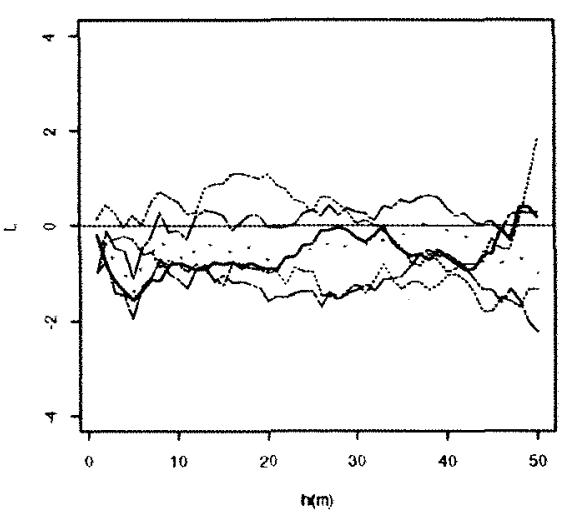

C.

$\mathrm{p}=30$

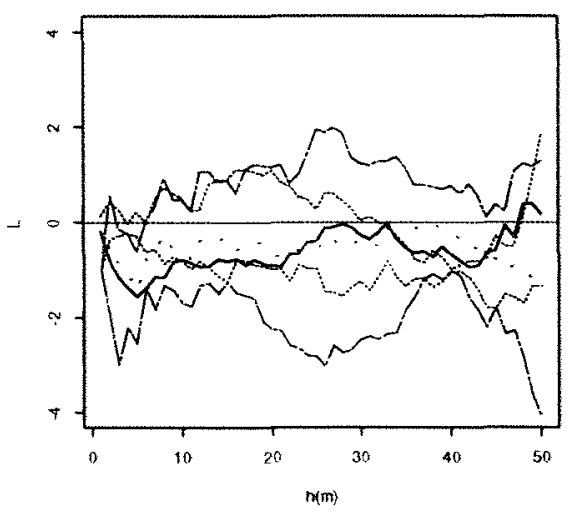

e

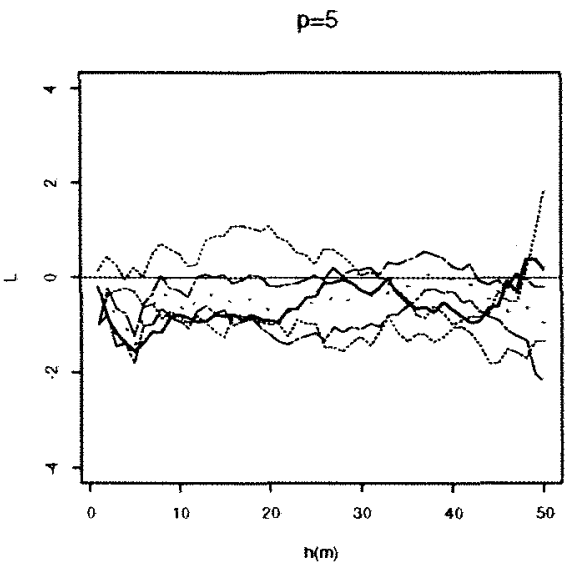

b

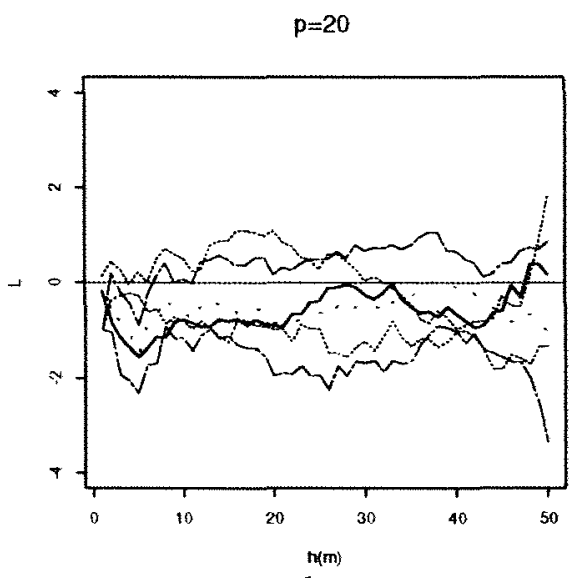

d

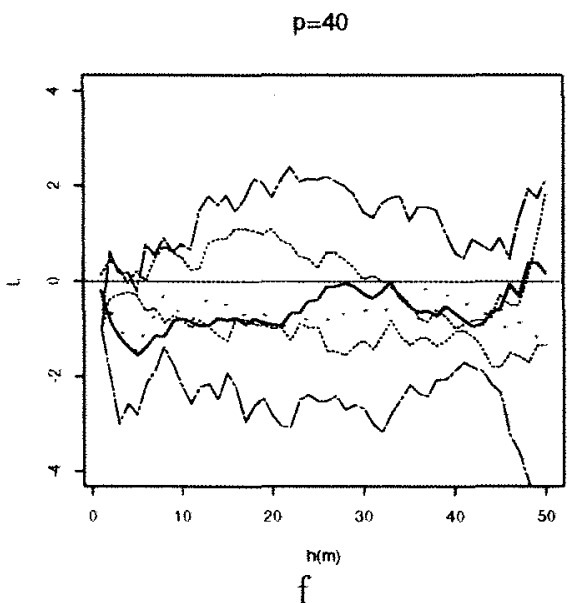

Figura 4.37: Efeito da perda de eventos (p) em um padrão regular simulado com

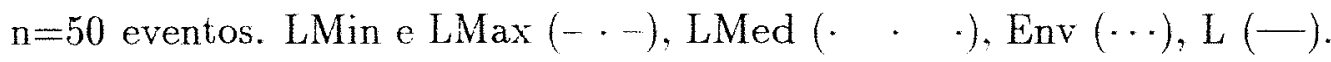




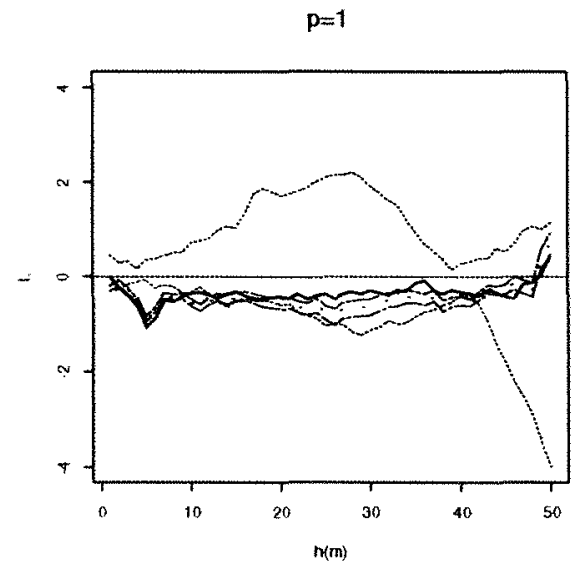

a

$p=10$

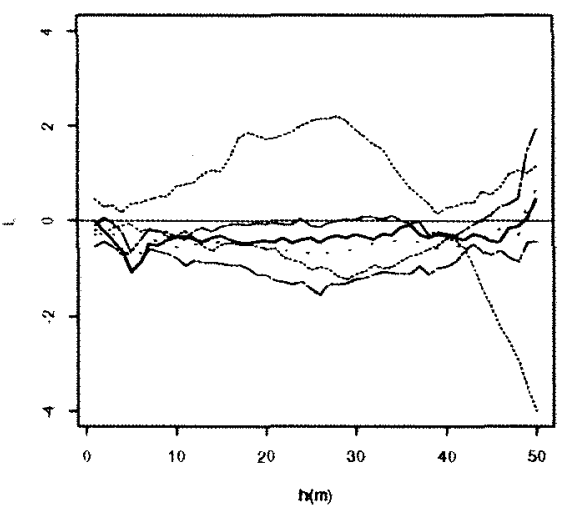

C

$p=30$

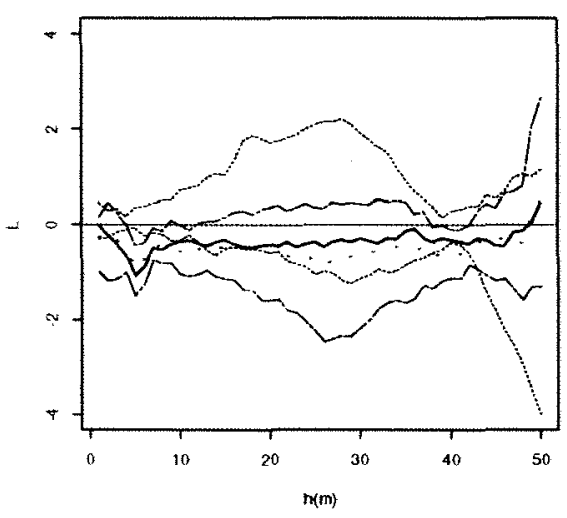

e

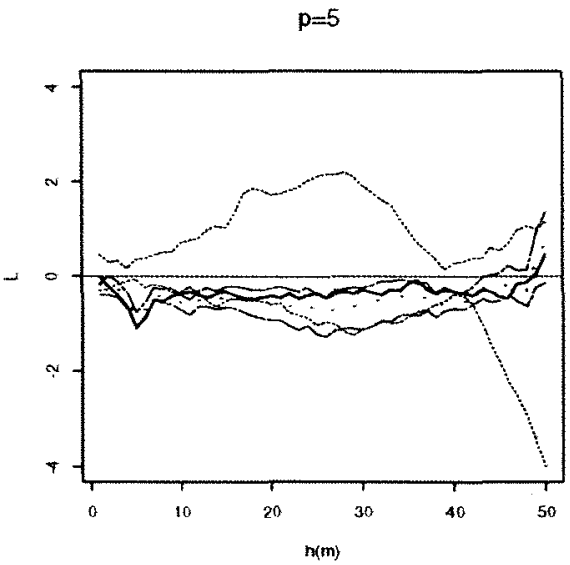

b

$p=20$

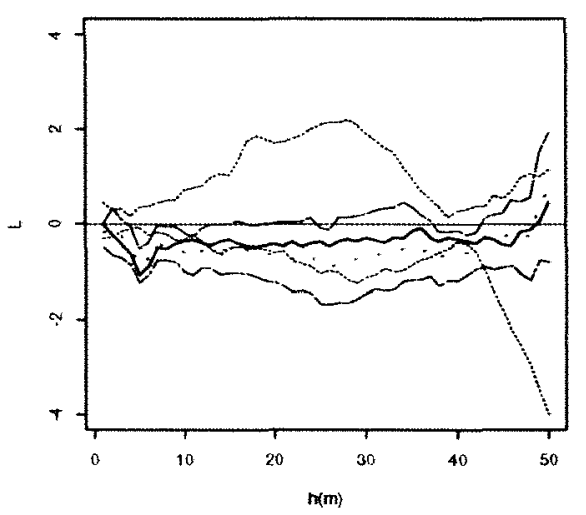

d

$p=40$

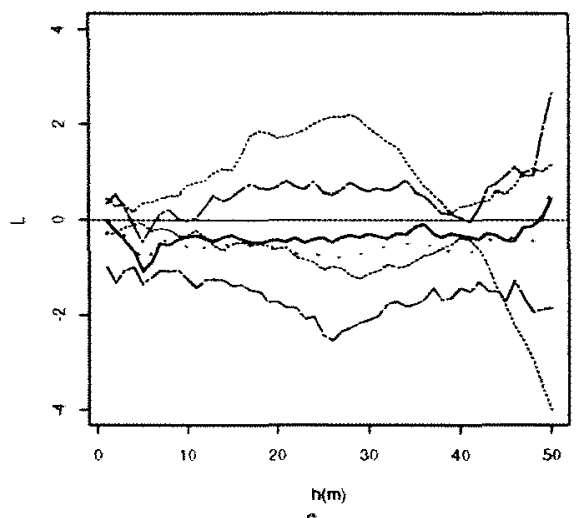

f

Figura 4.38: Efeito da perda de eventos (p) em um padrão regular simulado com $\mathrm{n}=100$ eventos. LMin e LMax $(-\cdot)$, LMed ( - · ·). Env $(\cdots), \mathrm{L}(-)$. 


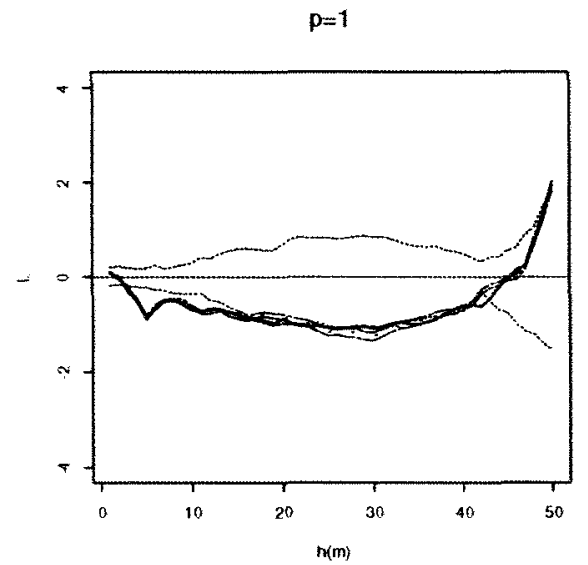

a

$p=101$

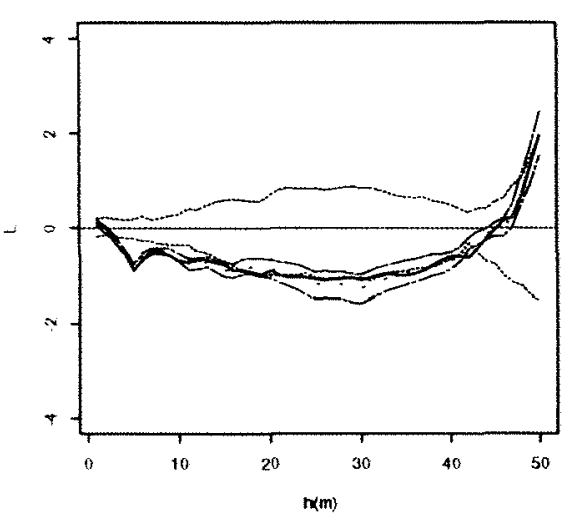

C

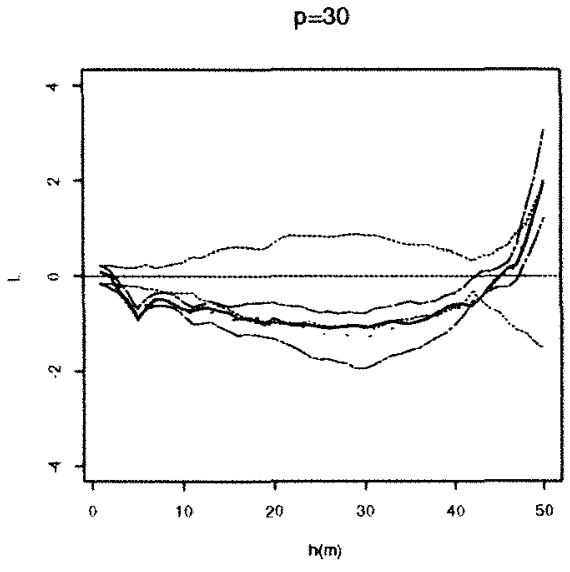

$\mathrm{e}$

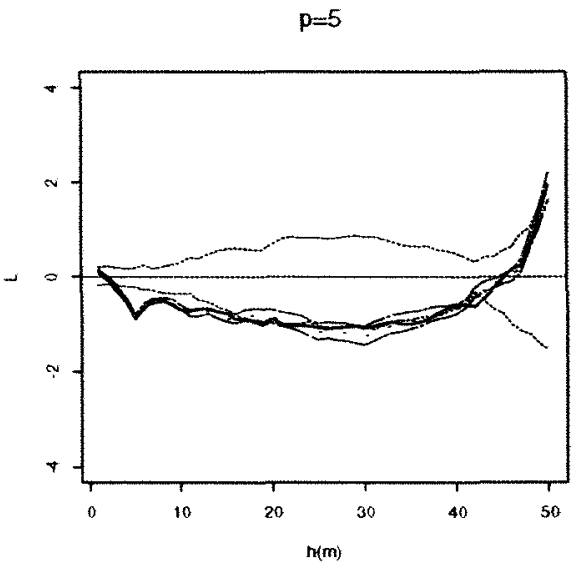

b

$p=20$

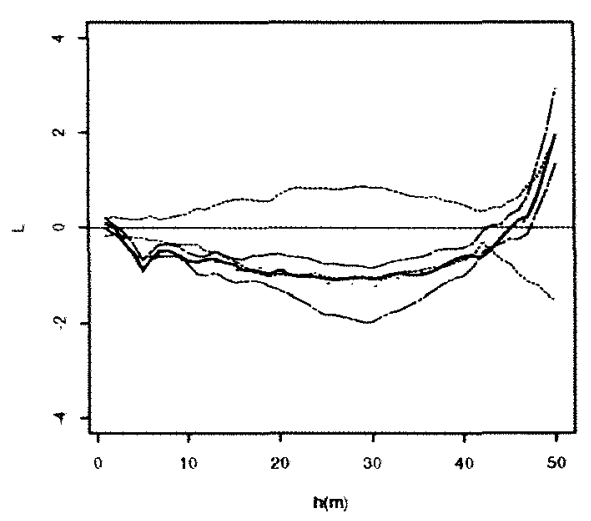

d

$p=40$

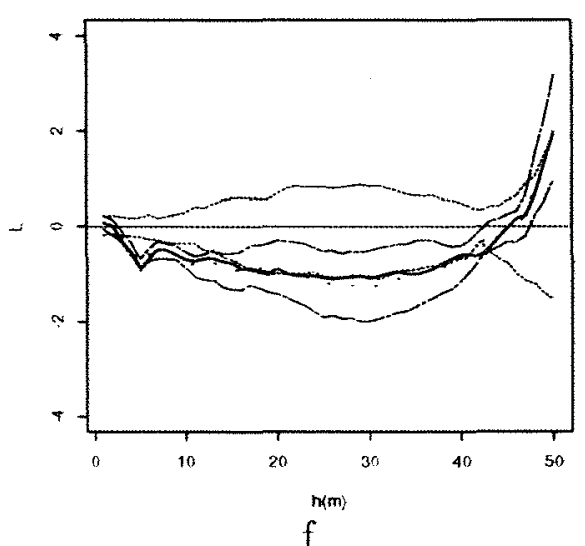

Figura 4.39: Efeito da perda de eventos (p) em um padrão regular simulado com

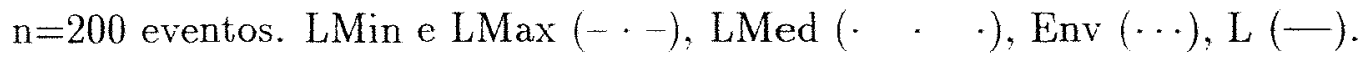




\subsubsection{Padrão Agregado}

Para um padrão simulado com 10 agregados e intensidade $\lambda=3$ de cada agregado, observa-se que quando ocorre perda de até 10 eventos, não ocorre alteração do padrão de distribuição, ou seja, o padrão de distribuição espacial continua sendo agregado (figura 4.40a. figura $4.40 \mathrm{~b}$, figura 4.40c). Quando ocorre perda de 20,30 ou eventos (figura 4.40d, figura 4.40e e figura 4.40f), os valores de LMin ultrapassam o envelope superior, levando à conclusão de que o padrão de disribuição espacial tem distribuição aleatória. Observa-se também que os valores de Lmed não diferem da função $L$ original.

Considerando uma intensidade $\lambda=7$ eventos para 10 agregados simulados na área de $50 \times 50 \mathrm{~m}$, pode-se verificar que quando ocorre perda de até 40 eventos, as conclusões, com relação ao padrão de distribuição espacial não se alteram (figura 4.41a, figura 4.41b, figura 4.41c, (figura 4.41d, figura 4.41e e figura 4.41f). Os valores de LMin vão alterando-se na direção de aleatoriedade, aumentando à medida que ocorrem maior perda de eventos. Os valores de Lmed também não variam muito em relação aos valores de $L$, calculado para o conjunto completo de eventos.

Quando tem-se um padrão agregado, simulado com 10 agregados com intensidade $\lambda=10$, o padrão de distribuição não altera-se quando ocorre a perda de até 10 eventos (figura $4.42 \mathrm{a}$, figura $4.42 \mathrm{~b}$, figura $4.42 \mathrm{c}$ ). Já, quando ocorre a perda de 20,30 ou 40 eventos, em alguns pontos pode-se concluir que o padrão é aleatório, ao invés de agregado, como no padrão inicial (figura 4.42d, figura 4.42e e figura 4.42f). Observa-se também que, nas distâncias inferiores a $10 \mathrm{~m}$, ocorrem as menores variações de padrão, ao contrário de distâncias maiores.

Agora, um padrão de distribuição, simulado com 15 agregados e intensidade $\lambda=3$, tem-se também que, até 10 eventos perdidos (figura 4.43a, 


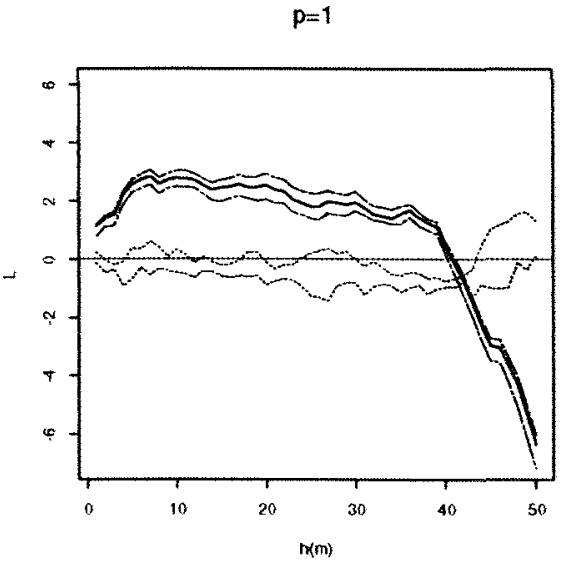

a

$p=10$

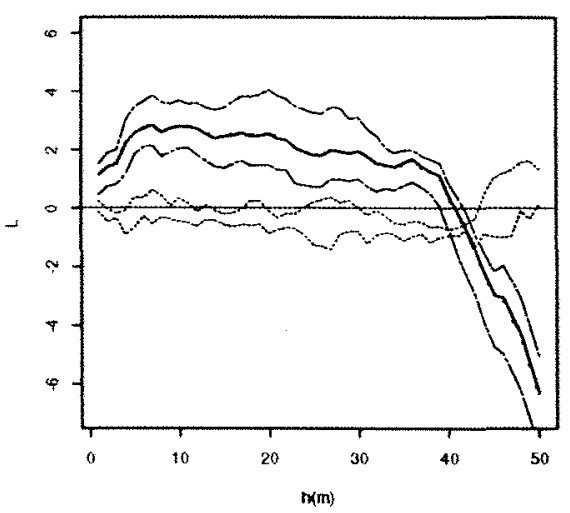

C

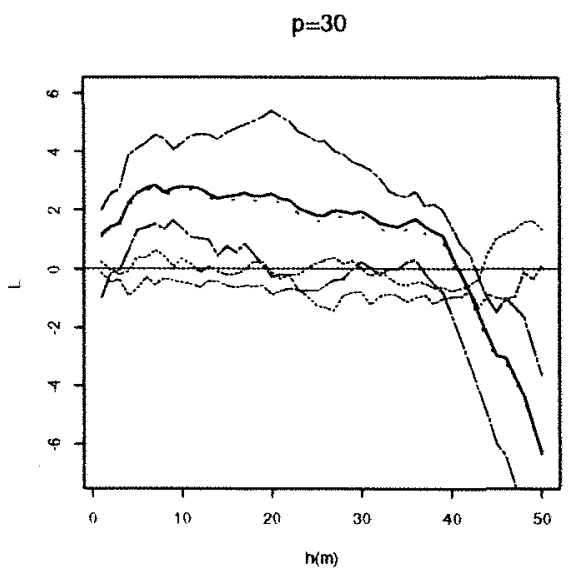

e

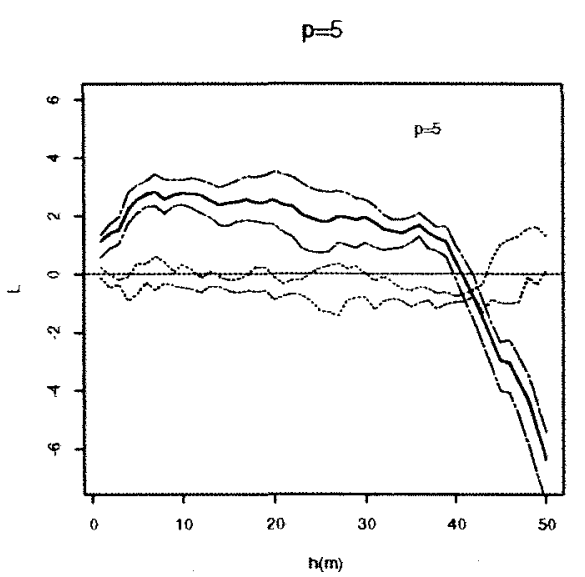

$\mathrm{b}$

$p=20$

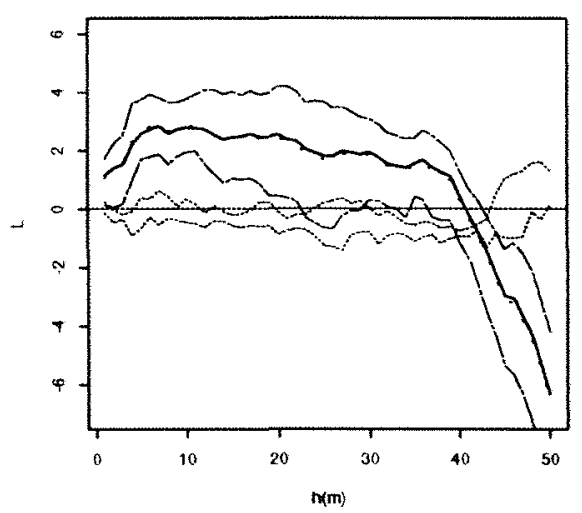

d

$p=40$

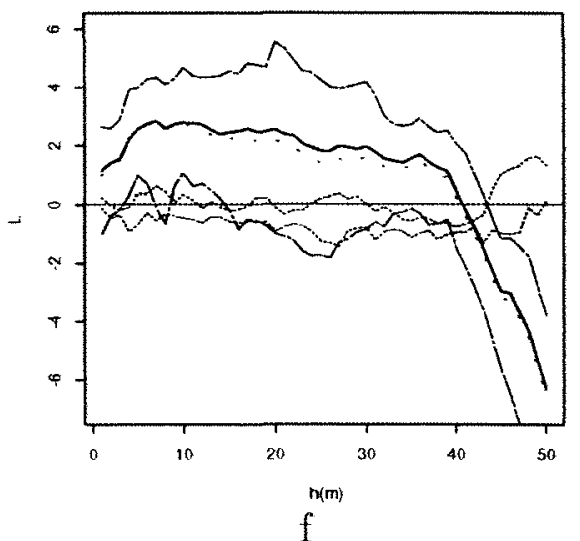

Figura 4.40: Efeito da perda de eventos (p) em um padrão agregado simulado com

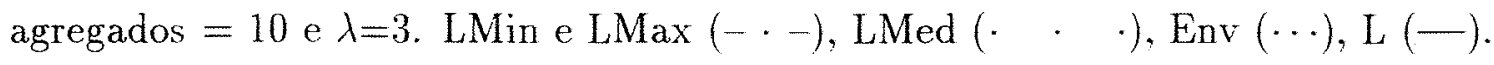




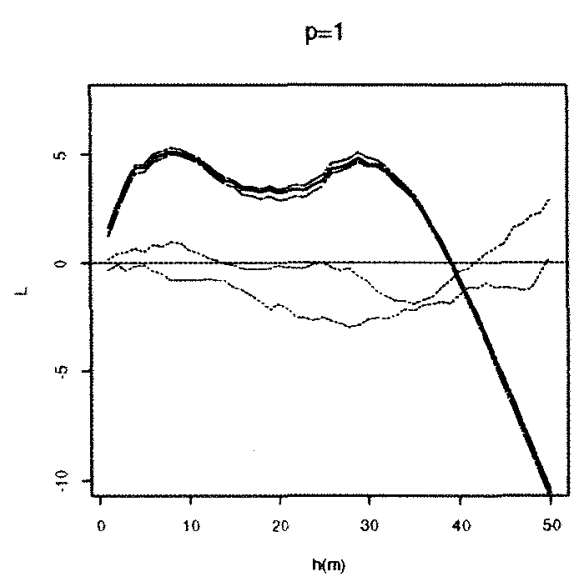

a

$p=10$

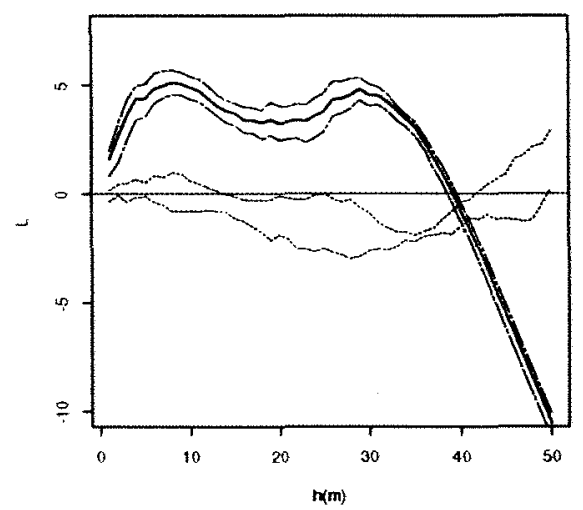

$\mathrm{C}$

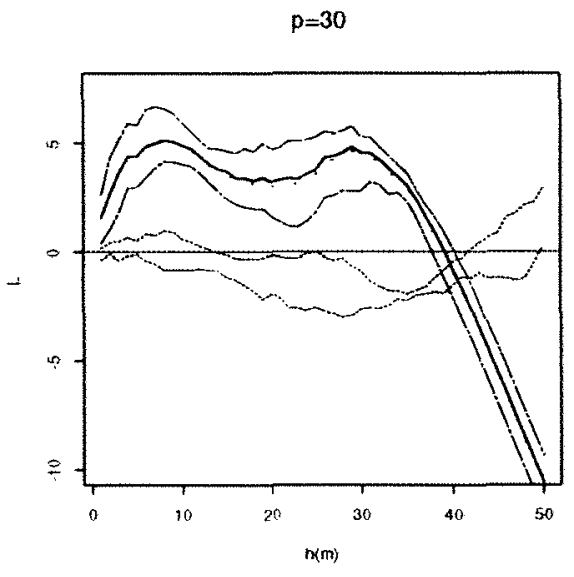

e

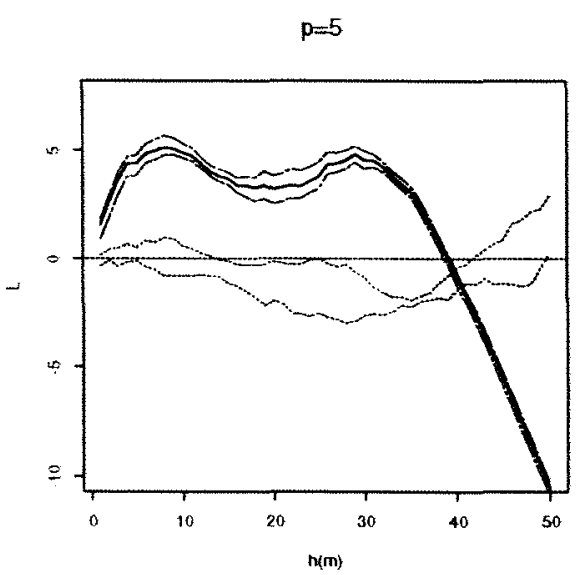

b

$p=20$

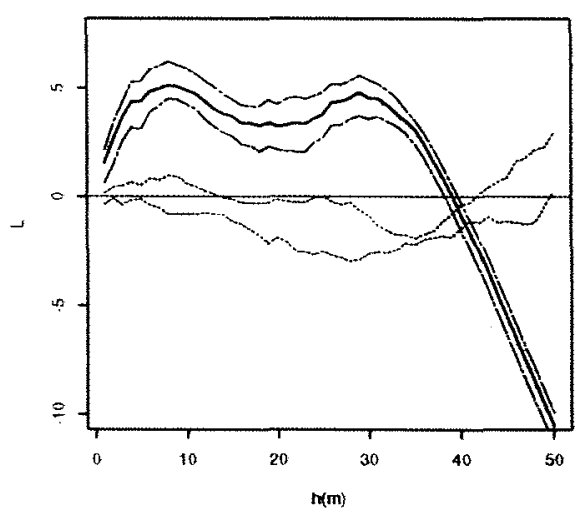

d

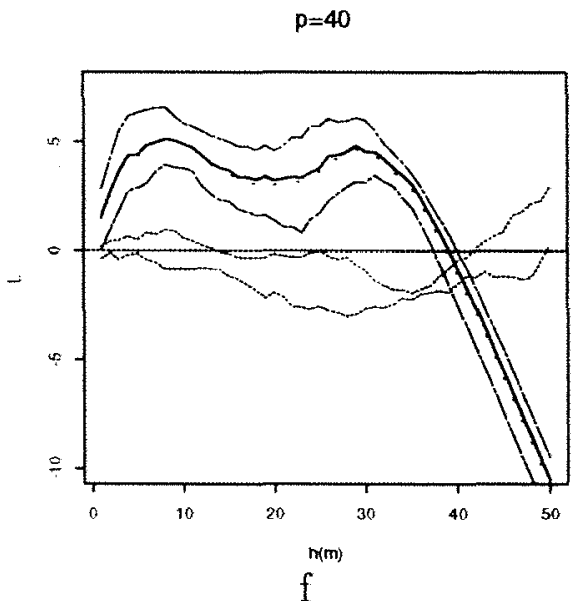

Figura 4.41: Efeito da perda de eventos (p) em um padrão agregado simulado com agregados $=10$ e $\lambda=7 . \operatorname{LMin}$ e $\operatorname{LMax}(-\cdot), \operatorname{LMed}(\cdot \quad \cdot \quad \cdot), \operatorname{Env}(\cdots), \mathrm{L}(-)$. 


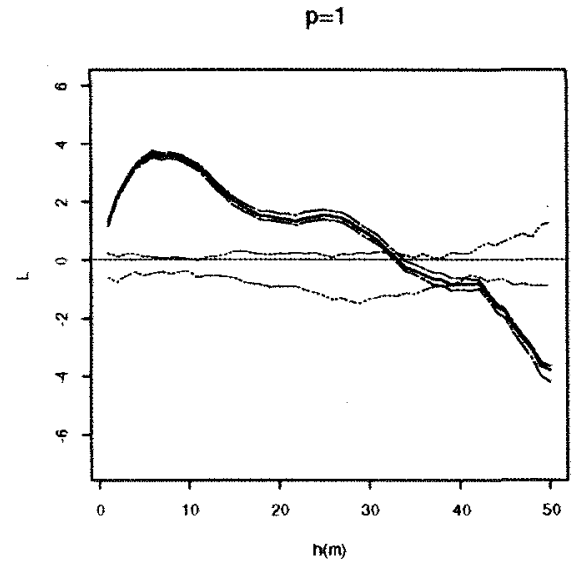

a

$p=10$

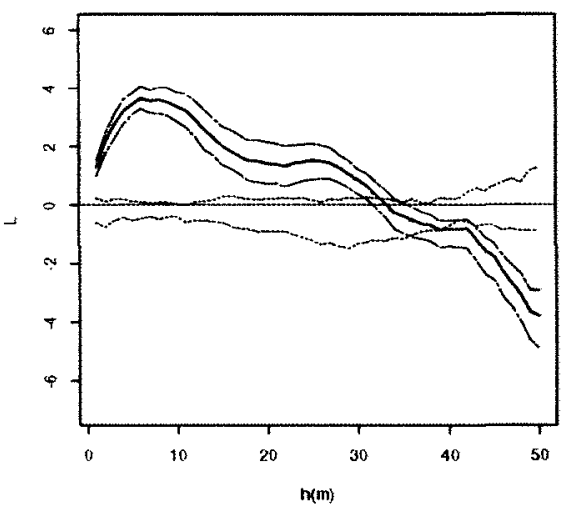

C

$\mathrm{p}=30$

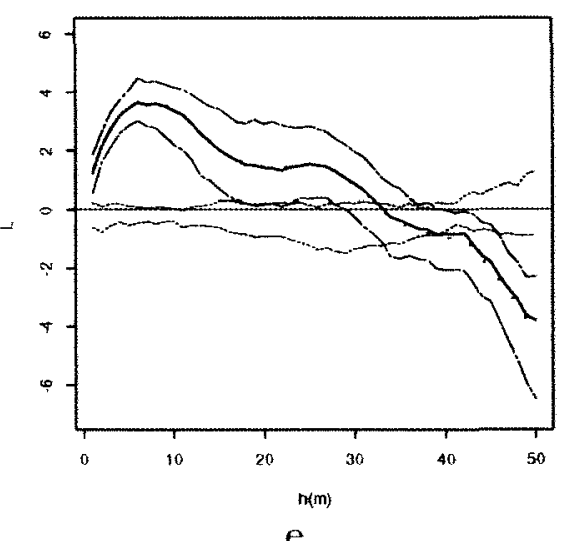

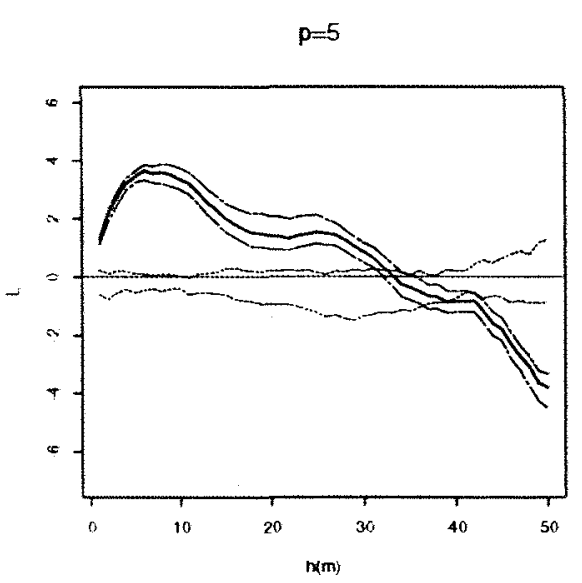

b

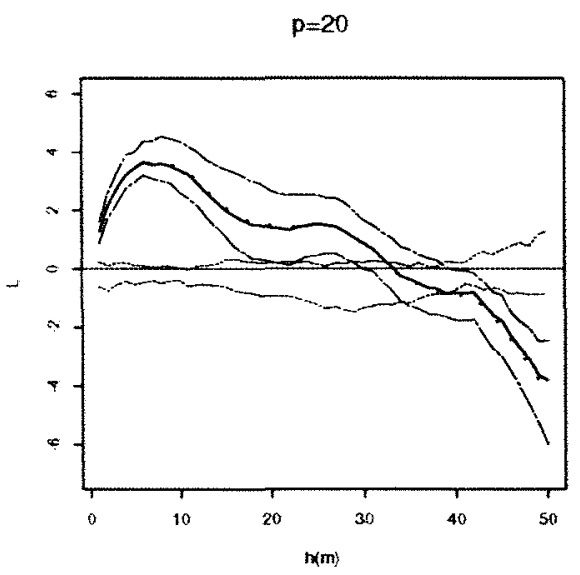

d

$p=40$

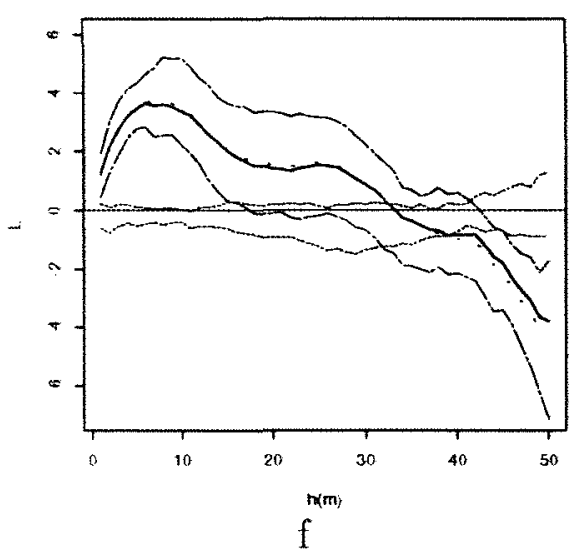

Figura 4.42: Efeito da perda de eventos ( $\mathrm{p}$ ) em um padrão agregado simulado com agregados $=10$ e $\lambda=10$. LMin e LMax $(-\cdot)$. LMed $(\cdot \quad \cdot \quad \cdot)$, Env $(\cdots)$, L (-). 
figura 4.43b e figura 4.43c), não há alterações das conclusões, com relação ao padrâo de disribuição original. Mas, quando ocorre a perda de 20,30 ou 40 eventos (figura 4.43d, figura 4.43e e figura 4.43f), o padrão de distribuição torna-se aleatório ou agregado quando era regular e torna-se regular ou aleatório onde antes era agregado. Os valores de Lmed praticamente seguem os mesmos valores da função $L$ original.

Para um padrão simulado com 15 agregados e intensidade $\lambda=7$, as conclusòes sobre o padrão de distribuição espacial não se alteram quando ocorre uma perda de até 40 eventos (figura $4.44 \mathrm{a}$, figura $4.44 \mathrm{~b}$, figura $4.44 \mathrm{c}$, figura $4.44 \mathrm{~d}$, figura $4.44 \mathrm{e}$ e figura 4.44f). Observa-se que à medida que o número de eventos perdidos aumenta, os valores de LMax e de LMin aumentam e diminuem, respectivamente. Os valores de LMed também tornam-se diferentes dos valores de L, à medida que o número de eventos perdidos aumenta.

Para 15 agregados simulados com uma intensidade $\lambda=10$, não há alterações nas conclusões com relação ao padrão de distribuição espacial (figura 4.45 a, figura $4.45 \mathrm{~b}$, figura $4.45 \mathrm{c}$, figura $4.45 \mathrm{~d}$, figura $4.45 \mathrm{e}$ e figura $4.45 \mathrm{f}$ ).

Finalmente, quando tem-se um padrão agregado simulado com 20 agregados, com intensidade $\lambda=3$, observa-se que quando há perdas de até 10 eventos (figura 4.46a, figura 4.46b, figura 4.46c), as conclusões sobre o padrão de distribuição não se alteram. Mas, quando há perda de 20,30 ou 40 eventos (figura 4.46d, figura 4.46e e figura 4.46f), os valores de LMin, na maior parte, sugerem um padrão aleatório e em algumas partes, levam a concluir que o padrão é regular onde antes era considerado agregado.

Quando tem-se um padrão agregado simulado com 20 agregados e uma intensidade $\lambda=7$, verifica-se que há pouca variação entre os valores de LMax e LMin, não alterando as conclusões a respeito do padrão de distribuição espacial 


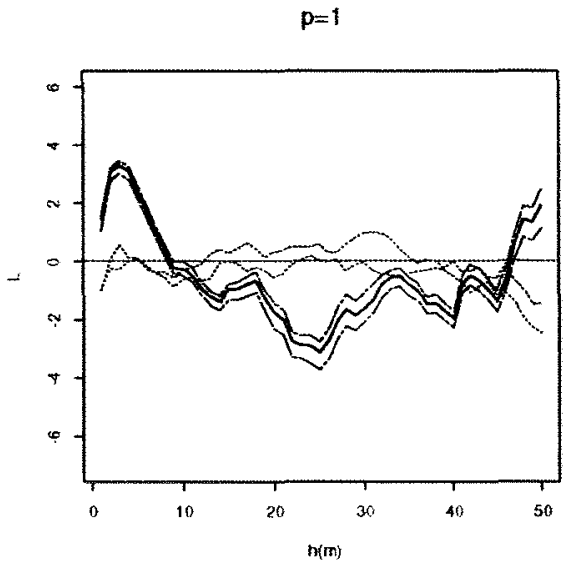

a

$p=10$

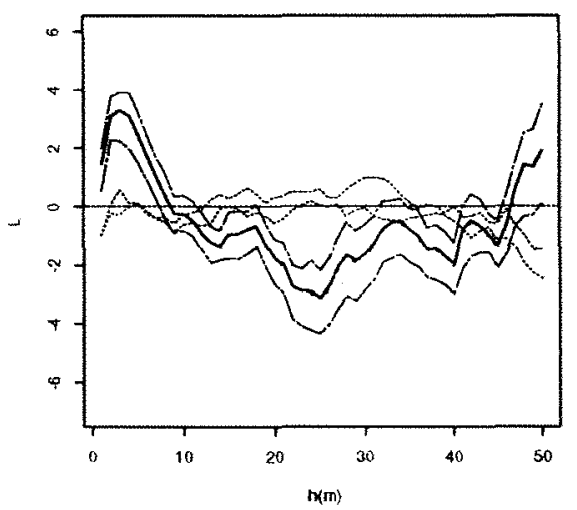

C

$\mathrm{p}=30$

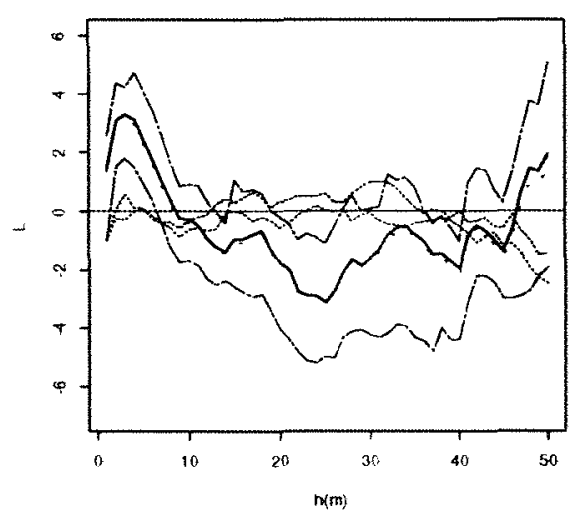

e

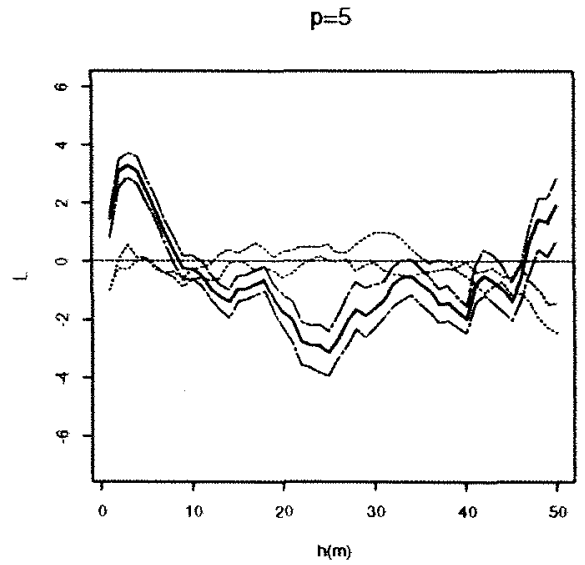

$\mathrm{b}$

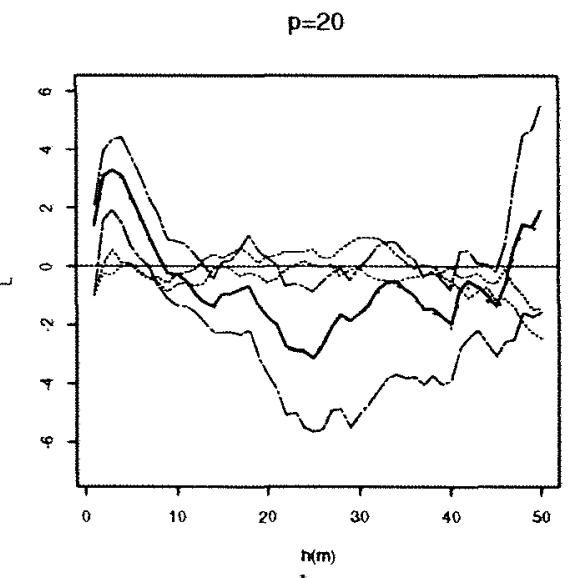

d

$\mathrm{p}=38$

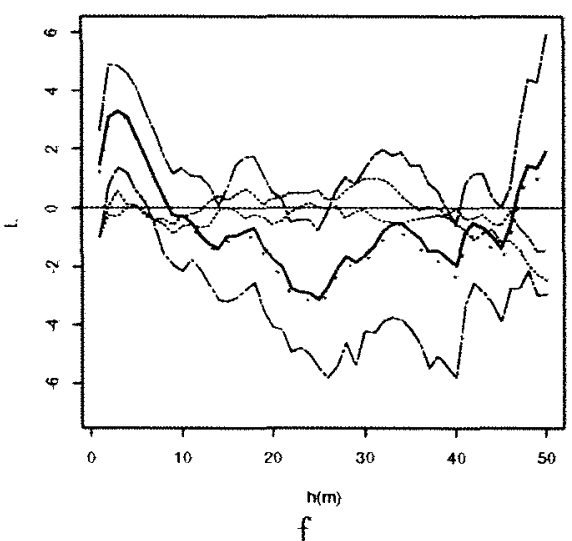

Figura 4.43: Efeito da perda de eventos (p) em um padrão agregado simulado com agregados $=15$ e $\lambda=3$. LMin e LMax $(-\cdot-)$, LMed $(\cdot \quad \cdot \quad \cdot), \operatorname{Env}(\cdots)$, L (-). 


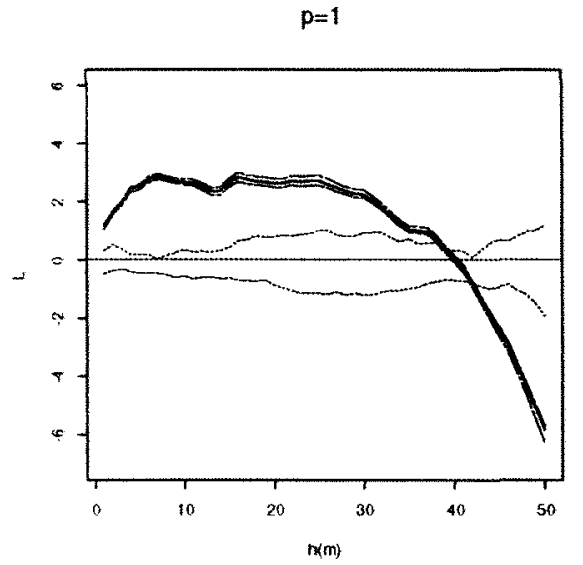

a.

$p=10$

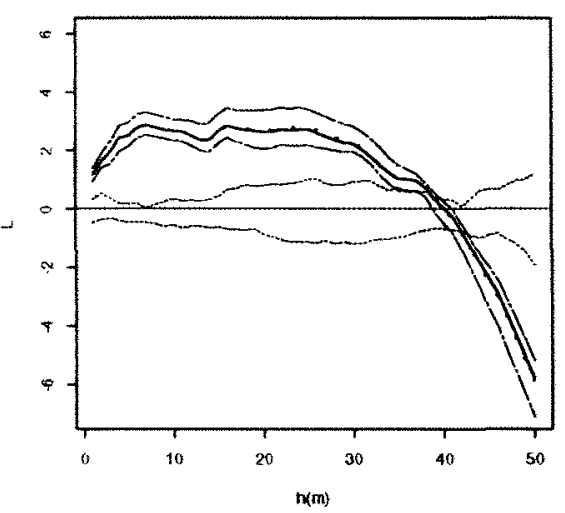

c

$\mathrm{p}=30$

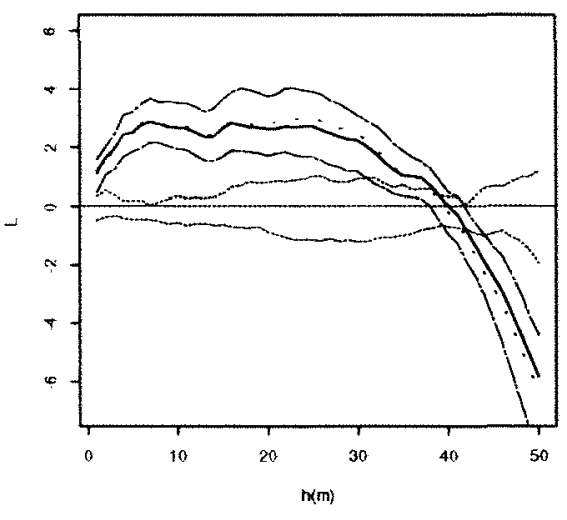

e

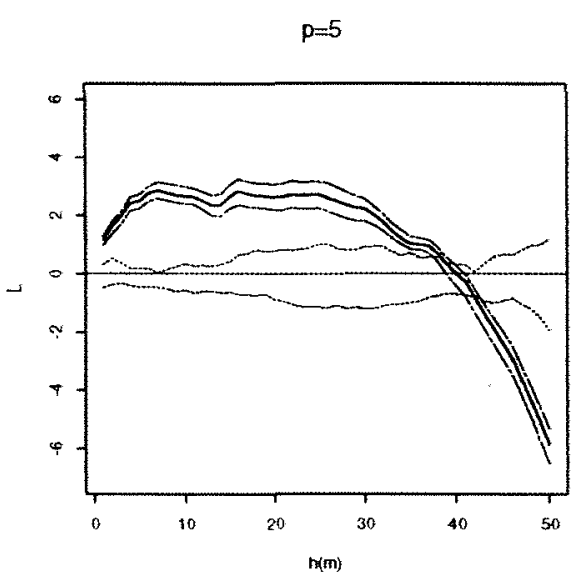

b

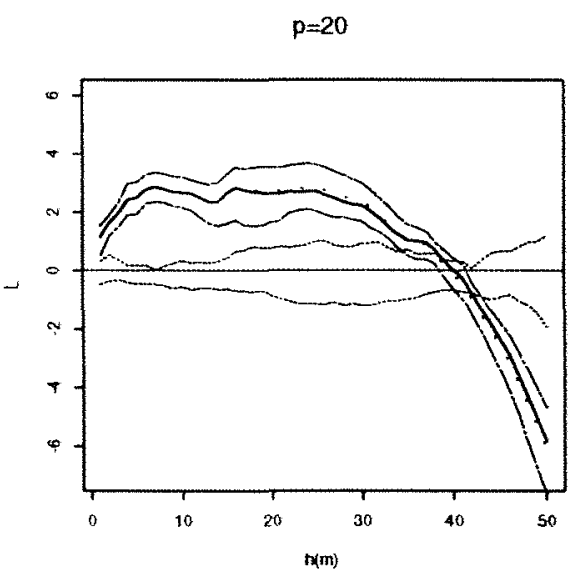

$\mathrm{d}$

$p=40$

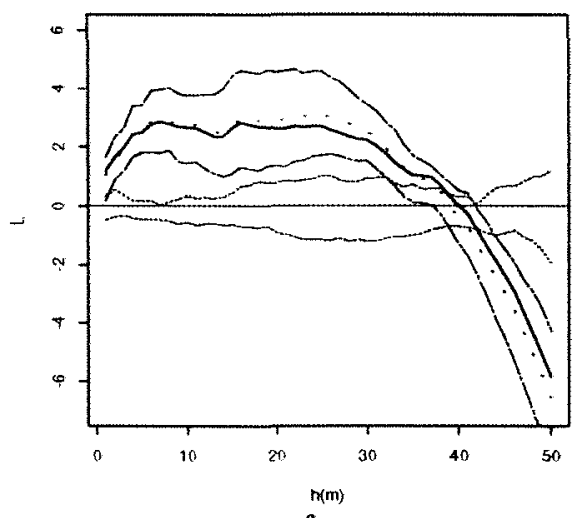

f

Figura 4.44: Efeito da perda de eventos (p) em um padrão agregado simulado com agregados $=15$ e $\lambda=7$. LMin e LMax $(-\cdots), \operatorname{LMed}(\cdot \cdot \cdot \cdot)$, Env $(\cdots), L(-)$. 


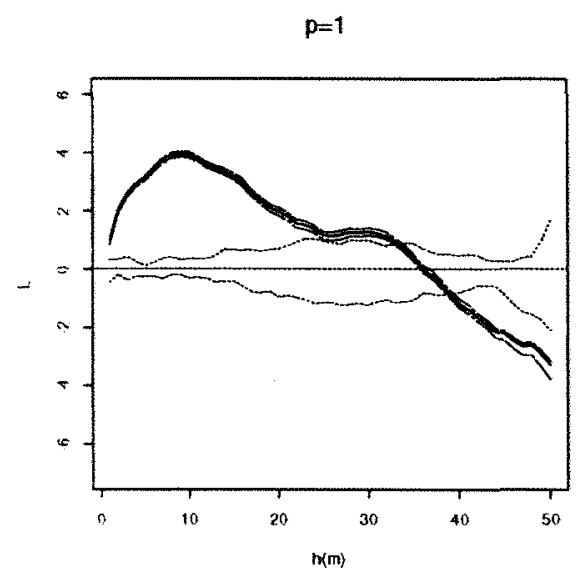

a.

$p=10$

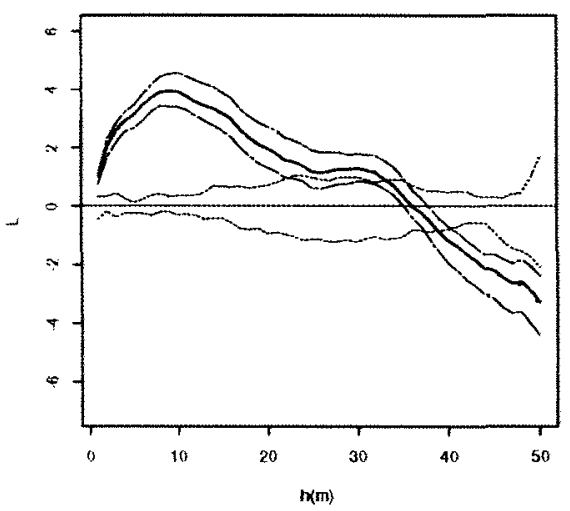

C

$p=30$

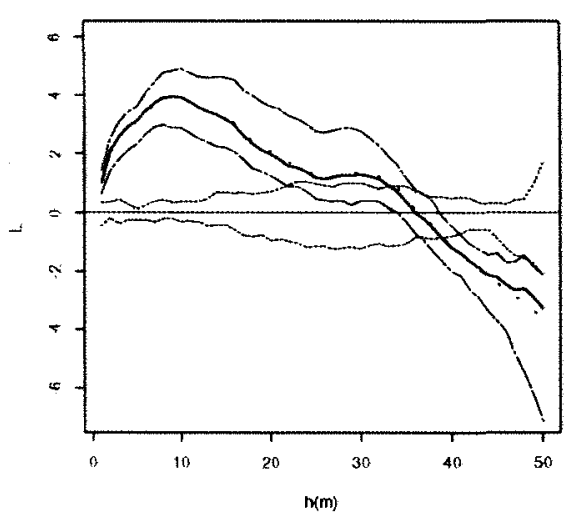

e

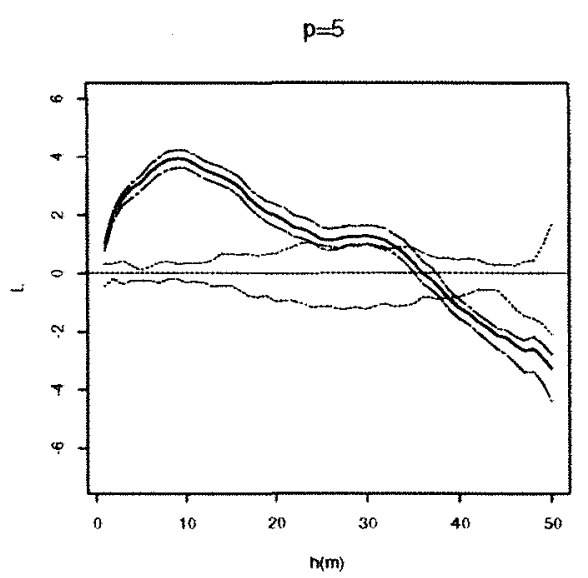

b

$p=20$

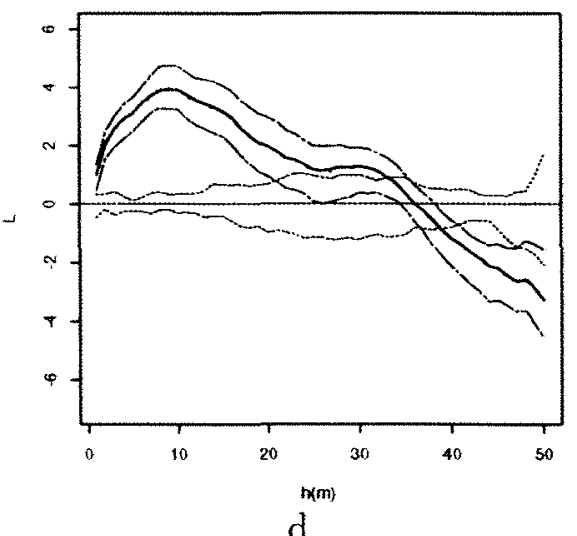

$p=40$

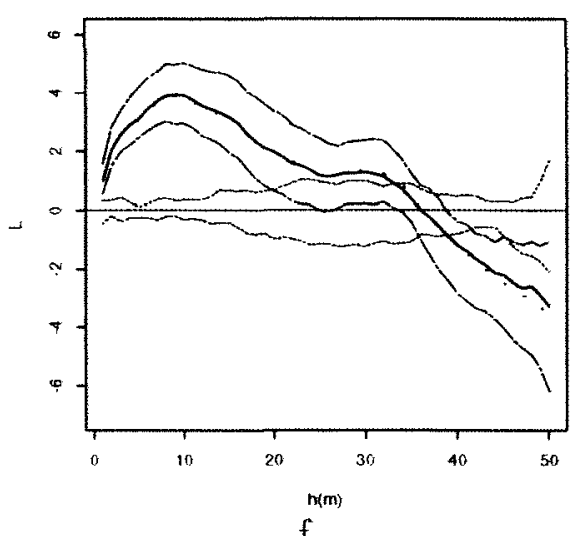

$\mathrm{f}$

Figura 4.45: Efeito da perda de eventos (p) em um padrão agregado simulado com agregados $=15$ e $\lambda=10 . \operatorname{LMin}$ e $\operatorname{LMax}(-\cdot), \operatorname{LMed}(\cdot \cdot \cdot)$, Env $(\cdots), \mathrm{L}(-)$. 
(figura $4.46 \mathrm{a}$, figura $4.46 \mathrm{~b}$, figura $4.46 \mathrm{c}$, figura $4.46 \mathrm{~d}$, figura $4.46 \mathrm{e}$ e figura $4.46 \mathrm{f}$ ).

Por último, quando tem-se 20 agregados com uma intensidade $\lambda=10$, também chega-se as mesmas conclusões da figura anterior, ou seja, não há alteração do padrão de distribuição espacial quando ocorrem até 40 eventos perdidos (figura $4.47 \mathrm{a}$, figura $4.47 \mathrm{~b}$, figura $4.47 \mathrm{c}$, figura $4.47 \mathrm{~d}$, figura $4.47 \mathrm{e}$, figura $4.46 \mathrm{f}$ ). 


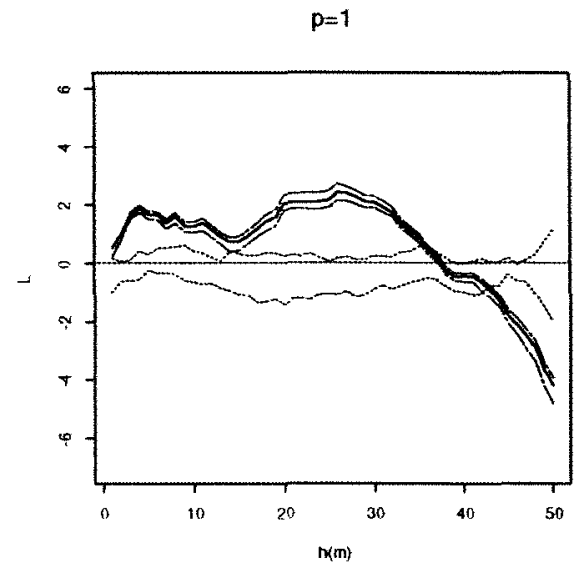

a

$p=10$

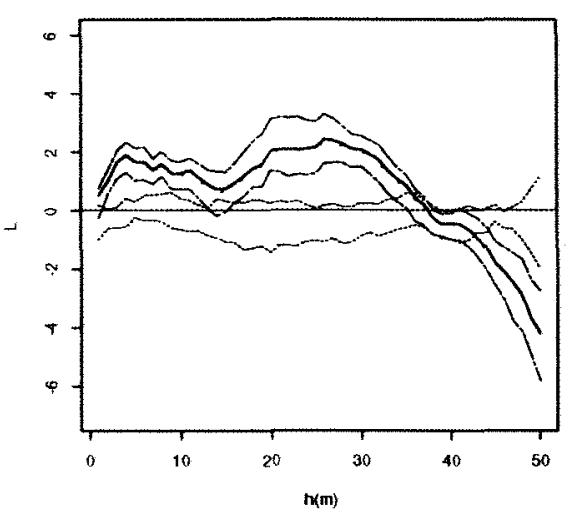

C.

$p=30$

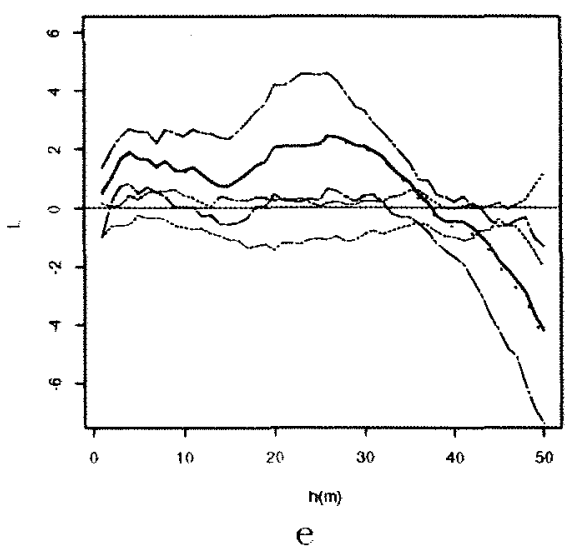

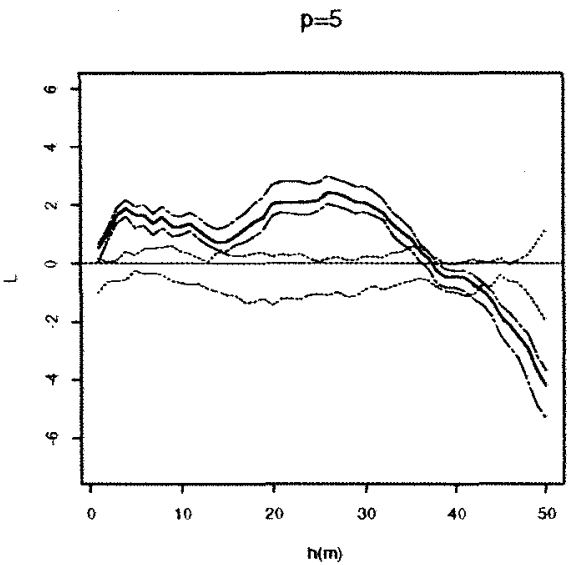

$\mathrm{b}$

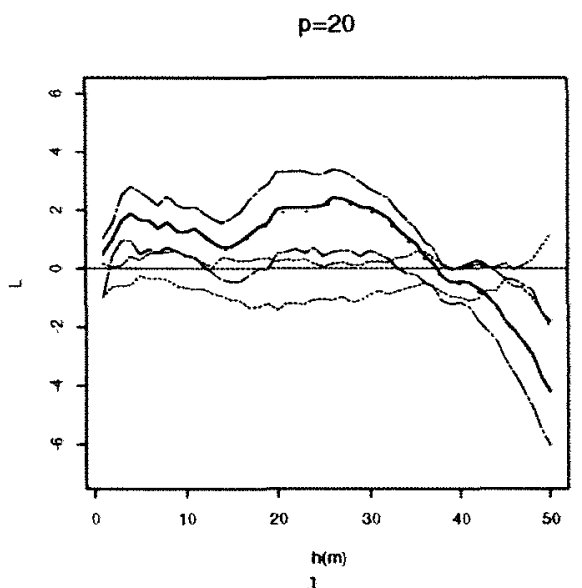

d

$p=40$

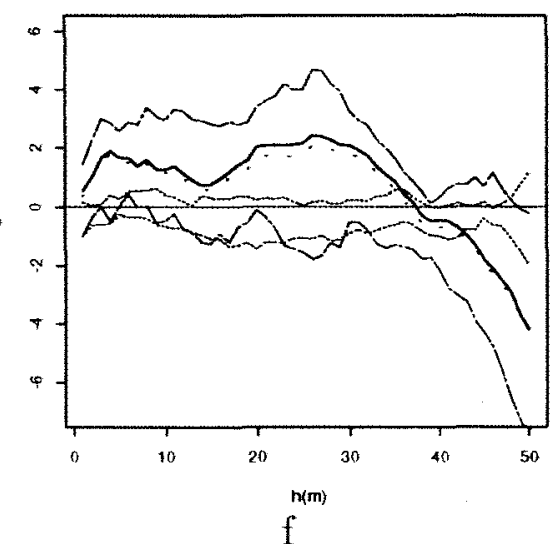

Figura 4.46: Efeito da perda de eventos (p) em um padrão agregado simulado com

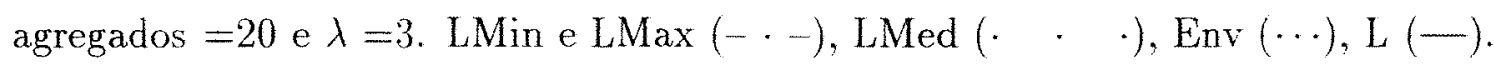




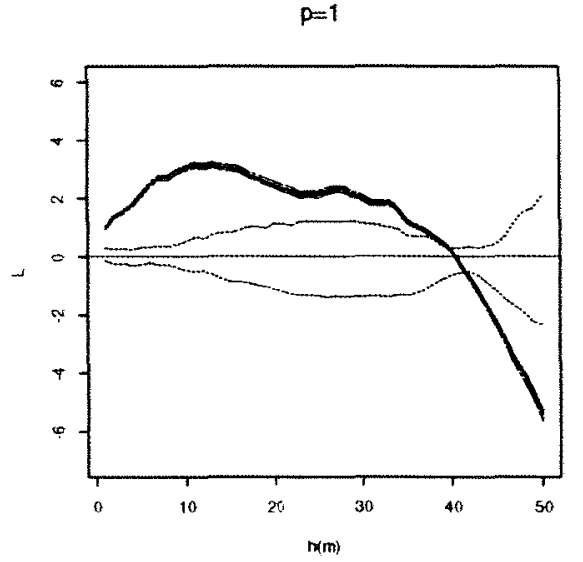

a.

$p=10$

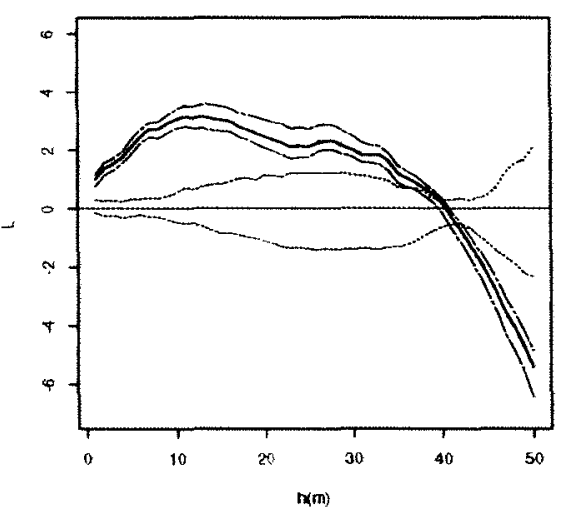

c

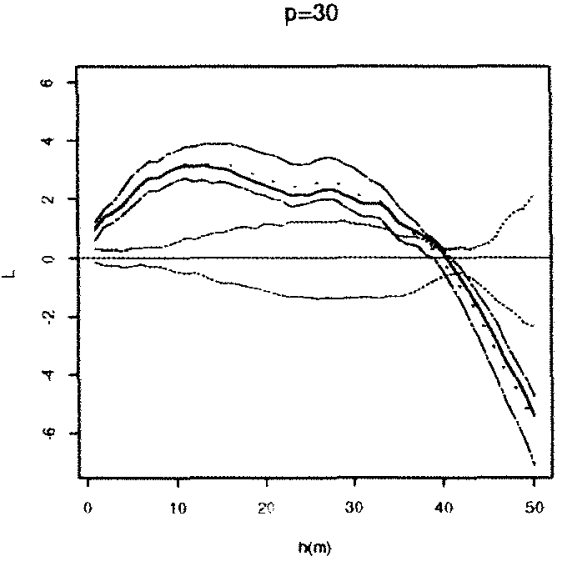

e

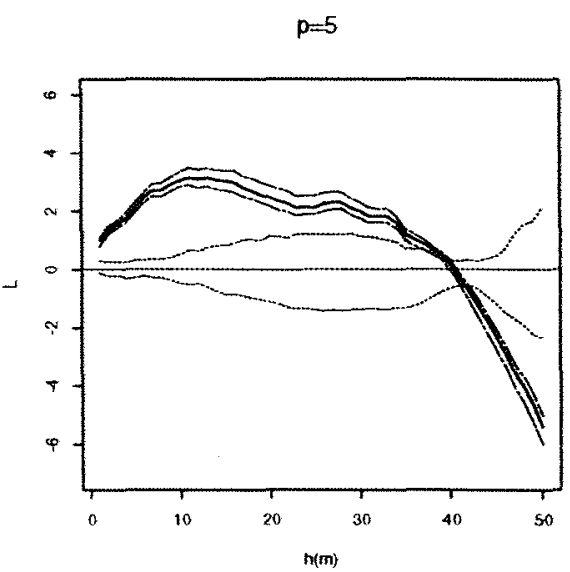

$b$

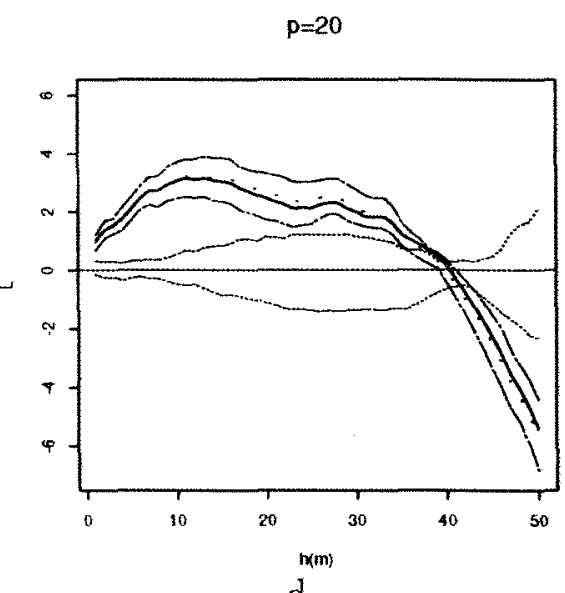

d

$\mathrm{p}=40$

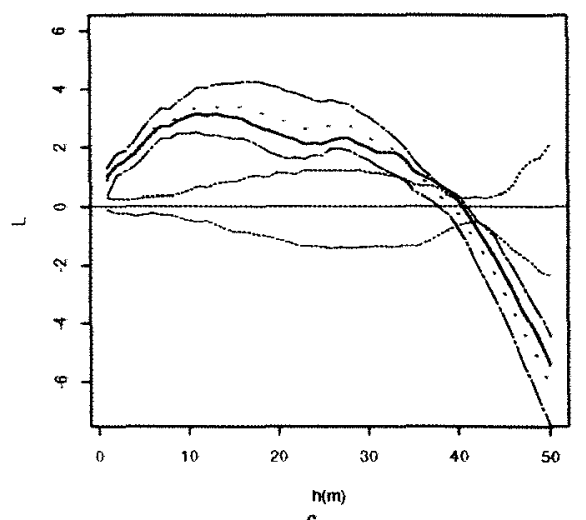

f

Figura 4.47: Efeito da perda de eventos (p) em um padrão agregado simulado com agregados $=20$ e $\lambda=7 . \operatorname{LMin}$ e $\operatorname{LMax}(-\cdot), \operatorname{LMed}(\cdot \cdot \cdot \cdot), \operatorname{Env}(\cdots), L(-)$. 


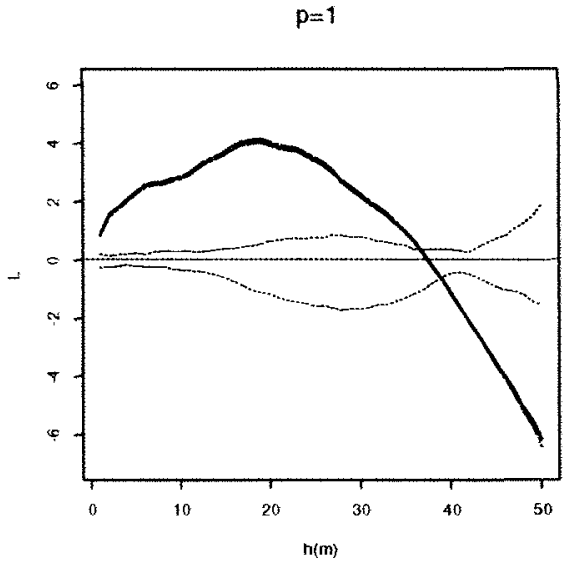

$a$

$p=10$

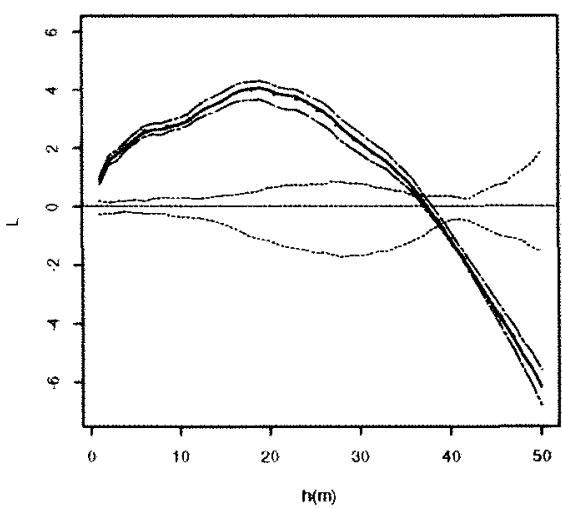

$c$

$\mathrm{p}=\mathbf{3 0}$

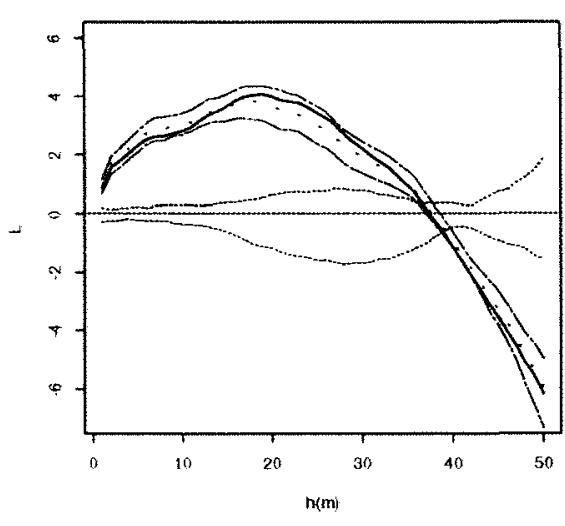

e

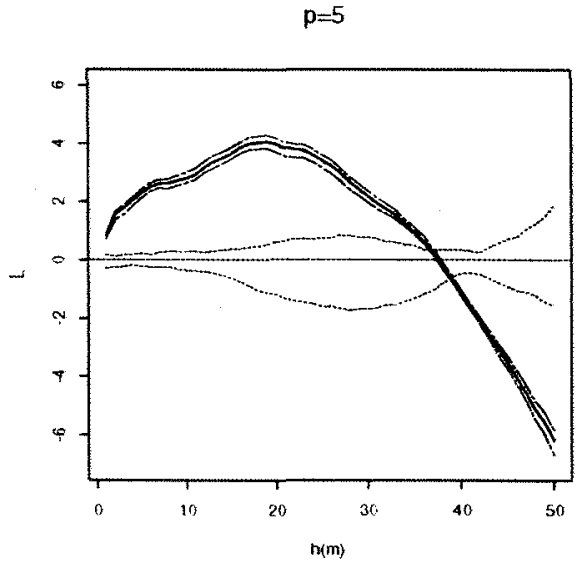

$b$

$p=20$

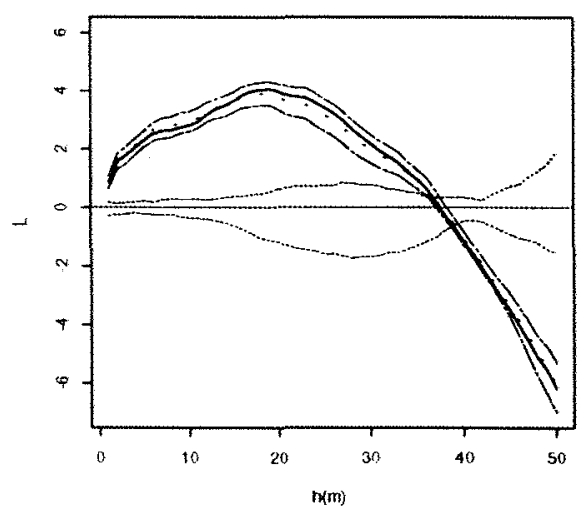

d

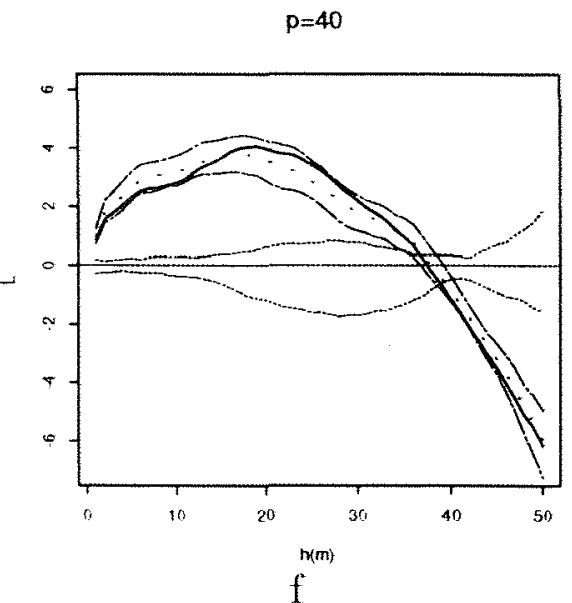

Figura 4.48: Efeito da perda de eventos (p) em um padrăo agregado simulado com

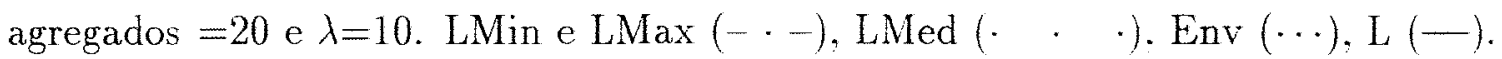




\subsection{Conclusões}

Para os diferentes padrões simulados aqui estudados (aleatório, agregado e regular), pode-se concluir que, em média, o padrão de distribuiçào espacial não é alterado quando ocorre perda (aleatória e independentemente) de eventos. À medida que a intensidade aumenta, o efeito da perda de eventos sobre um padrâo de distribuição espacial diminui. Por outro lado, a chance de ocorrerem valores extremos também aumenta à medida que aumentam o número de eventos perdidos. Estes extremos variam principalmente em função da intensidade e também do padrão de distrubuição do processo.

Independente do padrão de distribuição, observou-se que quando o número de eventos é grande, $(\mathrm{n} \geq 100)$, os efeitos da perda de eventos sobre o padrão de distribuição espacial diminuem.

No caso de uma população de Euterpe edulis, este procedimento de simulação pode ser utilizado para se avaliar qual o número máximo de plantas que poderiam ser exploradas (retiradas) em uma população natural, sem que ocorram alteraçòes no padrão de distribuição espacial. 


\section{CAPÍTULO 5}

\section{Análise do Efeito do Manejo em Regime de Rendimento Sustentável sobre o Padrão de Distribuição Espacial do Palmiteiro (Euterpe edulis) Através de Simulação}

\subsection{Introdução}

A Mata Atlântica hoje representa $16 \%$ da cobertura florestal do Estado de Santa Catarina, no sul do Brasil, na sua grande maioria, constituídas por formaçôes secundárias isoladas em fragmentos florestais (Hodge et al., 1997; Reis, 1995). Busca-se, encontrar sistemas produtivos que possibilitem rendimento econômico com preservação ambiental. Segundo Fantini et al. (1992), a exploração de florestas tropicais por tempo indeterminado deve basear-se na manutenção da biodiversidade, garantindo a exploração de forma cíclica e contínua, seguindo alguns princípios básicos:

- manutenção de plantas matrizes;

- avaliação do estoque disponível;

- avaliação de taxas de incremento; 
- avaliação da regeneração natural.

Para tanto, é importante que se faça um inventário florestal detalhado, considerando a estrutura populacional das espécies.

A exploração do palmiteiro (Euterpe edulis) é uma atividade de grande importância social nas regiōes sul e sudeste do Brasil, constituindo-se numa fonte de renda para um grande número de famílias que vivem em áreas de ocorrência da Mata Atlântica (Fantini et al., 1997). Esta espécie tem sido explorada de forma indiscriminada em quase todas as regiões em que ainda ocorre. Uma alternativa ecológica e economicamente viável, é a exploração em regime de manejo sustentável, aproveitando-se de algumas características favoráveis desta espécie, segundo Reis (1995):

- possui uma distribuição geográfica ampla:

- ocupa o estrato médio da floresta;

- ocorre com alta freqüência e grandes densidades;

- possui alto valor econômico;

- é fácil de ser explorada e industrializada;

- tem produção de sementes abundante;

- tem uma forte interação com a fauna.

Baseado no incremento anual em área basal e sua relação com classes diamétricas, pode-se estabelecer uma relação entre estas variáveis, que permite encontrar a classe diamétrica com máximo incremento, segundo Reis et al. ${ }^{2}$.

\footnotetext{
${ }^{2}$ REIS, M. S.; FANTINI, A. C.;NODARI, R. O. GUERRA, M. P. Sustainable yield management of Euterpe edulis MARTIUS (Palmae): a Tropical tree from the Atlantic Tropical Forest - Brazil. (Em elaboração)
} 
Plantas de palmiteiro, com DAP (diâmetro a altura do peito) superiores ao da classe diamétrica com máximo incremento estão sujeitas ao processo de exploração. Para garantir a perpetuação da espécie, os mesmos autores recomendam a manutenção de no mínimo 50 indivíduos reprodutivos por ha.

Reis (1995), enfatiza a necessidade de se manter a estrutura populacional da espécie em sistemas de manejo em regime de rendimento sustentável. Esta estrutura deve ser tanto vertical, ou scja, deve-se manter a pirâmide demográfica da espécie, quanto horizontal (distribuição espacial).

O objetivo deste capítulo é avaliar os efeitos da aplicação do manejo proposto sobre o padrão de distribuição espacial do palmiteiro através da simulação de cxploração de uma população natural, utilizando a função $K$ de Ripley. 


\title{
5.2 Material e Métodos
}

\author{
Dados
}

Os dados de distribuição espacial do palmiteiro (E. edulis), foram coletados na Fazenda Faxinal, localizada no município de Blumenau, SC, entre os paralelos $27^{\circ} 04^{\prime}$ e $27^{\circ} 05^{\prime}$ sul e os meridianos $49^{\circ} 05^{\prime}$ e $49^{\circ} 10^{\prime}$ a oeste de Greenwich.

A área possui uma cobertura vegetal de Mata Atlântica com pouca ou nenhuma exploração de madeira ou palmito (Reis, 1995). Dentro desta região foi demarcada uma área de 5,44 hectares $(160 \times 340 \mathrm{~m})$, onde foram registradas as posições de todas as plantas de palmiteiro que apresentavam estipe exposto a uma altura de 1,0 metro. Estas plantas foram classificadas em três estádios:

- Imaturos 1 - Plantas com altura de estipe exposto menor do que 1,30 m;

- Imaturos 2 - Plantas com altura de estipe exposto maior ou igual a 1,30 m mas, sem evidências de emissão de inflorescências;

- Adultos - Plantas com altura de estipe exposto maior ou igual a 1,30 m e com sinais de reprodução (cachos secos, cicatrizes) ou em reprodução.

A figura 5.49 mostra a distribuição das plantas de palmiteiro dentro da área explorada. 


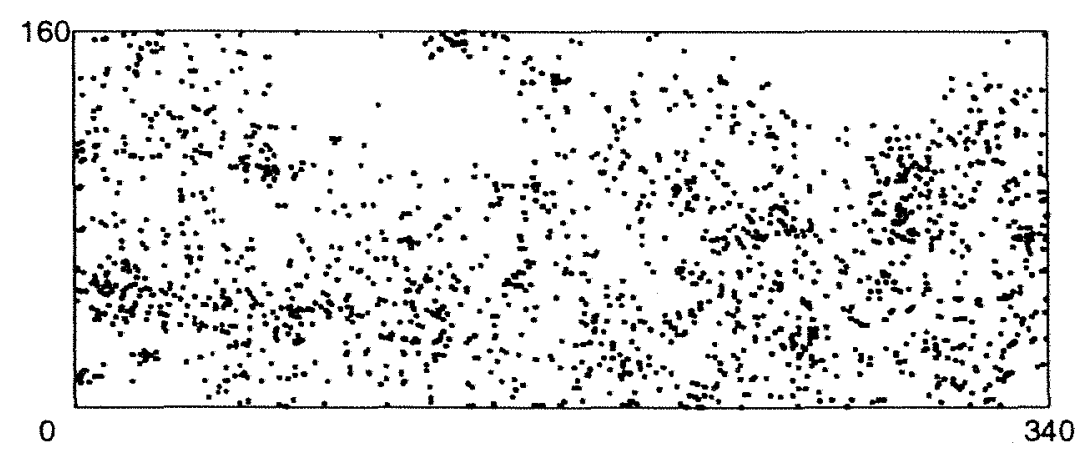

Figura 5.49: Distribuição das plantas de Euterpe edulis com estipe maior ou igual a 1,30 $\mathrm{m}$ e sem evidências de reprodução (imaturos 2).

\section{Análise estatística}

Para a análise do padrão de distribuição espacial utilizou-se a função K de Ripley, que é um método que considera a relação existente entre todos os pares de plantas (Diggle, 1983). Para correção do efeito de borda, utilizou-se o estimador proposto por Ohser \& Stoyan (1981). Este estimador permite que se façam análises em grandes escalas (Batista, 1994).

O estimador é dado por:

$$
\hat{K}(h)=\frac{1}{\hat{\lambda}} \sum_{i=1}^{n} \sum_{i=1}^{n} \omega_{i j}^{-1} I_{h}\left(\mathbf{x}_{\mathbf{i}}-\mathbf{x}_{\mathbf{j}}\right), \quad \text { para } \quad i \neq j \quad \text { e } \quad h>0
$$

onde

$\mathrm{E}[\hat{K}(h)]=$ número de pares ordenados de eventos até uma distância não maior do 
que $h$ inclusive;

$\hat{\lambda}$ é a intensidade ou número médio de eventos por área, estimado por $n / R$, onde $n$ é o número de eventos na região $R$;

$I_{h}\left(\mathbf{x}_{\mathbf{i}}-\mathbf{x}_{\mathbf{j}}\right)$ é uma função indicadora onde

$I_{h}=1$, se $\left(\mathbf{x}_{\mathbf{i}}-\mathbf{x}_{\mathbf{j}}\right)$ (a distância entre o i-ésimo e o j-ésimo evento em $R$ ) for $\leq h$

$I_{h}=0$, em caso contrário.

$\omega_{i j}^{-1}$ é a função de correção de borda para uma parcela retangular,

de lados a e b,

$$
\omega(x)=a b-x(2 a+2 b-x) / \pi
$$

definida para $x \leq \min (\mathrm{a}, \mathrm{b})$

A distância $h$ foi definida em $1 \mathrm{~m}$, ou seja, a função $K(h)$ de Ripley avalia a relação existente entre pares de eventos a cada $1 \mathrm{~m}$, até o min(a,b), onde $a$ e $b$ são os lados da região estudada.

Para visualização gráfica, utilizou-se a forma transformada da função $K(h)$ dada por:

$$
\hat{L}(h)=\sqrt{\frac{K(h)}{\pi h^{2}}}-h, \quad h>0
$$

Para um padrão com distribuição aleatória, o valor esperado de $L(h)=0$. Para um padrão agregado, $L(h)>0$ e para um padrão regular, $L(h)<0$. Para a avaliação da significância do padrão observado, construiu-se envelopes de confiança ao nível de 1\% de probabilidade (99 simulações). 


\section{Sistema de Exploração}

Fantini et al.(1997), encontraram, em uma população natural de Euterpe edulis no estado de São Paulo, que o diâmetro limite de corte (DLC) para que o creme de palmito tenha pelo menos $2,5 \mathrm{~cm}$ de diâmetro, deveria ser de no mínimo $10 \mathrm{~cm}$. Considerou-se como DLC o valor de $10 \mathrm{~cm}$, pois não se possuía os valores de incremento em área basal para estes dados. Dessa forma, todas as palmeiras que apresentam DAP $\geq 10 \mathrm{~cm}$ podem ser exploradas. Neste caso, consideraramse somente como plantas exploráveis, aquelas pertencentes ao estádio imaturos 2 , não se explorando as plantas adultas para que possa continuar existindo o processo regenerativo da espécie como recomendado por Fantini et al. (1992). 


\subsection{Resultados e Discussão}

As plantas do estádio imaturos 2 apresentam uma distribuição diamétrica em forma de " $\mathrm{J}$ " invertido, còmo mostra a figura 5.50.

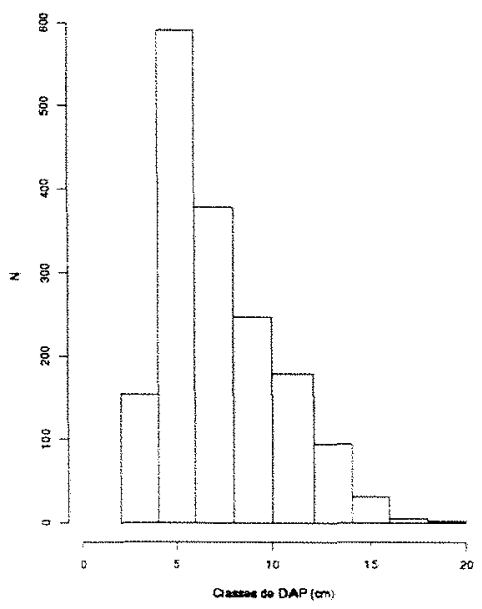

Figura 5.50: Classes diamétricas de plantas de palmiteiro do estádio imaturos 2 antes da exploração $(\mathrm{n}=1680)$.

A tabela 5.2 apresenta o número de plantas por estádio, existentes na área. 
Tabela 5.2: Número de plantas classificadas por estádios e diâmetro na área de 5,44 ha.

\begin{tabular}{cccc}
\hline \multicolumn{4}{c}{ Número de plantas } \\
\hline Fenologia & DAP $\geq 10 \mathrm{~cm}$ & DAP $<10 \mathrm{~cm}$ & Total \\
\hline Imaturos 1 & - & - & 1598 \\
Imaturos 2 & 311 & 1369 & 1680 \\
Adultos & 297 & 51 & 297 \\
\hline Total & 608 & 1420 & 3575 \\
\hline
\end{tabular}

As plantas de palmiteiro do estádio imaturos 2 apresentaram um padrão agregado de 2 até $100 \mathrm{~m}$, passando por aleatório na distância de 100 a $130 \mathrm{~m}$. Nas distâncias maiores do que $130 \mathrm{~m}$ estas palmeiras apresentam um padrão de distribuição regular dentro da área estudada (figura 5.51). Este padrão regular, reflete a distribuição dos agregados, conforme a figura 5.49.

As plantas dos estádios imaturos 1 e adultas, apresentaram um padrão de distribuição semelhante ao encontrado para plantas do estádio imaturos 2 .

$\Lambda$ figura 5.52 mostra a distribuição das palmeiras do estádio imaturos 2 que apresentam DAP $\geq 10 \mathrm{~cm}$. Todas estas plantas são passíveis de exploração nesta simulação.

O padrão de distribuição das plantas exploráveis (imaturos 2) segue um padrão de distribuição muito semelhante quando considera-se todas as plantas deste estádio.

Após a exploração (figura 5.54), o padrão de distribuição das plantas restantes, praticamente permaneceu inalterado. Isto demonstra que, para o padrão existente, o manejo proposto não altera o padrão de distribuição natural 


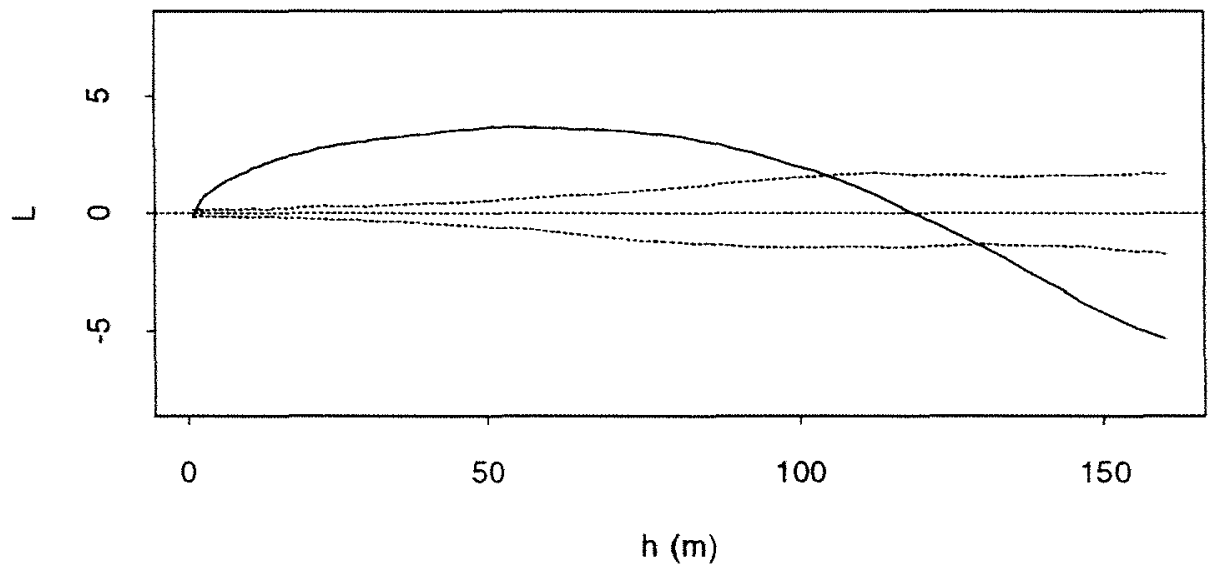

Figura 5.51: Função $\mathrm{K}$ de Ripley, aplicada as plantas do estádio imaturos 2, em uma área de 5,44 ha. antes da simulação de corte.

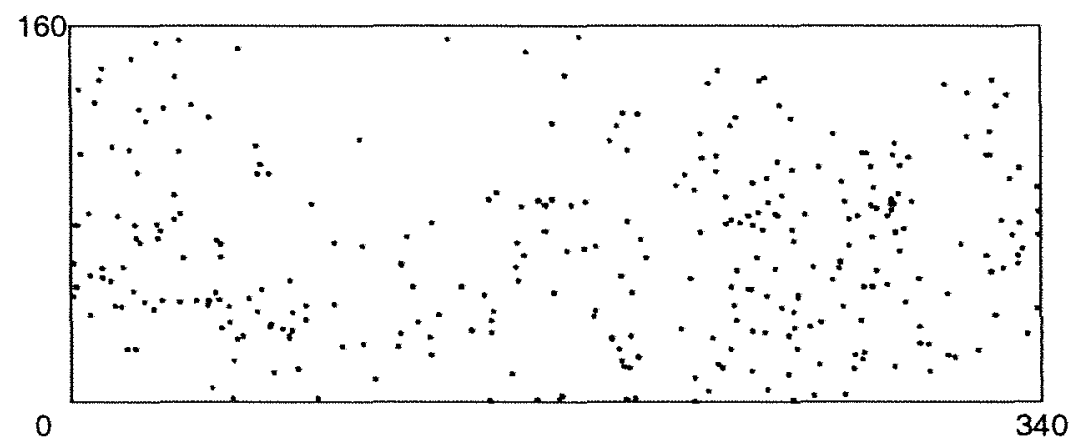

Figura 5.52: Distribuição das plantas de Euterpe edulis do estádio imaturos 2 com $\mathrm{DAP} \geq 10 \mathrm{~cm}$. 
da espécie. Em outras situações, é possível que ocorram mudanças na estrutura original da espécie, ou seja, que o padrão de distribuição seja alterado. Portanto, é necessário, que se avalie o padrão em outras regióes, para que se tenham garantias de que não ocorram alterações no padrão natural da espécie.

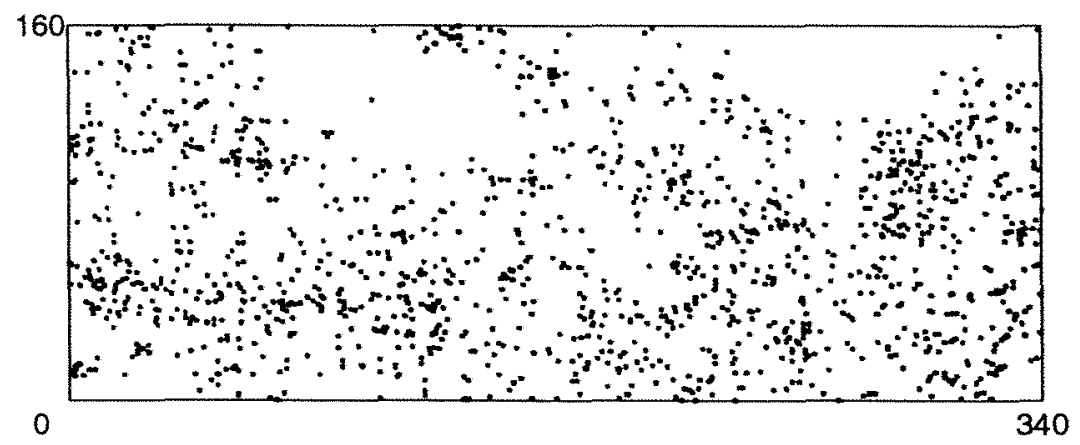

Figura 5.53: a) Plantas de Euterpe edulis do estádio imaturos 2 após exploração $(\mathrm{DAP}<10 \mathrm{~cm}, \mathrm{n}=1369)$, mapeadas dentro da parcela de $340 \times 160 \mathrm{~m}$. 
Assumindo que este padrão ocorra em todas as populações naturais, pode-se concluir que a estratégia de exploração recomendada não afeta a estrutura do padrão de distribuição espacial da espécie, utilizando a função K de Ripley, na área estudada.

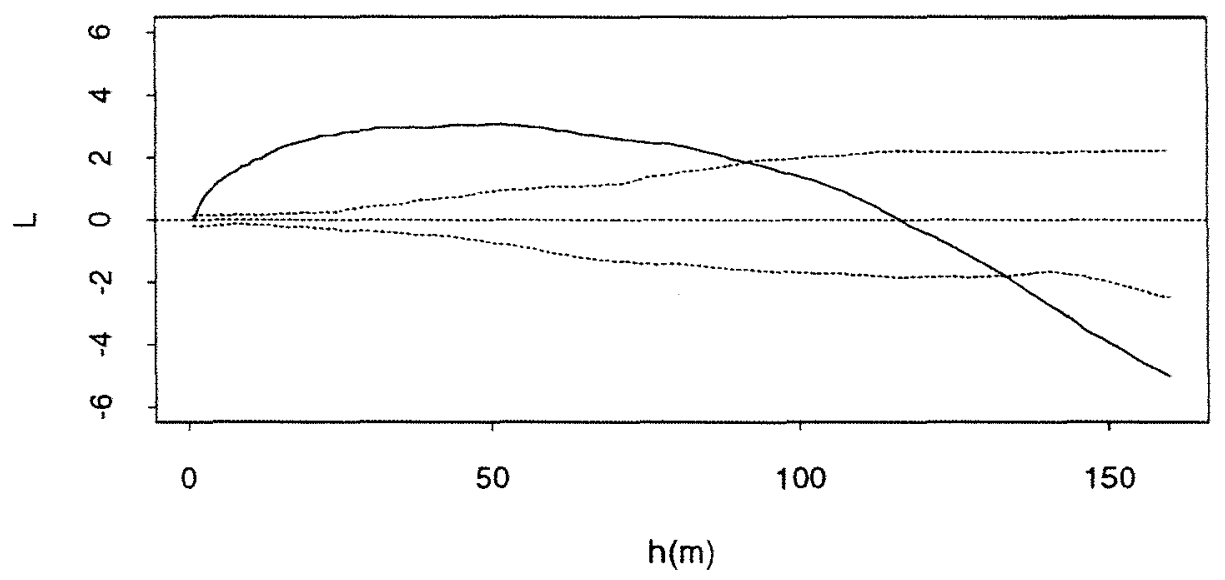

Figura 5.54: Função K de Ripley, aplicada as plantas do estádio imaturos 2 após a simulação de corte das plantas com DAP $\geq 10 \mathrm{~cm}$. 


\subsection{Conclusões}

Os resultados encontrados para a população de palmiteiro e área estudadas, indicam que existe um padrão de agregados com vários tamanhos, distribuídos com regularidade.

O sistema de manejo proposto, em regime de rendimento sustentável, não alterou a estrutura de distribuição espacial das palmeiras restantes $(\mathrm{DAP}<10 \mathrm{~cm})$, considerando a estrutura desta população.

É possível, que em outras situações, se ocorrerem padrões diferentes

do encontrado aqui, exista também diferenças no padrão de distribuição final da população restante.

Recomenda-se a inclusão de simulações através da função $\mathrm{K}$ de Ripley para elaboração de projetos de manejo em regime de rendimento sustentado não somente para a espécie Euterpe edulis, mas também para outras espécies que venham a ser exploradas. 


\section{CAPÍTULO 6}

\section{CONCLUSÕES}

A função $\mathrm{K}$ de Ripley mostrou ser um método que pode fornecer muita informação sobre a estrutura espacial horizontal de uma espécie florestal nativa. Pode ainda ser aplicado para avaliar a interferência no ambiente natural, através de uma exploração simulada ou não.

No estudo da perda de eventos, apesar de não se ter feito inferências do ponto de vista mais formal, crê-se que outros trabalhos possam ser desenvolvidos utilizando o método de Jacknife ou algo semelhante, para tentar compreender e quantificar os resultados gerados. Intuitivamente, os resultados mostram coerência, ou seja, espera-se que o efeito da perda de plantas seja menor à medida que aumenta. o número de eventos. Não foi testado o efeito que a escala pode causar na análise do padrão nestes casos. Sugere-se então que trabalhos posteriores possam ser feitos levando em conta a variação na escala.

Os programas de computador disponíveis somente avaliam os casos mais simples da função K (caso univariado). Qualquer outro tipo de análise requer a construção de funções que são complicadas do ponto de vista computacional. Também, quando o número de eventos é muito grande ( $\mathrm{n}>2000$ ), o tempo de análise aumenta significativamente. 


\section{REFERÊNCIAS BIBLIOGRÁFICAS}

ANDERSEN, M. Spatial analysis of two-species interactions. Oecologia, v.91, p.134-140, 1992.

BAILEY, T. C.; GATRELL, A.C. Interactive spatial data analysis. Essex: Longman Scientific \& Technical, 1995. 413p.

BATISTA, J. L. F. Spatial dynamics of trees in a brazilian atlantic tropical forest under natural and managed conditions. Washington, 1994. 32Tp. Thesis(Ph.D.) - College of Forest Resources, University of Washington.

BUDOWSKI, G. Distribution of tropical American rain forest species in the light of successional processes. Turrialba, v.15, p.40-42, 1965.

CLARK, P. J.; EVANS, F. C. Distance of nearest neighbor as a measure of spatial relationships in populations. Ecology, v.35, p.445-453, 1954.

CRESSIE, N. A. C. Statistics for spatial data. New York: John Wiley, 1993. $900 \mathrm{p}$.

DIGGLE, P. J. Statistical analysis of spatial point patterns. London: Academic Press, 1983. 148p.

FANTINI, A. C; NODARI, R. O.; REIS, M. S.; MANTOVANI, A.; ODORIZZI, J.; RIBEIRO, R. J. Estimativa da produção de palmito em plantas de palmiteiro (Euterpe edulis Martius) a partir de características fenotípicas. Revista Árvore, v.21, n.1, p.49-57, 1997.

FANTINI, A. C; REIS, A.; REIS, M. S.; GUERRA, M. P. Sustained yield management in tropical forest: a proposal based on the autoecology of the species. Sellowia, n.42/44, p.25-33, 1992. 
HAASE, P. Spatial pattern analysis in ecology based on Ripley's K-function: introduction and edge correction. Journal of Vegetations Science, v.6, p.575$582,1995$.

HELTSHE, J. F.; RITCHEY, T. A. Spatial pattern detection using quadrat samples. Biometrics, v.40, p.877-885, 1984.

HILL, M. O. The intensity of spatial pattern in plant communities. The Journal of Ecology, v.61, n.1, p.225-235, 1973.

HODGE, S. S.; QUEIROZ, M. H.; REIS, A. Brazil's national atlantic forest policy: a challenge for state-level environmental planning. the case of Santa Catarina. Journal of Environmental and Management, v.40, n.3, p.335-348, 1997.

KALUZNY, S. P.; VEGA, S. C.; CARDOSO, T. P.; SHELLY, A. A. S+spatialstats. user's manual: version 1.0. Seattle: Mathsoft, 1996.

KENKEL, N. C. Pattern of self-thinning in jack pine: testing the random mortality hypothesis. Ecology, v.69, n.4, p.1017-1024, 1988.

KUUluVAINEN, T.; PENTTINEN, A.; LEINONEN, K.; NYGREN, M. Statistical opportunities for comparing stand structural heterogeneity in managed and primeval forests: an example from boreal spruce forest in southern Finland. Silva Fennica. Climate change, biodiversity and boreal forest ecosystems, v.32, n.2/3, p.315-328, 1996. Special issue.

LEVIN, S. A. The problem of pattern and scale in ecology. Ecology, v.73, n.6, p.1943-1967, 1992.

LOTWICK, H. W.; SILVERMAN, B. W. Methods for analysing spatial processes of several types of points. Journal of the Royal Statistical Society, B. v.44, n.3, p.406-413, 1982.

MOEUR, M. Characterizing spatial patterns of trees using stem-mapped data. Forest Science, v.39, n.4, p.756-775, 1993. 
MONTEIRO, R.; CESAR, O. Padrões espaciais em espécies arbóreas na planície litorânea de Picinguaba (Parque Estadual da Serra do Mar - Ubatuba, SP.). Arquivos de Biologia e Tecnologia, v.38, n.2, p.533-540, 1995.

NEWBERY, D. McC.; RENSHAW, E.; BRÜNIG, E. F. Spatial pattern of trees in Kerangas forest, Sarawak. Vegetatio, v.65, p.77-89, 1986.

OHSER, J.; STOYAN, D. On the second-order and orientation analysis of planar stationary point processes. Biometrical Journal, v.23, n.6, p.523-533, 1981.

PENTTINEN, A.; STOYAN, D.;HENTTONEN, H. M. Marked point processes in forest statistics. Forest Science, v.38, n.38, p.806-824, 1992.

REIS, A. Dispersão de sementes de Euterpe edulis Martius - (Palmae) em uma floresta ombrófila densa montana da encosta atlântica em Blumenau, SC. Campinas, 1995. 154p. Tese (Doutorado)- Universidade Estadual de Campinas, Instituto Biológico.

REIS, M. S. dos. Distribuição e dinâmica da variabilidade genética em populações naturais de palmiteiro (Euterpe edulis). Piracicaba, 1996. 210p. Tese (Doutorado) - Escola Superior de Agricultura "Luiz de Queiroz", Universidade de São Paulo.

RIPLEY, B. D. Modelling spatial patterns. Journal of the Royal Statistical Society, v.39, n.2, p.172-212, 1977.

RIPLEY, B. D. Tests of 'randomness' for spatial point patterns. Journal of the Royal Statistical Society, Series B. v.41, n.3, p.368-374, 1979.

RIPLEY, B. D. Spatial statistics. London: John Wiley. 1981. 252p.

ROSSO, P. H.; BACCALÁ, N.; HAVRYLENKO, M.; FONTENLA, S. Spatial pattern of Austrocedrus chilensis wilting and the scope of autocorrelation analysis in natural forests. Forest Ecology and Management, v.67, p.273-279, 1994. 
STERNER, R. W.; RIBIC, C. A.; SCHATZ, G. E. Testing for life historical changes in spatial patterns of four tropical tree species. Journal of Ecology, v.74, p.621-633, 1986.

THOMSON, A. J. Trend surface analysis of spatial patterns of tree size, microsite effects and competitive stress. Canadian Journal of Forest Research, v.16, p.279-282, 1986.

VENABLES, W. N.; RIPLEY, B. D. Modern applied statistics with S-plus. New York: Springer-Verlag, 1994. 462p. 


\section{APÊNDICE A}

\section{Programa para Simulação de um Padrão Aleatório}

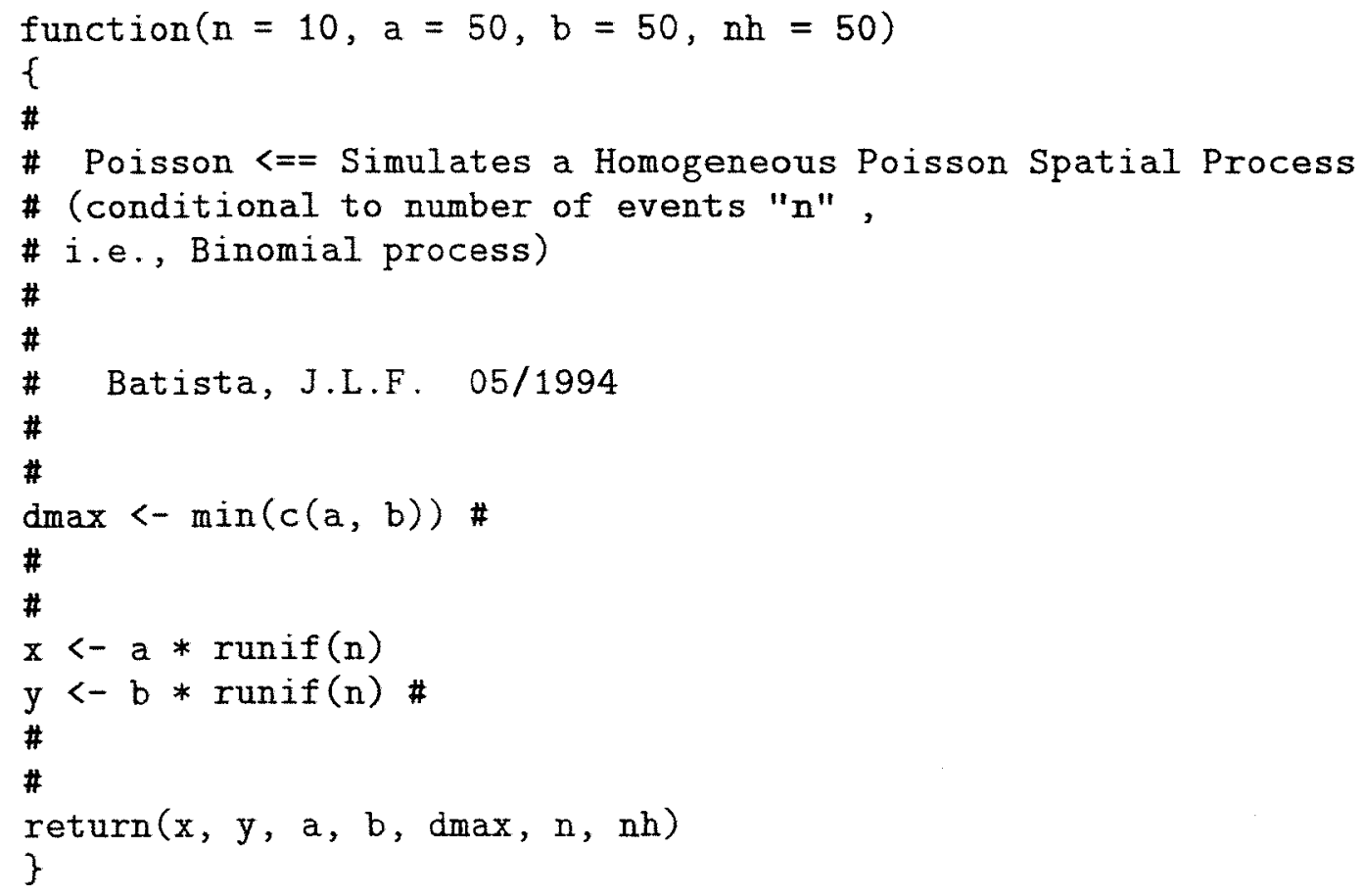




\section{APÊNDICE B}

\section{Programa para Simulação de um}

\section{Padrão Agregado}

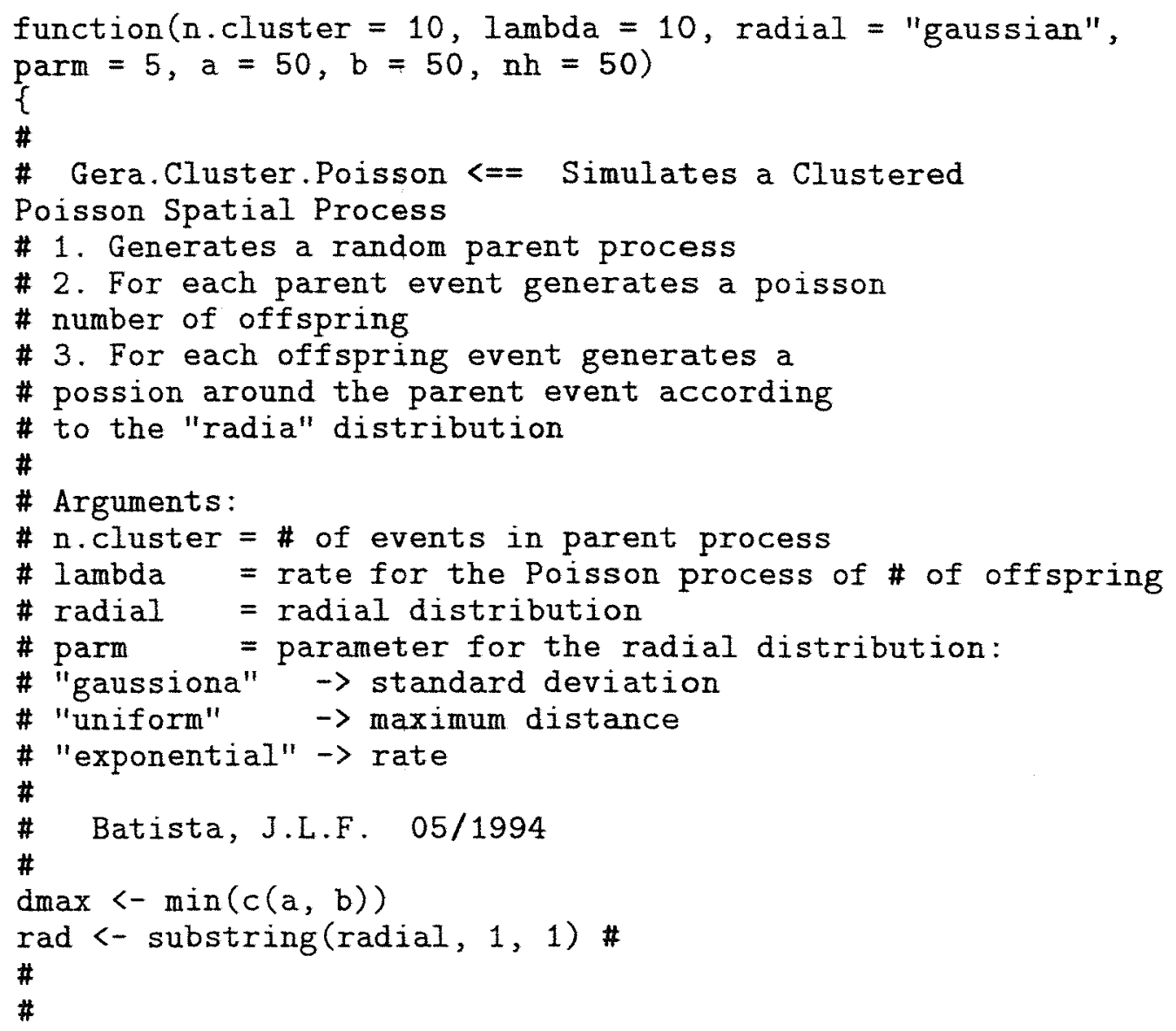




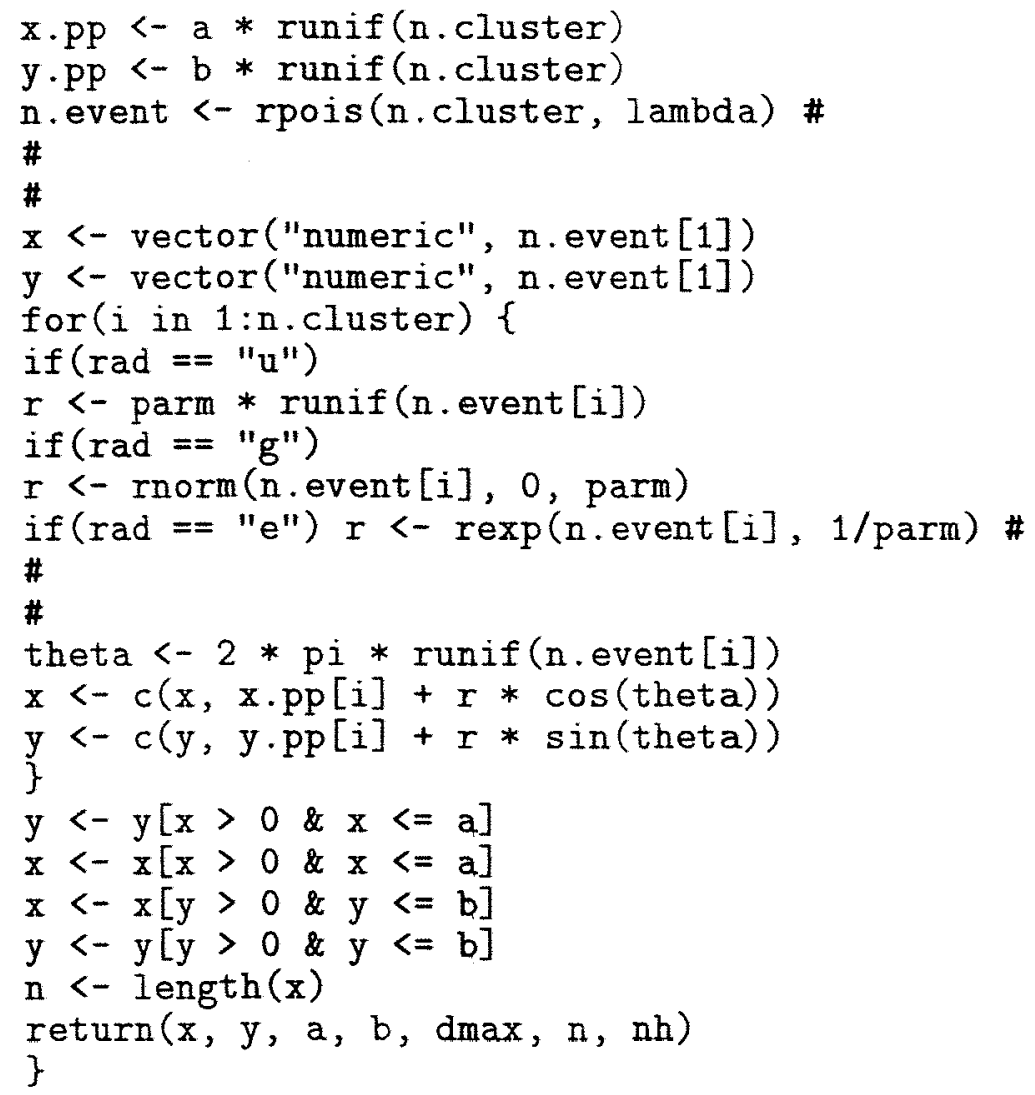




\section{APÊEDICE C}

\section{Programa para Simulação de um Padrão Regular}

win. $\operatorname{graph}()$

r100<-make pattern $(n=100$, process="Strauss", $\operatorname{rad}=5, c p a r=0.5$, boundary=bbox $(x=c(0,50), y=c(0,50)))$

plot(r100) 


\section{APÊNDICE D}

\section{Programa para Criação de uma Matriz Amostral (ret)}

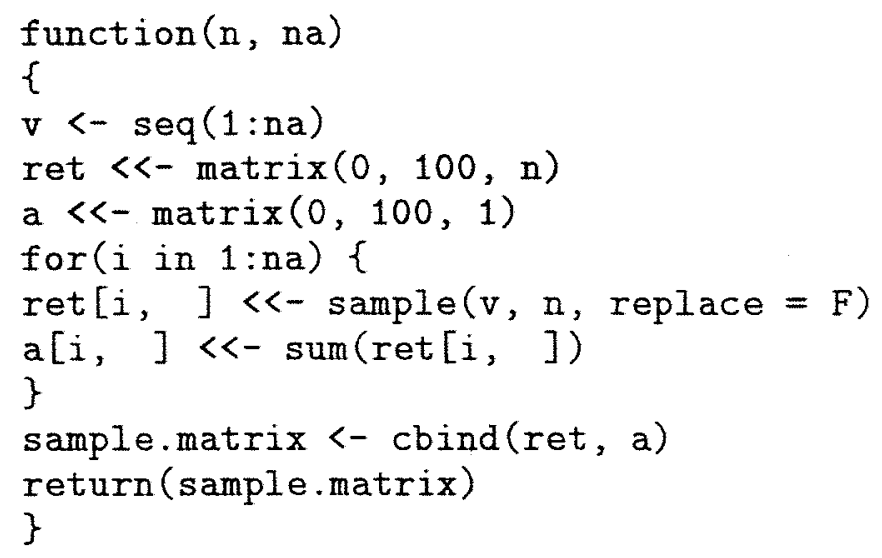

Este programa gera uma matriz onde os valores nas linhas representam as observações que serão retiradas durante a simulação de perda de eventos. 


\section{APÊNDICE E}

\section{Programa para Simulação de}

\section{Perda de Eventos}

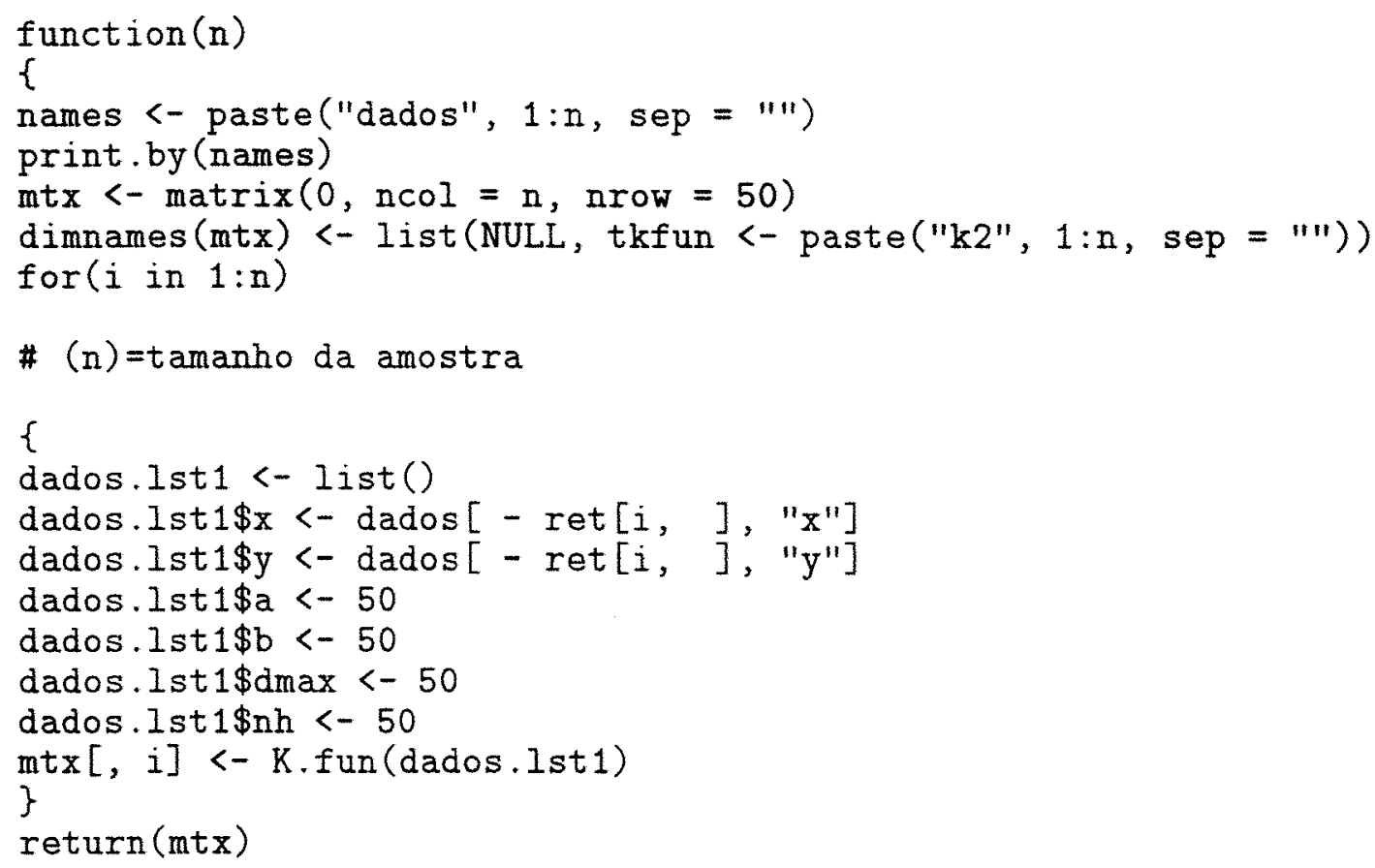

A matriz ret é uma matriz que define quais os pontos que serão retirados do conjunto de dados. 